\title{
WestVirginiaUniversity
}

THE RESEARCH REPOSITORY @ WVU

Graduate Theses, Dissertations, and Problem Reports

2005

\section{Flow system modeling with applications to fuel cell systems}

\author{
Christian Edward Shaffer \\ West Virginia University
}

Follow this and additional works at: https://researchrepository.wvu.edu/etd

\section{Recommended Citation}

Shaffer, Christian Edward, "Flow system modeling with applications to fuel cell systems" (2005). Graduate Theses, Dissertations, and Problem Reports. 1645.

https://researchrepository.wvu.edu/etd/1645

This Thesis is protected by copyright and/or related rights. It has been brought to you by the The Research Repository @ WVU with permission from the rights-holder(s). You are free to use this Thesis in any way that is permitted by the copyright and related rights legislation that applies to your use. For other uses you must obtain permission from the rights-holder(s) directly, unless additional rights are indicated by a Creative Commons license in the record and/ or on the work itself. This Thesis has been accepted for inclusion in WVU Graduate Theses, Dissertations, and Problem Reports collection by an authorized administrator of The Research Repository @ WVU. For more information, please contact researchrepository@mail.wvu.edu. 


\title{
Flow System Modeling with Applications to Fuel Cell Systems
}

\author{
Christian Edward Shaffer
}

\author{
Thesis submitted to the \\ College of Engineering and Mineral Resources \\ at \\ West Virginia University
}

In partial fulfillment of the requirements for the degree of

\author{
Master of Science \\ in \\ Mechanical Engineering
}

Ismail B. Celik, Ph.D., Chair

Larry E. Banta, Ph.D.

David A. Tucker, Ph.D.

Department of Mechanical and Aerospace Engineering

\author{
Morgantown, West Virginia
}

2005

Keywords: One-dimensional model, Numerical model, Fuel cell system, System model, CFD 


\title{
ABSTRACT \\ Flow System Modeling with Applications to Fuel Cell Systems
}

\author{
Christian Edward Shaffer
}

Fuel cell systems have garnered much attention recently as a possible source of clean, efficient energy. These systems are presently being designed in various arrangements to combine the use of fuel cells with other efficient power producing devices such as gas turbines, producing a system which is more efficient than either the fuel cell or gas turbine alone. The accurate modeling of these types of systems is an important contribution to the increasing development of such technologies. Of particular interest is the transient behavior of these systems, including the flow and thermal behavior of the air and fuel used. The contribution of this work is the development of a numerical, onedimensional, variable-area duct model to predict the transient flow and thermal behavior of gasses moving through the system. Additional transient models for plenum, tee, and elbow components are created, and these parts are connected with the duct model to perform simulations of simple flow systems. Some thermal and flow characteristics of these systems are analyzed and discussed. As a verification of the models created, a portion of an actual fuel cell system is modeled and the results are compared with experimental data. 


\section{Acknowledgements}

I would first and foremost like to thank my advisor Dr. Ismail Celik for both his academic and financial support over the past few years. This work would not have been possible without his help, and I deeply appreciate everything he has done for me. I would also like to thank my committee members Dr. Larry Banta and Dr. David Tucker for their help and encouragement. A great deal of thanks is due to the members of the CFD\&AMP Center for being such great co-workers, friends, and classmates. Mike Shelton likewise has been a good friend and helped tremendously with the NETL HYPER test data. I would be remiss not to thank the gifted professors and staff in the Mechanical and Aerospace Engineering Department who have made my six year stay in Morgantown a pleasant and memorable experience. Finally, I would like to thank my parents, sister and brother, and friends for their endless support, love, and encouragement. 


\section{Table of Contents}

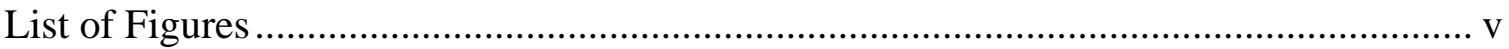

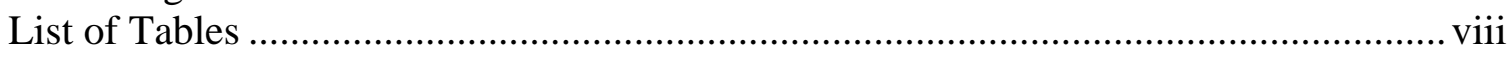

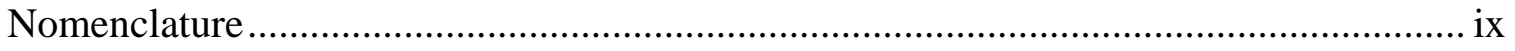

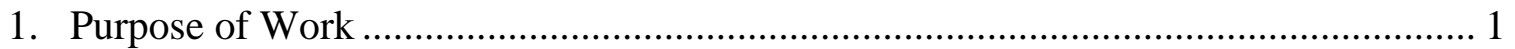

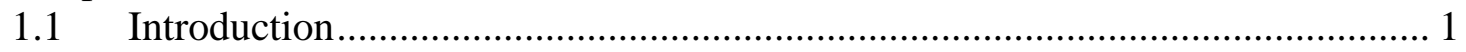

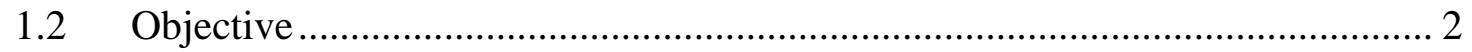

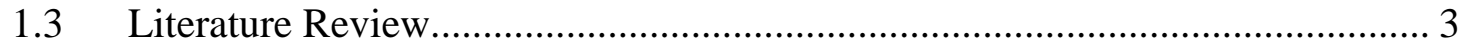

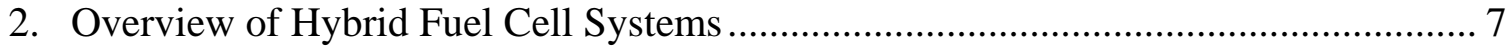

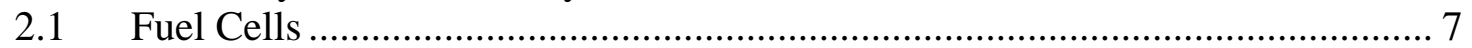

2.2 Hybrid Fuel Cell System Parts......................................................................... 8

2.3 Generic Examples of Hybrid Fuel Cell Systems .......................................... 9

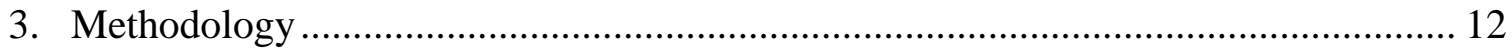

3.1 Discretization of Equations for One-Dimensional Variable-Area Duct Model 12

3.2 Discussion of Terms in Equations for the Duct Model.................................... 18

3.3 Pseudo-Compressibility Model.................................................................... 21

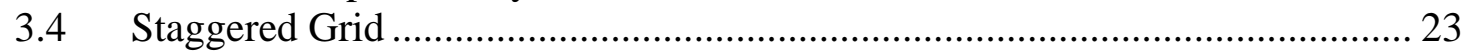

3.5 Minor Losses within the Duct..................................................................... 24

3.6 MacCormack Method and the FORTRAN Code.......................................... 26

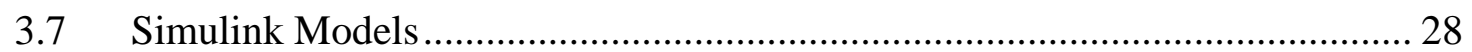

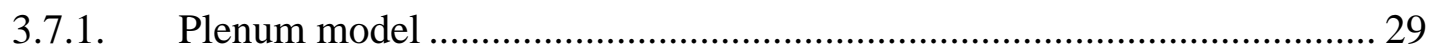

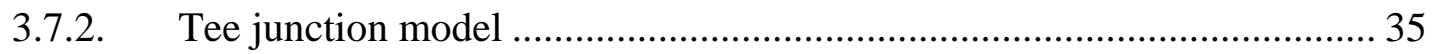

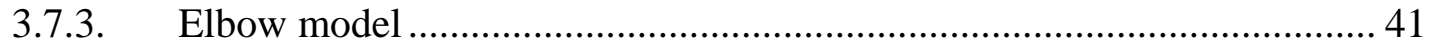

3.7.4. Duct model incorporation into Simulink ............................................ 43

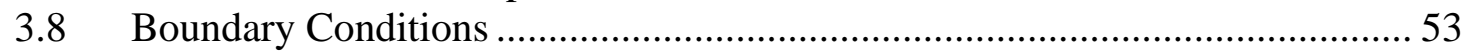

3.9 Application Issues and Limitations of Model ............................................. 55

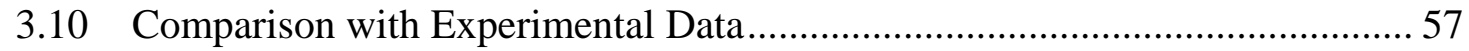

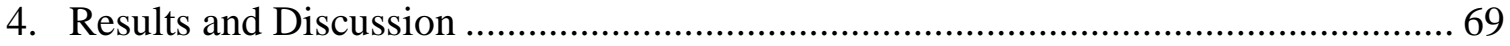

4.1 Isothermal Fully-Developed Laminar Pipe Flow using the FORTRAN Code. 69

4.2 Isothermal Plenum and Diffuser Flow using the FORTRAN Code ................ 70

4.3 Temperature Distribution in a Straight Pipe with the Simulink Duct Model ... 79

4.4 Flow Loss of Elbow vs. Tee Components with One Tee Port Closed.............. 80

4.5 Isothermal Behavior of Simple Flow Systems with Simulink Models............. 82

4.6 Thermal Behavior of a Simple Flow System with Simulink Models ............... 87

4.7 Comparison with Experimental NETL HYPER Data using Simulink Models 90

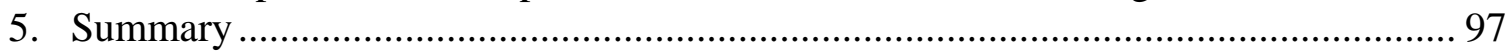

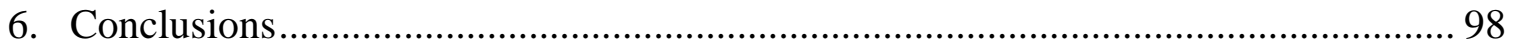

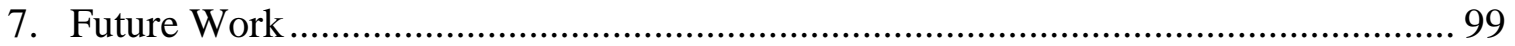

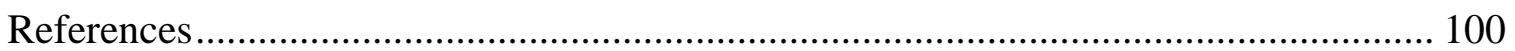

Appendix: Derivation of One-Dimensional Variable-Area Duct Flow Equations......... 103 


\section{List of Figures}

Figure 2-1 General schematic for the operation of a solid oxide fuel cell [24] ............... 7

Figure 2-2 Schematic of a $\mu$ GT-SOFC system as given by Massardo, et. al. [18]......... 10

Figure 2-3 Flow diagram of the NETL HYPER test facility as given by Tucker, et. al. [21].

Figure 3-1 Diagram of staggered grid for generic duct cross-section; solid circles refer to main nodes and open circles refer to velocity nodes.

Figure 3-2 Typical cells for (a) main nodes, and (b) velocity nodes; solid circles refer to main nodes and open circles refer to velocity nodes.

Figure 3-3 Curve fit for the dimensionless friction factor vs. $\mathrm{Re}_{\mathrm{D}}$ with an assumed $\varepsilon / \mathrm{D}$ ratio of 0.012 ....

Figure 3-4 Typical plenum showing location of plenum/duct interfaces as thin dashed lines with port numbers $i=1$ through $i=3$. Note that the thick dashed arrow represents a port where the flow is assumed positive into the plenum and the thick solid arrow represents a port where the flow is assumed positive out of the plenum.

Figure 3-5 Simulink plenum block diagram for connection with three ducts. ................ 32

Figure 3-6 Simulink plenum model interior showing both temperature and pressure

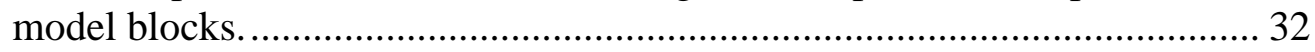

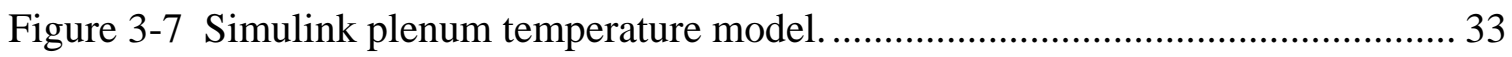

Figure 3-8 Simulink plenum pressure and minor loss model. ..................................... 34

Figure 3-9 Tee with one inlet branch $(\mathrm{i}=2)$ and two outlet branches $(\mathrm{i}=1$ and $\mathrm{i}=3) \ldots 36$ Figure 3-10 Tee with two inlet branches ( $i=1$ and $i=2)$ and one outlet branch $(i=3) . .37$ Figure 3-11 Test cases I, II, and III used to determine loss coefficients $\left(\mathrm{K}_{\text {loss }}\right)$ for use with equation (3-43) based on loss coefficients given by Munson[7] for use with

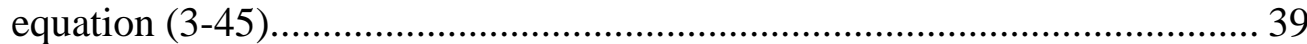

Figure 3-12 Simulink tee block diagram for connection with three ducts....................... 40

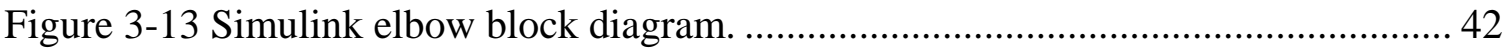

Figure 3-14 Typical Simulink duct model block diagram.......................................... 43

Figure 3-15 Upper left corner of inside of Simulink duct model block diagram. ............ 44

Figure 3-16 Upper right corner of inside of Simulink duct model block diagram. .......... 45

Figure 3-17 Lower left corner of inside of Simulink duct model block diagram............ 46

Figure 3-18 Lower right corner of inside of Simulink duct model block diagram.......... 47

Figure 3-19 Simulink momentum subsytem model block diagram for upwinding scheme.

Figure 3-20 Simulink pressure subsytem model block diagram.................................... 50

Figure 3-21 Simulink thermal energy subsytem model block diagram: top half. ........... 50

Figure 3-22 Simulink thermal energy subsytem model block diagram: bottom half. ...... 51

Figure 3-23 Typical Simulink block diagram illustrating connection of components. ... 52

Figure 3-24 Schematic of staggered grid and boundary value locations. ....................... 54

Figure 3-25 Diagram of the section of the NETL HYPER test facility used to validate the flow model. Note that dimensions are in inches and [mm]; internal diameter of all ductwork is $154 \mathrm{~mm}$..................................................................... 57

Figure 3-26 Diagram of Simulink model for the section of the NETL HYPER test facility used to validate the simulation. ................................................................. 58 
Figure 3-27 Curve fit for $\mathrm{C}_{\mathrm{f}} \mathrm{vs}$. $\mathrm{Re}_{\mathrm{D}}$ for the stainless steel pipe used in the NETL HYPER test facility.

Figure 4-1 Steady-state gage pressure vs. axial length (x) of straight pipe for momentum equation and kinetic energy equation; solution from Moody chart data: $\mathrm{u}=$ $1.034 \mathrm{~m} / \mathrm{s}$ for $\Delta \mathrm{P}=1 \mathrm{~Pa}$ for air $(\mu=19.5 \times 10-6 \mathrm{~Pa} \mathrm{~s})$; pipe length $=1 \mathrm{~m}$, pipe diameter $=0.0254 \mathrm{~m}$.

Figure 4-2 Steady-state average axial velocity vs. axial length (x) of straight pipe for momentum equation and kinetic energy equation; solution from Moody chart data: $\mathrm{u}=1.034 \mathrm{~m} / \mathrm{s}$ for $\Delta \mathrm{P}=1 \mathrm{~Pa}$ for air $(\mu=19.5 \times 10-6 \mathrm{~Pa}$ s); pipe length $=$ $1 \mathrm{~m}$, pipe diameter $=0.0254 \mathrm{~m}$. 70

Figure 4-3 Schematic of plenum/diffuser test case................................................. 71

Figure 4-4 Sketch of wall shear and effective wall shear on main flow........................ 72

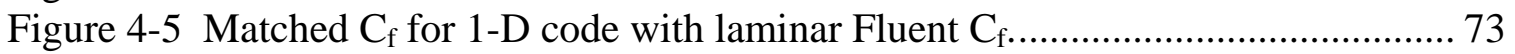

Figure 4-6 Steady-state, isothermal flow $(T=287 \mathrm{~K})$ gage pressure vs. $\mathrm{x}$ for laminar Fluent results and 1-D code with matched laminar $\mathrm{C}_{\mathrm{f}}$ and minor contraction loss $\left(\mathrm{K}_{\mathrm{o}}=0.9, \alpha=6.0\right)$.

Figure 4-7 Steady-state, isothermal flow $(\mathrm{T}=287 \mathrm{~K})$ axial velocity vs. $\mathrm{x}$ for laminar Fluent results and 1-D code with matched laminar $\mathrm{C}_{\mathrm{f}}$ and minor contraction loss $\left(\mathrm{K}_{\mathrm{o}}=0.9, \alpha=6.0\right)$.

Figure 4-8 Steady-state, isothermal flow $(\mathrm{T}=287 \mathrm{~K})$ gage pressure vs. $\mathrm{x}$ for laminar Fluent run and 1-D model with fully-developed pipe flow friction factor with diffuser and contraction minor losses $\left(\mathrm{K}_{0}=0.9, \alpha=6.0\right)$. 74

Figure 4-9 Steady-state, isothermal flow $(\mathrm{T}=287 \mathrm{~K})$ average axial velocity vs. $\mathrm{x}$ for laminar Fluent run and 1-D model with fully-developed pipe flow friction factor with diffuser and contraction minor losses $\left(\mathrm{K}_{0}=0.9, \alpha=6.0\right) \ldots \ldots \ldots . . .75$

Figure 4-10 Steady-state matched $\mathrm{C}_{\mathrm{f}}$ for1-D code with turbulent $\mathrm{k}-\varepsilon$ Fluent $\mathrm{C}_{\mathrm{f}}$............. 76 Figure 4-11 Steady-state, isothermal flow $(\mathrm{T}=287 \mathrm{~K})$ gage pressure vs. $\mathrm{x}$ for turbulent K$\varepsilon$ Fluent results and 1-D code with matched turbulent $\mathrm{C}_{\mathrm{f}}$ and minor contraction loss $\left(\mathrm{K}_{0}=0.7, \alpha=10.0\right)$.

Figure 4-12 Steady-state, isothermal flow $(\mathrm{T}=287 \mathrm{~K})$ axial velocity vs. $\mathrm{x}$ for turbulent $\mathrm{K}$ $\varepsilon$ Fluent results and 1-D code with matched turbulent $\mathrm{C}_{\mathrm{f}}$ and minor contraction loss $\left(\mathrm{K}_{\mathrm{o}}=0.7, \alpha=10.0\right)$ 77

Figure 4-13 Steady-state, isothermal flow $(T=287 \mathrm{~K})$ gage pressure vs. $\mathrm{x}$ for Fluent $\mathrm{K}-\varepsilon$ model and 1-D model with fully-developed pipe flow friction factor with contraction minor loss $\left(\mathrm{K}_{\mathrm{o}}=0.7, \alpha=10.0\right)$.

Figure 4-14 Steady-state, isothermal flow $(\mathrm{T}=287 \mathrm{~K})$ axial velocity vs. $\mathrm{x}$ for Fluent $\mathrm{K}-\varepsilon$ model and 1-D model with fully-developed pipe flow friction factor with contraction minor loss $\left(\mathrm{K}_{\mathrm{o}}=0.7, \alpha=10.0\right)$.

Figure 4-15 Comparison of Simulink duct model solution with that given by Bejan [29] for a steady-state flow through a circular duct with fully-developed flow, fully-developed temperature profile, and constant wall heat flux. Wall heat flux specified as $100 \mathrm{~W} / \mathrm{m} 2$, length of pipe as $1 \mathrm{~m}$, diameter of duct as 1 in., and air as the working fluid.

Figure 4-16 Setup simple system to test tee and elbow flow loss coefficients. 81 
Figure 4-18 Gage pressure specified at boundaries of tee and plenum three pipe systems.

Figure 4-19 Calculated mass flow at boundaries of tee, three pipe system. For this plot, the mass flows were assumed positive into the tee. 84

Figure 4-20 Sum of mass flows (net mass flow) into the tee system as calculated by the boundary values.

Figure 4-21 Calculated mass flow at boundaries of plenum, three pipe system. For this plot, the mass flows were assumed positive into the plenum.

Figure 4-22 Sum of mass flows into the plenum system as calculated by the boundary values.

Figure 4-23 Gage pressure specified at boundaries of plenum three pipe system........... 88

Figure 4-24 Calculated mass flow at east boundaries of the three pipes. For this plot, the mass flows were assumed positive from west to east.

Figure 4-25 Calculated temperatures at the east boundaries of the three pipes............... 89

Figure 4-26 East and west face pressure boundary conditions taken from the NETL HYPER experimental data...

Figure 4-27 West face temperature boundary condition taken from the NETL HYPER experimental data.

Figure 4-28 Comparison of the air mass flow rate at probe location given by experimental data and simulation.

Figure 4-29 Comparison of the experimental and simulated plenum pressures; (a) wide view and (b) zoomed view.

Figure 4-30 Comparison of east boundary air temperature given by experimental data and simulation.

Figure A-1 Generic variable-area control volume showing mass flux across open boundaries.

Figure A-2 Generic variable-area control volume showing momentum flux across open boundaries along with external forces.

Figure A-3 Axial view: surface area component normal to the axial direction of the duct.

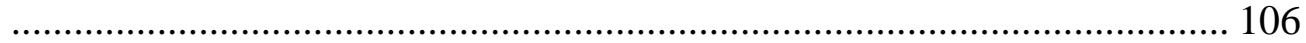

Figure A-4 Generic variable-area control volume showing net flux of energy, rate of work done, and rate of heat addition. 


\section{List of Tables}

Table 3-1 Percent error when using assumed $K_{\text {loss }}$ values of $K_{\text {branch-i }}=8.0$ and $K_{\text {line-i }}=$ 0.45 for individual branch velocities with (3-43) as compared with using $\mathrm{K}_{\text {loss }}$ inlet branch velocity and textbook values given by Munson [7] $\left(\mathrm{K}_{\text {branch-text }}=\right.$ 1.0 and $\mathrm{K}_{\text {line-text }}=0.2$ ) for the same flow rates with (3-45). Note that $\mathrm{i}=2$ is the inlet port, and $\mathrm{i}=1$ and $\mathrm{i}=3$ are the outlet ports as describe in Figure 3-9

Table 3-2 Properties of the piping, components, and insulation in the NETL HYPER test facility used for the simulation. ............................................................. 61

Table 4-1 Mass flow rates of tee and elbow two-pipe system at the west and east boundaries of pipes. ................................................................................ 82 


\section{Nomenclature}

$\begin{array}{ll}\text { Acronyms } & \\ \text { CFD } & \text { Computational Fluid Dynamics } \\ \text { DOE } & \text { Department of Energy } \\ \text { FC } & \text { Fuel Cell } \\ \text { GT } & \text { Gas Turbine } \\ \text { HYPER } & \text { Hybrid Performance } \\ \text { MCFC } & \text { Molten Carbonate Fuel Cell } \\ \text { NETL } & \text { National Energy Technology Laboratory } \\ \text { SOFC } & \text { Solid Oxide Fuel Cell } \\ \mu G T & \text { Micro Gas Turbine }\end{array}$

\section{Letters and Abbreviations}

A Cross-sectional area and coefficient for $\mathrm{C}_{\mathrm{v}}$ curve fit

$\mathrm{A}_{\text {ext-comp }} \quad$ External surface area of component

$\mathrm{A}_{\text {int-comp }}$ Internal surface area of component

B Coefficient for $\mathrm{C}_{\mathrm{v}}$ curve fit

C $\quad$ Coefficient for $\mathrm{C}_{\mathrm{v}}$ curve fit

$\mathrm{C}_{\mathrm{f}} \quad$ Dimensionless friction factor

$\mathrm{C}_{\mathrm{f}}^{*} \quad$ Effective friction factor

$\mathrm{C}_{\mathrm{p}} \quad$ Specific heat at constant pressure

$\mathrm{C}_{\text {press }} \quad$ Pressure coefficient

$\mathrm{C}_{\mathrm{v}} \quad$ Specific heat at constant volume

D Diameter and coefficient for $\mathrm{C}_{\mathrm{v}}$ curve fit

$\mathrm{D}_{\mathrm{ch}} \quad$ Characteristic diameter for plenum

$\mathrm{D}_{\mathrm{h}} \quad$ Hydraulic diameter

$\mathrm{D}_{\mathrm{o} \text {-ins }} \quad$ Outer diameter of the insulation

$\mathrm{K} \quad$ Kinetic energy (per unit mass)

$\mathrm{K}_{\text {loss }} \quad$ Loss coefficient

$\mathrm{K}_{\mathrm{o}} \quad$ Contraction loss coefficient at $\mathrm{x}=0$

$\mathrm{L}_{\mathrm{ch}} \quad$ Characteristic length of plenum

$\mathrm{Nu}_{\text {Do-ins,ext }} \quad$ External Nusselt number based on outer diameter of the insulation

$\mathrm{Nu}_{D \text {,int }}$ Internal Nusselt number based on internal diameter of pipe or component

$\mathrm{Nu}_{\text {eff }} \quad$ Effective Nusselt number

$\mathrm{P} \quad$ Pressure

$\mathrm{P}_{\mathrm{o}} \quad$ Stagnation pressure

Pr Prandtl number

Q $\quad$ Heat rate

$\mathrm{R} \quad$ Ideal gas constant for particular gas (per unit mass)

$\mathrm{R}_{\text {bend }} \quad$ Bend radius of an elbow

$\mathrm{Re}_{\mathrm{D}} \quad$ Reynolds number based on the internal diameter

$\mathrm{Re}_{\text {eff }} \quad$ Effective Reynolds number for plenum

$\overline{\mathrm{R}} \quad$ Universal gas constant

$S_{k} \quad$ Sutherland constant for thermal conductivity

$\mathrm{S}_{\text {minor }} \quad$ Minor loss term 


$\begin{array}{ll}\mathrm{S}_{\mu} & \text { Sutherland constant for viscosity } \\ \mathrm{T} & \text { Temperature } \\ \mathrm{T}_{\mathrm{o}} & \text { Standard temperature for Sutherland equation } \\ \mathrm{U} & \text { Average velocity of the flow over a section of the pipe } \\ \mathrm{U}_{\text {eff }} & \text { Effective velocity through the plenum for use with } \mathrm{Re}_{\mathrm{eff}} \\ \forall & \text { Volume } \\ \dot{\forall} & \text { Volumetric flow rate } \\ \mathrm{c} & \text { Heat capacity of solid material } \\ \mathrm{C}_{\mathrm{ht}} & \text { Constant coefficient for effective Nusselt number relationship } \\ e & \text { Internal energy } \\ \mathrm{h} & \text { Specific enthalpy } \\ \mathrm{h}_{\mathrm{eff}} & \text { Effective heat transfer coefficient } \\ \mathrm{h}_{\mathrm{ext}} & \text { External heat transfer coefficient } \\ \mathrm{h}_{\mathrm{int}} & \text { Internal heat transfer coefficient } \\ \mathrm{i} & \text { Port number } \\ \mathrm{k} & \text { Thermal conductivity } \\ \mathrm{k}_{\mathrm{o}} & \text { Thermal conductivity at standard temperature for Sutherland equation } \\ \mathrm{m} & \text { Mass, exponent for effective Nusselt number relationship } \\ \mathrm{m} * & \text { Mass per unit length } \\ \dot{\mathrm{m}} & \text { Mass flow rate } \\ \overline{\mathrm{m}} & \text { Molecular weight } \\ \mathrm{n} & \text { Exponent for effective Nusselt number relationship } \\ \mathrm{q} & \text { Heat flux } \\ \mathrm{q}^{*} & \text { Heat transfer rate per unit length of pipe } \\ \mathrm{r} & \text { Internal radius of pipe } \\ \mathrm{t} & \text { Time } \\ \mathrm{u} & \text { Average velocity of flow in axial direction } \\ \mathrm{v} & \text { Specific volume }=1 / \rho \\ \mathrm{x} & \text { Axial direction of the duct } \\ & \end{array}$

\section{Greek Symbols}

$\Delta \mathrm{x} \quad$ Grid spacing

$\alpha \quad$ Contraction loss coefficient, elbow loss coefficient, and $C_{p}$ coefficient

$\beta \quad$ Coefficient for $C_{p}$ curve fit

$\delta \quad$ Coefficient for $\mathrm{C}_{\mathrm{p}}$ curve fit

$\delta_{\mathrm{ij}} \quad$ Kronecker delta

$\varepsilon \quad$ Coefficient for $\mathrm{C}_{\mathrm{p}}$ curve fit

$v \quad$ Kinematic viscosity

$\Phi \quad$ Perimeter of duct

$\gamma \quad$ Polytropic exponent and coefficient for $\mathrm{C}_{\mathrm{p}}$ curve fit

$\gamma^{*} \quad$ Second Polytropic exponent $=(\gamma-1) / \gamma$

$\kappa \quad$ Specific heat ratio $\left(\mathrm{C}_{\mathrm{p}} / \mathrm{C}_{\mathrm{v}}\right)$

$\lambda \quad$ Polytropic reference ratio

$\rho \quad$ Density 


$\begin{array}{ll}\mu & \text { Dynamic viscosity } \\ \mu_{\mathrm{o}} & \text { Dynamic viscosity at standard temperature for Sutherland equation } \\ \tau & \text { Flow-through time for plenum } \\ \tau_{\mathrm{w}} & \text { Wall shear stress } \\ \tau_{\mathrm{ij}} & \text { Shear stress tensor } \\ \tau_{\mathrm{xx}} & \text { Shear stress in the axial direction of the duct } \\ \omega & \text { Friction factor scale factor } \\ \xi & \text { Bulk viscosity }\end{array}$

\section{Subscripts}

C

D

$\mathrm{D}_{\text {o-ins }}$

E

W

air

amb

body-ins

branch

ch

comp

e

elbow

external

gas

ghost

ij

in

inlet

i-Simulink

i-text

internal

inviscid

$\mathrm{k}$

line

loss

$\mathrm{m}$

nxp

nxu

out

pipe

pipe-ins

plenum

ref

tee
Center node of the discretization

Based on characteristic internal diameter of the pipe or component

Based on characteristic outer diameter of the insulation

Far east node of the discretization

Far west node of the discretization

Air as the working gas

Ambient

Bulk properties of the metal body and insulation

Branch part of tee

Characteristic

Component

Local east node of the discretization

Elbow component

External part of the pipe or component

Gas being used

Ghost node for velocity node boundary

Tensor indices

Into the component

Inlet port

Port i from the Simulink pressure result (local branch loss term)

Port i from text loss coefficients (inlet loss term)

Internal part of the pipe or component

Inviscid case

Tensor index

Line part of the tee

Loss term

Mean value

Last pressure (main) node

Last velocity node

Out of the component

Pipe

Bulk properties of the metal pipe and insulation

Plenum component

Reference

Tee component 
First pressure (main) node

Third pressure (main) node

First velocity node

Second velocity node 


\section{Purpose of Work}

\subsection{Introduction}

"This new technology has the potential to alter the landscape of tomorrow's power industry. It offers a preview of the day when more of our electricity will be generated by super-clean, high-efficiency power units sited near the consumer. Distributed generation could play a key role in strengthening the security and reliability of our power supply, and fuel cell-turbine hybrids could help make distributed power a reality."

— U.S. Secretary of Energy Spencer Abraham, March 27, 2002[1]

This statement by Secretary of Energy Spencer Abraham was made at the unveiling of the world's first operating fuel cell-gas turbine hybrid system at the University of California - Irvine [1]. The system referred to combines a Siemens Westinghouse solid oxide fuel cell (SOFC) and an Ingersoll Rand microturbine in a hybrid system in which both components produce power [1]. Because the exhaust from an SOFC in such a system is at a temperature and pressure which can be effectively used by a micro gas turbine ( $\mu \mathrm{GT})$, these systems generate power more efficiently than either the SOFC or the $\mu \mathrm{GT}$ can on their own. The cost per power generated of these types of systems is still relatively high compared with more common methods of energy production (e.g. coal and natural gas fired power plants), and many technological barriers must still be overcome. However, this unveiling underscores the vision that hybrid fuel cell system technology will provide a clean, efficient source of usable energy on a wide scale in the near future. This push for cleaner, more efficient sources of energy has been highlighted in recent years by the growing demand for energy throughout the world (e.g. China and India), and the desire of the United States to become more energy independent.

The National Energy Technology Laboratory (NETL) as a lab under the United States Department of Energy (DOE) has been at the forefront of the research effort for advancing hybrid fuel system technology. As such, the NETL in Morgantown, West Virginia has developed a hybrid performance (HYPER) power generation test facility. This HYPER system contains a micro gas turbine along with a hardware-in-the-loop model which mimics the operation of an SOFC. This hardware-in-the-loop model is 
composed of a plenum, combustor, and piping which mimic the capacity and thermal characteristics of an SOFC [21].

In addition to the experimental testing of the physical HYPER system built at NETL, the modeling of the system is another point of focus. The purpose of modeling the system is simple: if an adequate model can be used to test new ideas, setups, etc. for the HYPER system, then fewer experiments will have to be performed. In particular if an adequate transient model can be developed, the transient behavior of the system will be better understood, leading to the development of better control strategies and system performance. A good model will therefore save both money and time, and expedite the technology development process.

Several levels of modeling are being developed at NETL for use with the HYPER system. A low-fidelity transient system model utilizing the commercial software package Protrax was developed and used to analyze a start-up from cold conditions. As a slightly higher-fidelity model, a lumped-parameter process model was developed utilizing the Simulink software package to try to incorporate more detail, while retaining a reasonable model execution speed. As yet a further level of refinement, an additional Simulink model is being developed which will refine the lumped-parameter model and include an emphasis on more detailed modeling of the piping, heat exchangers, compressor and turbine maps, etc. Due to its added complexity, and hence expected execution time, this refined system model is intended to be used in a more advanced design stage and to gather a more detailed understanding of the system dynamics [8].

\subsection{Objective}

It is in the final more-refined model discussed in the previous section that the work contained in this thesis is intended. In particular the objective is to develop a onedimensional, variable area Computational Fluid Dynamics (CFD) duct flow model capable of accurately predicting the transient flow and thermal behavior of gases through the ductwork of hybrid fuel cell systems such as the NETL HYPER test facility. This one-dimensional model will be implemented using a FORTRAN code and the MacCormack Method. The same one-dimensional model will also be developed in the Simulink workspace, and additional models will be created to simulate the transient 
behavior of connection pieces such as plenums, tees, and elbows. The Simulink onedimensional duct model, plenum model, tee model, and elbow model will all make use of the numerical integrators and subsystem blocks in the Simulink workspace.

While the main objective and contribution of this work is to develop the transient one-dimensional, variable-area duct flow model and component models discussed, the overall objective is to further the ability to model and understand the behavior of hybrid fuel cell systems. Therefore, the following literature review took on a two-path approach for information about (1) one-dimensional fluid flow models and (2) hybrid fuel cell systems.

\subsection{Literature Review}

Shelton [9] performed work using the commercial software Protrax to model the startup transient operation of the HYPER test facility at NETL. This was a low-fidelity, quick-operating model aimed at testing the basic process behavior and controls of the system. Celik and Shelton [8], in addition to the Protrax model, also developed a lumped-parameter system model using Simulink in attempt to add some fidelity to the system model while maintaining a reasonably quick execution time. As alluded to before, the work in this thesis is intended to be part of the next level of refinement in the modeling process of the NETL HYPER system.

The lumped-parameter model developed by Celik and Shelton [8] makes extensive use of the work by Schobeiri, et. al. [10]. In particular, Schobeiri et. al. [10] develop generic one-dimensional, transient, discretized equations for fluid flow and then customize these equations for use in simulating flow through the following types of categories: (1) connecting pipes, diffusers, nozzles, etc., (2) combustion chambers, afterburners, and heat exchangers, etc. and (3) compressors and turbines. The onedimensional, discretized, continuity, momentum, and energy equations derived in their paper [10] are similar to those developed in this thesis. However, some differences do exist, including (1) the fact that the energy equation developed in this thesis is expressed in terms of temperature, while the ones developed by Schobeiri et. al. [10] are expressed in terms of total temperature or total pressure, and (2) Schobeiri et. al. [10] do not appear to include the axial conduction term in the energy equation. In this paper Schobeiri et. al. 
[10] make use of their model to simulate the transients for several types of thrust, power, and thrust/power generation engines.

Chiang et. al. [11] developed a one-dimensional code capable of predicting the transient behavior of compressible flow in ducts of varying cross-section. The equations derived by Chiang et. al. [11] are very similar to the ones used in this thesis. The continuity equation used by Chiang et. al. [11] is exactly the same, while the momentum equation is only slightly different in that it doesn't include the normal viscous stress term. In the thermal energy equation, Chiang el. al. [11] do not include the effects of the axial conductivity or viscous dissipation. The authors [11] use their model to predict the behavior of the air flow into a radiator of an automobile.

Goodson and Leonard [12] review an approach to modeling the behavior of fluid in lines in a manner often used with dynamic systems and control strategy. By manipulating the continuity, momentum and energy equations with several assumptions, Goodson and Leonard [12] come up with equations in the s-domain with which to model the transients of the fluid in the transfer lines. Goodson and Leonard [12] give three models each with varying levels of assumptions, for which the most refined is the "Dissipative Model”, which includes viscosity and heat transfer effects. This Dissipative Model is also used in a more recent paper by Wongputorn et. al. [13] in which the authors describe a new way of using this model without "questionable assumptions associated with friction approximations and lumped model techniques associated with fluid transients.” [13]. The Dissipative Model, at least as described by Goodson and Leonard [12], appears to make several assumptions that the model in this thesis does not. For example, the Dissipative Model neglects the convection term in the momentum equation and the axial conduction term in the energy equation. Additionally, as mentioned by both Wongputorn et. al. [13] and Goodson and Leonard [12], a laminar flow assumption is made, and it is assumed that the duct through which the fluid flows has a uniform crosssection and a constant diameter. Therefore, this model seems to be more suited for ducts with fluids which have a zero mean velocity and oscillations in the flow due to pressure waves, etc. Examples where this model could be applied include brake lines transients in an automobile and water hammer in a pipe network. 
Pence [14] developed a rather simple, one-dimensional, steady-state, incompressible numerical model for pressure and temperature calculations through a micro-fractal branching network. In her model, the author [14] appears to neglect axial viscosity and heat conduction terms. Pence does however assume that the flow redevelops at each bifurcation of the branching network and accounts for the subsequent developing flow in each new branch by utilizing an effective friction coefficient given by White [3] for laminar flow in the entrance region of a straight pipe. In the paper by Alharbi, Pence, et. al. [15], the authors test the validity of the model given by Pence [14] by comparing its results with those acquired using a 3-D CFD code. It was found that the results from Pence's model [14] were in fairly good agreement with the ones from the 3D code. The major conclusions from the Alharbi paper [15] were that temperaturedependent fluid properties and minor loss terms for the branching sections were needed to improve the accuracy of Pence's one-dimensional model. Also, while the 3-D CFD code predicted that the flow only redeveloped at the interior part of the "Y" for each bifurcation, the redeveloping flow assumption was a good one because it predicted “...plausible trends in the pressure distribution near the inlet of each channel branch.” [15].

In the papers by Kimijima and Kasagi [16] and Uechi, Kimijima, and Kasagi [17], the authors develop a steady-state model for a $30 \mathrm{~kW}$ total power output micro gas turbine - solid oxide fuel cell ( $\mu \mathrm{GT}$-SOFC) hybrid system. It is reported that the efficiency of the $30 \mathrm{~kW}$ system designed will be approximately 65\% (based on lower heating value (LHV)) [17]. Since the $30 \mathrm{~kW}$ design is smaller than most of the other designs in the literature, the authors [16] use the same basic model to simulate a $300 \mathrm{~kW}$ total power $\mu \mathrm{GT}$-SOFC hybrid system and compare the results with similar models developed by other authors in the same power output range. It was found that out of the five models compared (four from other authors and the one $300 \mathrm{~kW}$ model), the estimated efficiencies (LHV) ranged from about 57 to $65 \%$.

Massardo et. al. [18] report that an efficiency of around 60\% was possible with the technology at the time of publication for a $\mu$ GT-SOFC hybrid system. This figure was based on a system design outputting approximately $389 \mathrm{~kW}$ total power, running on natural gas fuel. The authors [18] also report that an efficiency in the $80 \%$ range is very 
possible if the waste heat is used for applications such as heating, drying, cooling, or desalination. Additionally, the authors [18] go over projected improvements in microturbine technology and discuss $\mu$ GT-SOFC hybrid system technological issues.

In the paper by Gemmen, et. al. [19], the authors describe the generic setup for topping and bottoming cycles for $\mu \mathrm{GT}$-FC hybrid systems. The authors [19] go one step further by reporting theoretical efficiencies for these generic $\mu \mathrm{GT}$-FC hybrid systems to be in the range of “...58\% for small hybrids to $72 \%$ for large hybrids and up to 80 percent for large hybrids combined cycle systems.” The authors [19] additionally give descriptions and schematics of a generic SOFC topping hybrid system and a generic molten carbonate fuel cell (MCFC) bottoming hybrid system.

In his master's thesis, Hahn [20] develops a transient model for an SOFC - Gas Turbine hybrid power plant system. This work is intended to capture an overall behavior of the system suitable for developing control strategies, etc. (similar to the work performed by Shelton [9]). The work by Zitney et. al. [22] describes the coupling of CFD models and reduced order models (ROMs) with process simulation models. This paper illustrates the type of model described by Celik and Shelton [8] in the next level of higher-fidelity model.

In their paper Tucker, et. al. [21] give a description of the NETL HYPER test facility and discuss issues with startup from cold state. In particular the authors [21] talk about the dynamic behavior differences between an ordinary compressor/turbine system which has very little capacity between the compressor and turbine, and the hybrid SOFC system model which has much greater capacity and more parts between the compressor and turbine. The added capacity and additional parts in the SOFC system model create a greater pressure drop between the compressor and turbine. Therefore, the pressure ratio across the compressor must be greater in an SOFC hybrid system in order to produce the same power output from the turbine, and as a consequence the compressor is pushed closer to its stall condition. The authors [21] go through a method using bleed air to give an extra surge margin during startup which allows them to keep away from the surge/stall condition. 


\section{Overview of Hybrid Fuel Cell Systems}

\subsection{Fuel Cells}

"A fuel cell is an electrochemical device composed of non-consumable anode and cathode, an electrolyte, and suitable controls. It converts the free energy of the reactants into electrical energy and heat.” [23]

A fuel cell is very similar to a battery such as the lead acid variety found in most cars. The major differences between a battery and a fuel cell are that (1) a battery consumes its electrodes and (2) a fuel cell generally has a continuous flow of fuel and oxidizer moving through it while a battery does not. In a fuel cell half-reactions take place at the electrode/electrolyte interfaces. These half-reactions either produce or consume the ions that travel through the electrolyte and the electrons that flow through the external circuit. Figure 2-1, adapted from Pakalapati [24], illustrates the electrolyte, electrodes (anode and cathode), flow channels, and external circuit setup for a solid oxide fuel cell, along with the half-reactions which occur at the electrodes.

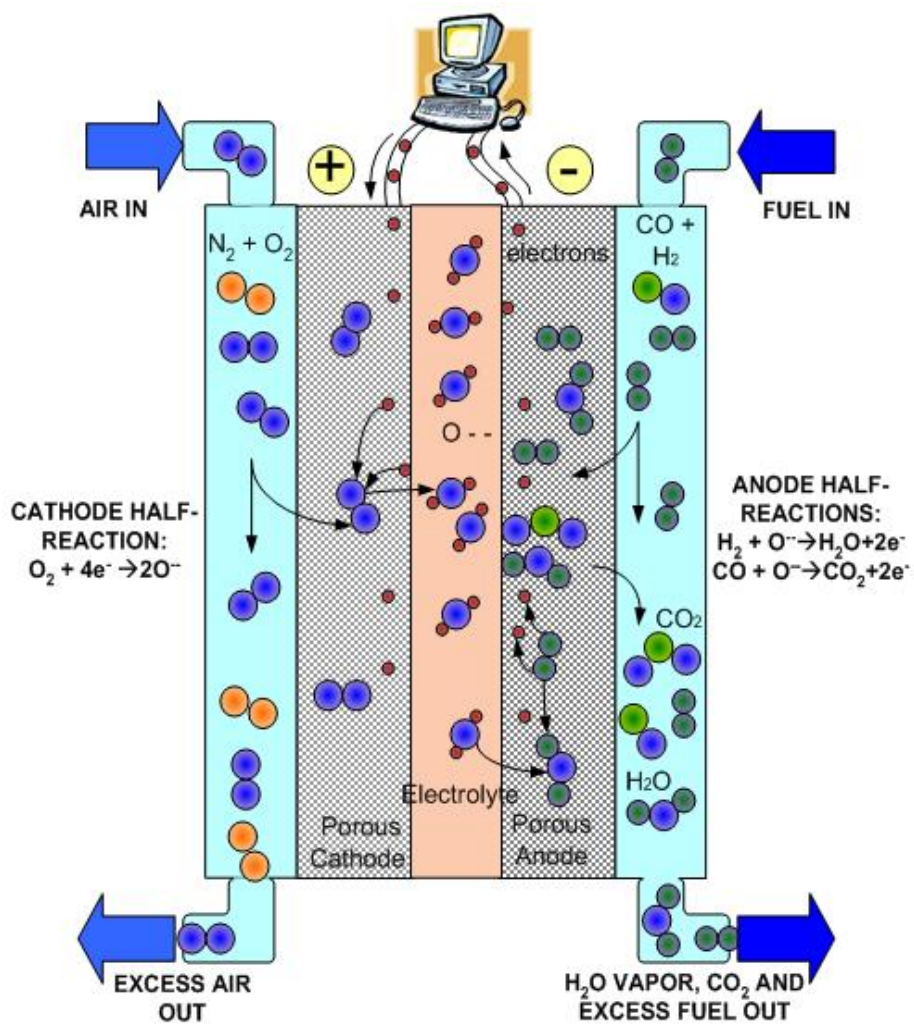

Figure 2-1 General schematic for the operation of a solid oxide fuel cell [24]. 
There are several types of fuel cells presently being used and researched. Among these types are the SOFC. The SOFC uses a solid electrolyte which allows the passage of $\mathrm{O}^{-}$ions from the cathode to the anode. The SOFC is a high temperature fuel cell generally operating in the $500-1000{ }^{\circ} \mathrm{C}$ temperature range [25]. Due to its high operating temperature, the SOFC is ideal for use in direct-fired hybrid fuel cell-gas turbine systems as will be discussed further in the next two sections. Additionally, when pressurized, the SOFC has a higher power density, reducing costs and increasing its efficiency [2]. This fact also makes the SOFC suitable for use in hybrid systems where it falls between the compressor and turbine in a high pressure location.

\subsection{Hybrid Fuel Cell System Parts}

A hybrid fuel cell system such as modeled by the NETL HYPER test facility, has many components in addition to the $\mu \mathrm{GT}$ and the fuel cell. Some of the major components used in most hybrid fuel cell systems include compressors, combustors, turbines, generators, reformers, and heat exchangers. This section gives a brief description of the purpose and operation of these parts.

The function of a compressor is simply to take in a gas and compress it to a higher pressure. In a hybrid fuel cell system, the gas being compressed is generally air or a hydrocarbon fuel such as methane. A combustor mixes air flowing through the system with fuel and facilitates the exothermic combustion reaction that occurs between the two. The purpose of the combustor is to add thermal energy to the system. Turbines convert thermal and internal energy of the fluid flowing through the system into kinetic energy. A turbine output shaft is usually coupled to the compressor and a generator. The generator converts this power transferred via a shaft into electrical power, and the compressor uses it to compress fluid moving through the system.

Reformers take in a hydrocarbon fuel which is not directly suited for use with a fuel cell and chemically convert it into hydrogen and byproducts. This reformation process may occur inside the cell itself (internal reforming) or external to the fuel cell (external reforming) [26]. Finally, heat exchangers transfer thermal energy from one stream of fluid flow to another due to the temperature gradient between the two streams. In flow systems heat exchangers are generally used to transfer heat from a stream that 
would otherwise waste or not efficiently use the thermal energy to a fluid stream that can use the energy in a more effective manner, thereby improving the overall efficiency of the system.

\subsection{Generic Examples of Hybrid Fuel Cell Systems}

Figure 2-2 shows the schematic for a $\mu \mathrm{GT}$-SOFC hybrid system given by Massardo, et. al. [18]. In this figure the fuel cell is placed between the compressor and turbine and supplements the combustor that usually appears alone in a gas turbine engine. This setup is possible because the exothermic reaction that occurs in the SOFC adds thermal energy to the flow going through the air channel (cathode-side of the fuel cell). Figure 2-3 shows a flow diagram of the NETL HYPER test facility used to model a $\mu$ GTSOFC hybrid system, as given by Tucker, et. al. [21]. In the NETL HYPER test facility, an air plenum and combustor are used to model the capacitance and thermal behavior of an SOFC in the system. Figures 2-2 and 2-3 both give examples of direct-fired systems where the SOFC (or the hardware model of the SOFC) lies between the compressor and turbine, and the exhaust from the cell is then passed through the turbine after going through an additional combustor. The SOFC is ideal for use in this type of direct-fired system because of its high temperature operation and possible use at high pressures as discussed previously.

As opposed to a direct-fired hybrid system, an indirect-fired system uses a heat exchanger between the compressor and turbine to add thermal energy to the gas stream rather than using a combustor or a fuel cell [2]. The hot stream of this heat exchanger comes from the exhaust of an un-pressurized fuel cell such as an MCFC. Other designs include placing the fuel cell (generally an MCFC) downstream of the turbine where the input into the cell cathode comes from the exhaust of the turbine. A good example of this type of setup is given by Gemmen, et. al. [19]. In this type of setup, the fuel cell is unpressurized and operates at a lower temperature (than the direct fired hybrid system). 


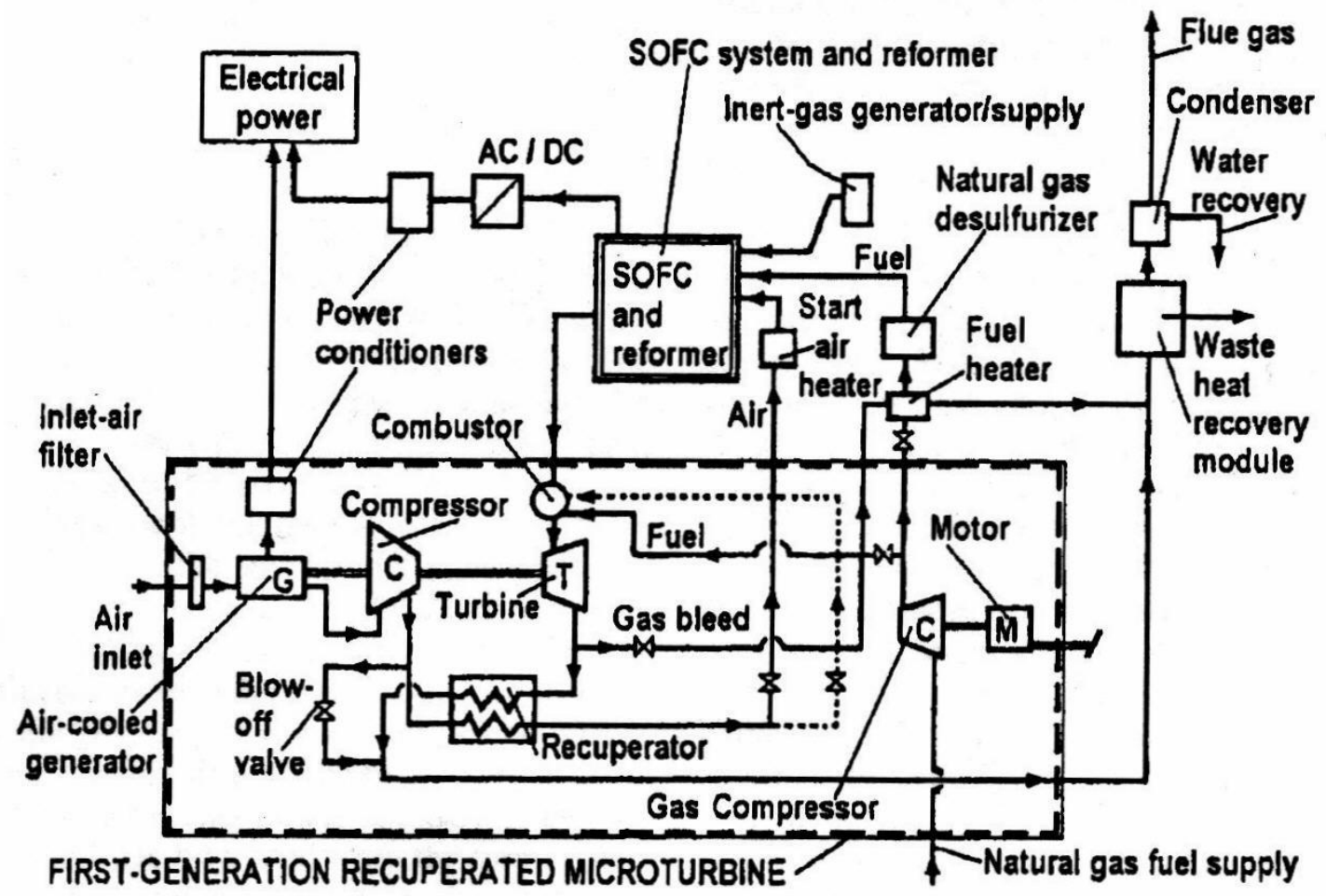

Figure 2-2 Schematic of a $\mu$ GT-SOFC system as given by Massardo, et. al. [18].

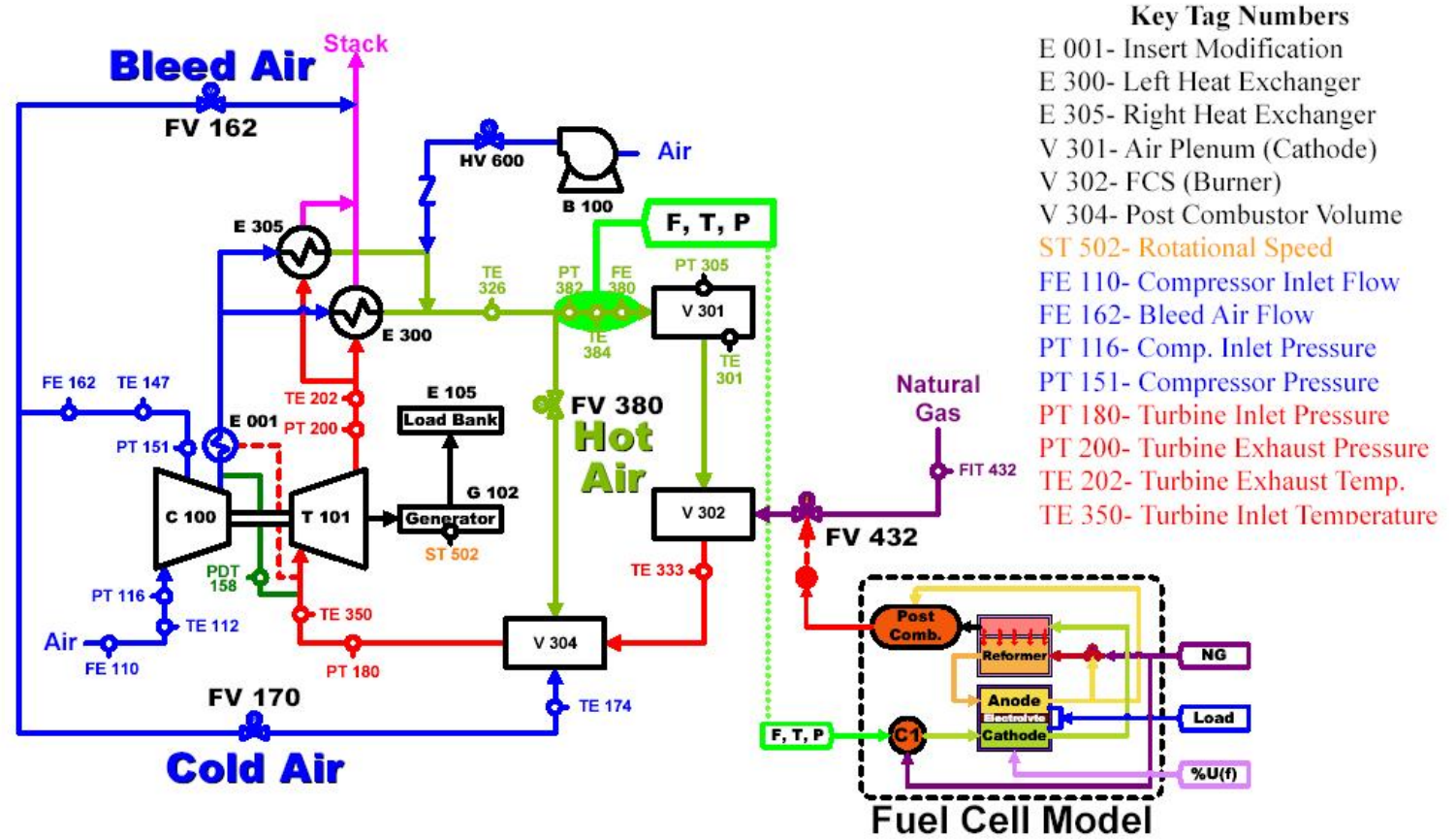

Figure 2-3 Flow diagram of the NETL HYPER test facility as given by Tucker, et. al. [21]. 
The hybrid systems discussed here should only be taken as examples of typical designs. A number of different configurations are possible, left to the imagination of the designer. Even though the setup of the fuel cell hybrid systems all, in one way or another, appear to be a derivative of the recuperative gas turbine cycle, there are significant operational differences in these different setups. It is in the direct-fired SOFC hybrid pressurized systems (e.g. Figures 2-2 and 2-3) that the work presented in this thesis will most likely find its greatest use. In these types of systems, the modeling of the transient behavior of the high pressure flow distribution in the system is critical because of compressor stall and surge issues as discussed by Tucker et. al. [21]. In particular if the transient behavior of the flow between the compressor and turbine can be better modeled, then a better understanding of the system dynamics will be learned. This will in turn lead to more efficient startup procedures and control strategies which will avoid compressor surge and stall conditions. 


\section{Methodology}

\subsection{Discretization of Equations for One-Dimensional Variable-Area Duct Model}

The conservative form of the continuity equation for a one-dimensional duct flow model with variable area was derived as

$$
\frac{\partial(\rho A)}{\partial t}+\frac{\partial(\dot{m})}{\partial x}=0
$$

where $\rho$ = density of the fluid

$$
\begin{aligned}
& \mathrm{A}=\text { cross-sectional area of duct } \\
& \dot{m}=\rho u A=\text { mass flow rate } \\
& \mathrm{u}=\text { axial velocity } \\
& \mathrm{t}=\text { time } \\
& \mathrm{x}=\text { axial direction of duct }
\end{aligned}
$$

The details of this derivation are given in the Appendix. Assuming that the area is constant in time, A on the left-hand side of (3-1) can be taken out of the differential. Dividing by the area (A) and moving the convection term to the right-hand side of the equation yields the following form of the continuity equation:

$$
\frac{\partial \rho}{\partial t}=-\frac{1}{A} \frac{\partial(\dot{m})}{\partial x}
$$

The conservative form of the differential momentum equation for a onedimensional duct flow model with variable area was derived as (see Appendix)

$$
\begin{aligned}
& \frac{\partial}{\partial t}(\dot{m})=-\frac{\partial}{\partial x}(u \dot{m})-A \frac{\partial P}{\partial x}+2 A \frac{\partial}{\partial x}\left[\mu \frac{\partial u}{\partial x}\right]-\tau_{w}\left(\pi D_{h}\right)-S_{\text {minor }} \\
& \text { where } \mathrm{P}=\text { pressure } \\
& \mu=\text { dynamic viscosity } \\
& \tau_{\mathrm{w}}=\text { wall shear stress } \\
& \mathrm{D}_{\mathrm{h}}=\text { hydraulic diameter of duct } \\
& \mathrm{S}_{\text {minor }}=\text { minor loss term due to sudden contraction, etc. }
\end{aligned}
$$

Discretizing (3-3) and assuming that the viscosity is constant over the cell in question yields 


$$
\begin{aligned}
\frac{\partial \dot{m}_{C}}{\partial t}= & -\frac{1}{(\Delta x)}\left[(\dot{m} u)_{e}-(\dot{m} u)_{w}\right]-\frac{\bar{A}}{(\Delta x)}\left[P_{e}-P_{w}\right] \\
& +\frac{2 \bar{A} \mu_{C}}{(\Delta x)^{2}}\left[u_{E}-2 u_{C}+u_{W}\right]-\overline{\tau_{w}}\left(\pi \overline{D_{h}}\right)-S_{\text {minor }}
\end{aligned}
$$

The C, E, W, e, and w subscripts in (3-4) refer to the location at which the quantities are evaluated. The interpretations of these subscripts depend on the integration method used, and are discussed in future sections (see Figures 3-1 and 3-2). The bar over the $A, D_{h}$, and $\tau_{\mathrm{w}}$ refers to the average values over the axial length of the cell to which (3-4) is applied.

Equation (3-3) can be put into non-conservative form by multiplying the continuity equation (3-1) by $\mathrm{u}$ and subtracting it from (3-3). The result is the nonconservative form of the momentum equation:

$\frac{\partial u}{\partial t}=-u \frac{\partial u}{\partial x}-\frac{1}{\rho} \frac{\partial P}{\partial x}+\frac{2}{\rho} \frac{\partial}{\partial x}\left[\mu \frac{\partial u}{\partial x}\right]-\tau_{w} \frac{\pi D_{h}}{\rho A}-\frac{S_{\text {minor }}}{\rho A}$

Again assuming that the viscosity is constant over the cell in question and discretizing (3-5) gives the following expression:

$$
\begin{aligned}
\frac{\partial u_{C}}{\partial t}=- & \frac{u_{C}}{(\Delta x)}\left[u_{e}-u_{w}\right]-\frac{1}{\rho_{C}(\Delta x)}\left[P_{e}-P_{w}\right] \\
& +\frac{2 \mu_{C}}{\rho_{C}(\Delta x)^{2}}\left[u_{E}-2 u_{C}+u_{w}\right]-\overline{\tau_{w}} \frac{\pi \overline{D_{h}}}{\rho_{C} \bar{A}}-\frac{S_{\text {minor }}}{\rho_{C} \bar{A}}
\end{aligned}
$$

Since momentum is a vector quantity, equations (3-3) through (3-6) are only accurate if the radius of curvature of the duct is much larger than the diameter of the duct. The term on the left-hand side of (3-6) is the instantaneous rate of increase of average momentum (per unit mass) within the cell. The first term on the right-hand side of (3-6) accounts for the net flux of momentum into the cell with the fluid passing through the duct. The second term on the right-hand side of (3-6) describes the pressure forces (in the axial (x) direction) on the cell at the east and west faces, as well as at the walls of the duct due to the irregular boundaries. The third term on the right-hand side of (3-6) 
accounts for the normal viscous forces on the cell, while the fourth term on the right-hand side of (3-6) is the force on the cell due to wall shear stress. Finally, the last term on the right-hand side of (3-6) accounts for minor losses that occur due to sudden contractions, etc. Note that this discussion of the terms was done in reference to equation (3-6), but the similar terms in equations (3-3) through (3-5) have essentially the same meaning, properly adjusted for units.

The conservative form of the differential mechanical energy equation for a onedimensional duct flow model with variable area was derived as (see Appendix)

$$
\frac{\partial}{\partial t}(\rho A K)=-\frac{\partial}{\partial x}(\dot{m} K)-u A \frac{\partial P}{\partial x}+2 u A \frac{\partial}{\partial x}\left[\mu \frac{\partial u}{\partial x}\right]-u \tau_{w} \pi D_{h}-u S_{\text {minor }}
$$

where $\mathrm{K}=$ kinetic energy per unit mass $=\mathrm{u}^{2} / 2$

Discretizing (3-7) assuming that $\mu$ is constant over the cell in question gives

$$
\begin{aligned}
\frac{\partial\left(\rho_{C} \bar{A} K_{C}\right)}{\partial t}= & -\frac{1}{(\Delta x)}\left[(\dot{m} K)_{e}-(\dot{m} K)_{w}\right]-\frac{u_{C} \bar{A}}{(\Delta x)}\left[P_{e}-P_{w}\right] \\
& +\frac{2 u_{C} \bar{A} \mu_{C}}{(\Delta x)^{2}}\left[u_{E}-2 u_{C}+u_{w}\right]-u_{C} \overline{\tau_{w}} \pi \overline{D_{h}}-u_{C} S_{\text {minor }}
\end{aligned}
$$

As was done with the momentum equation, the conservative form of the continuity equation (3-1) can be multiplied by $\mathrm{K}$ and subtracted from the conservative form of the kinetic energy equation (3-7). The result is the differential, non-conservative form of the kinetic energy equation for the one-dimensional, variable-area duct flow model:

$$
\frac{\partial K}{\partial t}=-u \frac{\partial K}{\partial x}-\frac{u}{\rho} \frac{\partial P}{\partial x}+\frac{2 u}{\rho} \frac{\partial}{\partial x}\left[\mu \frac{\partial u}{\partial x}\right]-\frac{u \tau_{w} \pi D_{h}}{\rho A}-\frac{u S_{\text {minor }}}{\rho A}
$$

Once again assuming that the viscosity is constant over the cell, and discretizing (3-9): 


$$
\begin{aligned}
\frac{\partial\left(K_{C}\right)}{\partial t}= & -\frac{u_{C}}{\Delta x}\left[K_{e}-K_{w}\right]-\frac{u_{C}}{\rho_{C}(\Delta x)}\left[P_{e}-P_{w}\right] \\
& +\frac{2 u_{C} \mu_{C}}{\rho_{C}(\Delta x)^{2}}\left[u_{E}-2 u_{C}+u_{w}\right]-\frac{u_{C} \overline{\tau_{w}} \pi \overline{D_{h}}}{\rho_{C} \bar{A}}-\frac{u_{C} S_{\text {minor }}}{\rho_{C} \bar{A}}
\end{aligned}
$$

All parameters in (3-10) are defined in previous equations. The term on the lefthand side of (3-10) stands for the time rate of increase of kinetic energy within the given cell, and the first term on the right-hand side is the net flux of kinetic energy into the cell across its boundaries. The second term on the right-hand side of (3-10) accounts for the rate of pressure work done on the control volume as well as the rate of reversible conversion of kinetic energy into internal energy (the compression effect). The third term on the right-hand side of equation (3-10) accounts for the normal viscous work done on the fluid as well as the irreversible rate of conversion of kinetic energy into internal energy. The second to last term in (3-10) models the wall friction effect, and the last term in (3-10) accounts for the minor losses that may occur in the duct. Note once again that this discussion of terms was done with reference to form (3-10) of the kinetic energy equation. The similar terms in equations (3-7) through (3-9) have the same meanings, properly adjusted for units.

The conservative differential form of the thermal energy equation for a onedimensional duct flow model with variable area was derived as (see Appendix)

$$
\begin{aligned}
& \frac{\partial}{\partial t}(\rho A h)=-\frac{\partial}{\partial x}(\dot{m} h)+A \frac{\partial P}{\partial t}+u A \frac{\partial P}{\partial x}+\frac{\partial}{\partial x}\left(k A \frac{\partial T}{\partial x}\right)+q^{*} \\
&+2 \mu \frac{\partial u}{\partial x} \frac{\partial(u A)}{\partial x}+u \tau_{w} \pi D_{h} \\
& \text { where } \mathrm{h}=\text { specific enthalpy of the fluid } \\
& \mathrm{T}=\text { temperature of the fluid } \\
& \mathrm{k}=\text { thermal conductivity of the fluid } \\
& \mathrm{q}^{*}=\text { rate of heat transfer into the fluid per unit length of axial direction }
\end{aligned}
$$

Note that in the derivation of equation (3-11) it was again assumed that the area of the duct was fixed in time. If the area were to change in time, the area (A) in the transient pressure term would fall inside the derivative. Since this assumption was made, the area 
(A) in the left-hand side of the equation could also have been removed from the differential. However, it is customary to leave the A inside when giving the conservative form of the equation. Discretizing (3-11), the following form of the thermal energy equation is obtained assuming that the thermal conductivity is constant over the cell in question:

$$
\begin{aligned}
\frac{\partial\left(\rho_{C} \bar{A} h_{C}\right)}{\partial t}= & -\frac{1}{(\Delta x)}\left[(\dot{m} h)_{e}-(\dot{m} h)_{w}\right]+\bar{A} \frac{\partial P_{C}}{\partial t}+\frac{u_{C} \bar{A}}{(2 \Delta x)}\left[P_{E}-P_{W}\right] \\
& +\frac{k_{C}}{(\Delta x)}\left[\left(A_{e} \frac{T_{E}-T_{C}}{\Delta x}\right)-\left(A_{w} \frac{T_{C}-T_{W}}{\Delta x}\right)\right]+q^{*} \\
& +\frac{2 \mu_{C}}{(\Delta x)^{2}}\left[u_{e}-u_{w}\right]\left[(u A)_{e}-(u A)_{w}\right]+u_{C} \bar{\tau}_{w} \pi \bar{D}_{h}
\end{aligned}
$$

Equation (3-11) can be rearranged and put into the non-conservative differential form of the thermal energy equation:

$$
\begin{aligned}
\frac{\partial h}{\partial t}= & -u \frac{\partial h}{\partial x}+\frac{1}{\rho} \frac{\partial P}{\partial t}+\frac{u}{\rho} \frac{\partial P}{\partial x}+\frac{1}{\rho A} \frac{\partial}{\partial x}\left(k A \frac{\partial T}{\partial x}\right)+\frac{q^{*}}{\rho A} \\
& +\frac{2 \mu}{\rho A} \frac{\partial u}{\partial x} \frac{\partial(u A)}{\partial x}+\frac{u \tau_{w} \pi D_{h}}{\rho A}
\end{aligned}
$$

Discretizing (3-13) assuming that the thermal conductivity is constant over the cell the following form of the thermal energy equation is obtained:

$$
\begin{aligned}
\frac{\partial h_{C}}{\partial t}= & -\frac{u_{C}}{(\Delta x)}\left[h_{e}-h_{w}\right]+\frac{1}{\rho_{C}} \frac{\partial P_{C}}{\partial t}+\frac{u_{C}}{\rho_{C}(2 \Delta x)}\left[P_{E}-P_{W}\right] \\
& +\frac{k_{C}}{\rho_{C} \bar{A}(\Delta x)}\left[\left(A_{e} \frac{T_{E}-T_{C}}{\Delta x}\right)-\left(A_{w} \frac{T_{C}-T_{W}}{\Delta x}\right)\right]+\frac{\overline{q^{*}}}{\rho_{C} \bar{A}} \\
& +\frac{2 \mu_{C}}{\rho_{C} \bar{A}(\Delta x)^{2}}\left[u_{e}-u_{w}\right]\left[(u A)_{e}-(u A)_{w}\right]+\frac{u_{C} \bar{\tau}_{w} \pi \bar{D}_{h}}{\rho_{C} \bar{A}}
\end{aligned}
$$

The specific enthalpy of an ideal gas is related to the temperature, $T$, through the relationship $d h=C_{p} d T$. For relatively small changes in temperature the specific heat of an 
ideal gas can generally be considered a constant at the average temperature. If the assumption is made that the temperature difference between the east and west faces of the cell is not drastic, the specific heat can be considered constant in the flow direction (x); for each cell though it should be calculated as a function of the temperature. Additionally, if the temperature change over the time step used by the solver is relatively small, the specific heat can also be considered constant over that time interval. Applying these assumptions to equation (3-13), the result is the removal of $C_{p}$ from the time derivative on the left-hand side and from the $\mathrm{x}$ derivative term on the right-hand side. Further dividing both sides by $\mathrm{C}_{\mathrm{p}}$ yields the differential form of the thermal energy equation in terms of temperature:

$$
\begin{aligned}
\frac{\partial T}{\partial t}= & -u \frac{\partial T}{\partial x}+\frac{1}{\rho C_{p}} \frac{\partial P}{\partial t}+\frac{u}{\rho C_{p}} \frac{\partial P}{\partial x}+\frac{1}{\rho A C_{p}} \frac{\partial}{\partial x}\left(k A \frac{\partial T}{\partial x}\right)+\frac{q^{*}}{\rho A C_{p}} \\
& +\frac{2 \mu}{\rho A C_{p}} \frac{\partial u}{\partial x} \frac{\partial(u A)}{\partial x}+\frac{u \tau_{w} \pi D_{h}}{\rho A C_{p}}
\end{aligned}
$$

Finally, discretizing (3-15) with the assumption once again that thermal conductivity is constant over the cell gives the following form of the thermal energy equation:

$$
\begin{aligned}
\frac{\partial T_{C}}{\partial t}= & -\frac{u_{C}}{(\Delta x)}\left[T_{e}-T_{w}\right]+\frac{1}{\rho_{C} C_{p_{C}}} \frac{\partial P_{C}}{\partial t}+\frac{u_{C}}{\rho_{C} C_{p_{C}}(2 \Delta x)}\left[P_{E}-P_{W}\right] \\
& +\frac{k_{C}}{\rho_{C} \bar{A} C_{p_{C}}(\Delta x)}\left[\left(A_{e} \frac{T_{E}-T_{C}}{\Delta x}\right)-\left(A_{w} \frac{T_{C}-T_{W}}{\Delta x}\right)\right]+\frac{\overline{q^{*}}}{\rho_{C} \bar{A} C_{p_{C}}} \\
& +\frac{2 \mu_{C}}{\rho_{C} \bar{A} C_{p_{C}}(\Delta x)^{2}}\left[u_{e}-u_{w}\right]\left[(u A)_{e}-(u A)_{w}\right]+\frac{u_{C} \bar{\tau}_{w} \pi \bar{D}_{h}}{\rho_{C} \bar{A} C_{p_{C}}}
\end{aligned}
$$

The term on the left-hand side of (3-16) stands for the rate of increase of temperature within the cell, and the first term on the right-hand side of (3-16) is the net flux of temperature into the cell due to convective transport. The second and third terms on the right-hand side of (3-16) take into account the pressure effects on the temperature change. The fourth term on the right-hand side of equation (3-16) represents the thermal conduction in the flow direction, while the fifth term is the $\mathrm{q}^{*}$ term which accounts for the heat flux into the cell through the wall of the duct. The second to last term in (3-16) 
will be discussed in detail in the next section and accounts for the viscous dissipation as well as a term which is the consequence of the geometry. Detailed derivations of all equations presented in this section can be found in the Appendix.

\subsection{Discussion of Terms in Equations for the Duct Model}

The Newtonian relationship of a fluid relates the viscous stresses with the gradients of velocity. This relationship is given by White [3] in tensor notation as

$$
\tau_{i j}=\xi \frac{\partial u_{k}}{\partial x_{k}} \delta_{i j}+\mu\left(\frac{\partial u_{i}}{\partial x_{j}}+\frac{\partial u_{j}}{\partial x_{i}}\right)
$$

$$
\text { where } \begin{aligned}
\tau_{i j} & =\text { the viscous stress tensor } \\
\xi & =\text { the coefficient of bulk viscosity } \\
\delta_{i j} & =\text { Kronecker delta }=\left\{\begin{array}{l}
1 \text { if } \mathrm{i}=\mathrm{j} \\
0 \text { if } \mathrm{i} \neq \mathrm{j}
\end{array}\right.
\end{aligned}
$$

The effect of the $\xi \frac{\partial u_{k}}{\partial x_{k}}$ bulk viscosity term is only important in conditions such as when dealing sound absorption, shock waves, strong acoustic waves, etc. White [3] mentions that in general the effect of this bulk viscosity term is very small, and neglecting the effect of this term is usually a good assumption. Therefore, in this study the effects of the bulk viscosity term were neglected giving the following simplified Newtonian relationship:

$$
\tau_{i j}=\mu\left(\frac{\partial u_{i}}{\partial x_{j}}+\frac{\partial u_{j}}{\partial x_{i}}\right)
$$

In the one-dimensional model developed here, the wall shear stress accounts for the $\tau_{12}$ and $\tau_{13}$ terms, and only the axial (x) direction stress term ( $\tau_{11}$ or $\tau_{x x}$ ) remains explicitly in the equations in the previous section. From (3-18) this axial viscous stress term is given by

$$
\tau_{x x}=2 \mu \frac{\partial u}{\partial x}
$$


Relationship (3-19) was used in the derivations in the previous section and in order to discuss the viscous dissipation it can be re-inserted into the kinetic and internal energy equations (3-9 and 3-15) yielding the following:

$\frac{\partial K}{\partial t}=-u \frac{\partial K}{\partial x}-\frac{u}{\rho} \frac{\partial P}{\partial x}+\frac{u}{\rho} \frac{\partial}{\partial x}\left[\tau_{x x}\right]-\frac{u \tau_{w} \pi D_{h}}{\rho A}-\frac{u S_{\text {minor }}}{\rho A}$

and

$$
\begin{aligned}
\frac{\partial T}{\partial t}= & -u \frac{\partial T}{\partial x}+\frac{1}{\rho C_{p}} \frac{\partial P}{\partial t}+\frac{u}{\rho C_{p}} \frac{\partial P}{\partial x}+\frac{1}{\rho A C_{p}} \frac{\partial}{\partial x}\left(k A \frac{\partial T}{\partial x}\right)+\frac{q^{*}}{\rho A C_{p}} \\
& +\frac{1}{\rho A C_{p}} \tau_{x x} \frac{\partial(u A)}{\partial x}+\frac{u \tau_{w} \pi D_{h}}{\rho A C_{p}}
\end{aligned}
$$

The normal viscous stress term in equation (3-20) can be rewritten in the following manner:

$$
\begin{aligned}
\frac{u}{\rho} \frac{\partial}{\partial x}\left[\tau_{x x}\right] & =\frac{1}{\rho A}\left[u A \frac{\partial}{\partial x}\left[\tau_{x x}\right]\right] \\
& =\frac{1}{\rho A}\left[\frac{\partial}{\partial x}\left[u A \tau_{x x}\right]-\tau_{x x} \frac{\partial(u A)}{\partial x}\right] \\
& =\frac{1}{\rho A}\left[\frac{\partial}{\partial x}\left[2 \mu u A \frac{\partial u}{\partial x}\right]-2 \mu \frac{\partial u}{\partial x} \frac{\partial(u A)}{\partial x}\right] \\
& =\frac{1}{\rho A}\left[\frac{\partial}{\partial x}\left[2 \mu u A \frac{\partial u}{\partial x}\right]-2 \mu\left[\frac{1}{A}\left[\frac{\partial(u A)}{\partial x}-u \frac{\partial A}{\partial x}\right] \frac{\partial(u A)}{\partial x}\right]\right] \\
& =\frac{1}{\rho A}[\underbrace{\frac{\partial}{\partial x}\left[2 \mu u A \frac{\partial u}{\partial x}\right]}_{1}-\frac{2 \mu}{A}[\underbrace{\left.\frac{\partial(u A)}{\partial x}\right]^{2}}_{2}-\underbrace{u \frac{\partial(u A)}{\partial x} \frac{\partial A}{\partial x}}_{3}]]
\end{aligned}
$$

Term 1 in equation (3-22) accounts for the rate of viscous normal work done on the fluid, term 2 is the loss of kinetic energy due to viscous dissipation, while term 3 is a consequence of the variable-area geometry of the duct. Likewise, in the thermal energy equation the normal viscous term can be rearranged into the following form: 


$$
\begin{aligned}
\frac{1}{\rho A C_{p}} \tau_{x x} \frac{\partial(u A)}{\partial x} & =\frac{2 \mu}{\rho A C_{p}} \frac{\partial u}{\partial x} \frac{\partial(u A)}{\partial x} \\
& =\frac{2 \mu}{\rho A^{2} C_{p}}[\underbrace{\left[\frac{\partial(u A)}{\partial x}\right]^{2}}_{2}-\underbrace{u \frac{\partial(u A)}{\partial x} \frac{\partial A}{\partial x}}_{3}]
\end{aligned}
$$

The terms listed as 2 and 3 in (3-23) are the same terms as in (3-22). However, as should be the case, the viscous dissipation acts as a source in the thermal energy equation (3-23) and a sink in the kinetic energy equation (3-22) as indicated by the plus and minus signs.

When the area of the duct becomes a constant value, the equations derived in the previous section simplify to the one-dimensional Navier-Stokes equations with the proper source terms. The texts by Bird et. al. [28] and White [3] both gave detailed derivations for the Navier-Stokes equations in three-dimensions. The derivations in both of these books were used as models with which to compare and contrast. Further giving credence to the validity of the derivations, the momentum and thermal energy equations were compared with those by Celik et. al. [27] and were found to be essentially the same, the only difference being that the ones used here account for normal shear stress, viscous dissipation, and axial heat conduction.

The methodology behind including the minor loss terms in the momentum equation was implemented in the following manner. In a duct flow, an effective pressure loss due to a minor loss can be calculated based on an empirical coefficient and the kinetic energy of the flow (based on applying the Bernoulli equation locally):

$$
\Delta P_{\text {loss }}=K_{\text {loss }} \frac{1}{2} \rho u^{2}
$$

Taking the derivative of (3-24) with respect to the axial direction (x) yields the relationship $\left.\frac{\partial P}{\partial x}\right|_{\text {loss }}=K_{\text {loss }} \rho u \frac{\partial u}{\partial x}$, where locally the density can be considered to remain approximately constant. Multiplying both sides by the cross-sectional area gives a loss term which is consistent with pressure term in the momentum equation (3-3): $A \frac{\partial P}{\partial x}$. A minor loss term can now be defined as 


$$
S_{\text {minor }}=K_{\text {loss }} \rho A u \frac{\partial u}{\partial x}
$$

where $\mathrm{K}_{\text {loss }}=$ loss coefficient for the particular type of minor loss

Discretizing equation (3-25) yields the following loss term used with the momentum equation (3-4):

$$
S_{\text {minor }}=K_{\text {loss }} \rho_{C} \bar{A} u_{C} \frac{\left(u_{e}-u_{w}\right)}{\Delta x}
$$

\subsection{Pseudo-Compressibility Model}

The numerical simulation of duct flows with nearly incompressible flow of gases such as air can be a difficult task. Many of the difficulties stem from the fact that a very small change in density can accompany a rather large change in pressure, making the system of equations stiff. To avoid this problem, many models are based on an incompressible flow (constant density) assumption. While the incompressible flow model gives fairly good results for low Mach number flows, a more accurate model takes the compressibility effect into account. In order to simplify the solution process the pseudo-compressibility model can be used to allow the pressure to be solved for in an explicit manner. The pseudo-compressibility model is based on the polytropic relationship between density and pressure:

$$
\frac{P}{\rho^{\gamma}}=\frac{P_{r e f}}{\rho_{r e f}^{\gamma}}
$$

$$
\begin{aligned}
& \text { where } \mathrm{P}=\text { absolute pressure } \\
& \rho=\text { density of the fluid } \\
& \mathrm{P}_{\text {ref }}=\text { absolute reference pressure } \\
& \rho_{\text {ref }}=\text { reference density of the fluid } \\
& \gamma=\text { polytropic exponent }
\end{aligned}
$$

The polytropic exponent, $\gamma$, is a free parameter of the model. If $\gamma=C_{p} / C_{v}$ (ratio of specific heats), the polytropic relationship becomes an isentropic relationship. If $\gamma=1$, the polytropic relationship becomes an isothermal relationship. Solving (3-27) for density yields 
$\rho=\left(\frac{P}{\lambda}\right)^{1 / \gamma}$

where $\lambda=\frac{P_{r e f}}{\rho_{r e f}^{\gamma}}=$ polytropic reference ratio

Substituting (3-28) into the continuity equation (3-2) gives a relationship for pressure as a function of the mass flow, reference pressure, and reference density:

$$
\begin{array}{r}
\frac{\partial P}{\partial t}=-\frac{\gamma \lambda^{1 / \gamma}}{A} P^{\gamma^{*}}\left(\frac{\partial \dot{m}}{\partial x}\right) \\
\text { where } \gamma^{*}=\frac{\gamma-1}{\gamma}
\end{array}
$$

Discretizing (3-29) yields the following relationship:

$$
\frac{\partial P_{C}}{\partial t}=-\frac{\gamma \lambda^{1 / \gamma}}{\bar{A}} P_{C}^{\gamma^{*}}\left(\frac{\dot{m}_{e}-\dot{m}_{w}}{\Delta x}\right)
$$

This relationship allows for the calculation of pressure in an explicit manner from the mass flow rate and the pressure itself. Additionally, this expression can be used in the right-hand side of the thermal energy equation. In the numerical solution of (3-30), the reference density and pressure ( $\rho_{\text {ref }}$ and $P_{\text {ref }}$ ) are updated at each new time level to reflect the changing temperature of the fluid. The density can be calculated at each time level after solving for the pressure and temperature by the ideal gas relationship $\rho=\frac{P}{R T}$

where $\mathrm{R}$ = ideal gas constant for fluid being used

Two things should be noted here. First, for an isothermal flow, equations (3-31) and (3-28) with $\gamma=1$ are equivalent because the temperature does not change. Additionally for an isothermal flow, since the temperature does not change, the reference density and pressure can be taken as constant values and never updated. This can be shown by the rearrangement of (3-31): 


$$
\frac{P_{1}}{\rho_{1}}=R T_{r e f}=\frac{P_{r e f}}{\rho_{r e f}}
$$

The second thing to note is the value of $\gamma$ used for a temperature varying flow. As mentioned before $\gamma$ is a free parameter of the model. If the value of $\gamma$ is set to equal one, this is the equivalent to assuming that over the time step in question using (3-30), the temperature is the reference temperature as calculated by the ideal gas relationship (3-32). This is not a bad assumption in and of itself, especially if a predictor-corrector or similar method is used. However, if a value of $\gamma$ can be calculated dynamically that more accurately reflects the temperature-varying relationship between time steps, the fidelity of the model should be improved.

\subsection{Staggered Grid}

Figure 3-1 shows a sketch of a staggered grid for a duct with generic axiallyvarying cross-section. Pressure, density, and temperature are evaluated at the solid nodes (referred to as pressure or main nodes) while velocity and mass flow rate are evaluated on the open nodes (referred to as velocity nodes). The crosshatched area in Figure 3-2(a) illustrates a typical cell for a main node. Equations such as (3-30), (3-28), and (3-16) are solved at typical main node cells like this one for pressure, density and temperature respectively. The velocity and mass flow terms on the right-hand side of these three equations are evaluated at the 'e' and 'w' velocity nodes (see, e.g. (3-30)). The pressure values are evaluated at the ' $C$ ', ' $E$ ', or ' $W$ ' main nodes. The ' $e$ ' and ' $w$ ' temperature terms in the convective transport term of the energy equations are actually evaluated at the ' $E$ ', ' $C$ ', or ' $W$ ' main nodes. However, the exact method used to determine the location depends on the numerical method used, as will be discussed in later sections.

The crosshatched area in Figure 3-2(b) illustrates a typical cell for a velocity node. Equation (3-4) or (3-6) is solved at velocity nodes like this for mass flow rate or velocity. If the kinetic energy model is being used, equation (3-8) or (3-10) is also solved at these nodes. All pressure, density, and temperature terms in these equations are evaluated at the respective 'e', 'C', or ' $w$ ' nodes as dictated by the discretization, where the values at the $\mathrm{C}$ node are taken as the average of the values at the ' $\mathrm{e}$ ' and ' $\mathrm{w}$ ' main nodes. Using the staggered grid will help guard against the checkerboarding effect which 
can occur due to using central differencing on an unstaggered grid [4]. The boundary conditions used with this staggered grid are discussed in a future section.

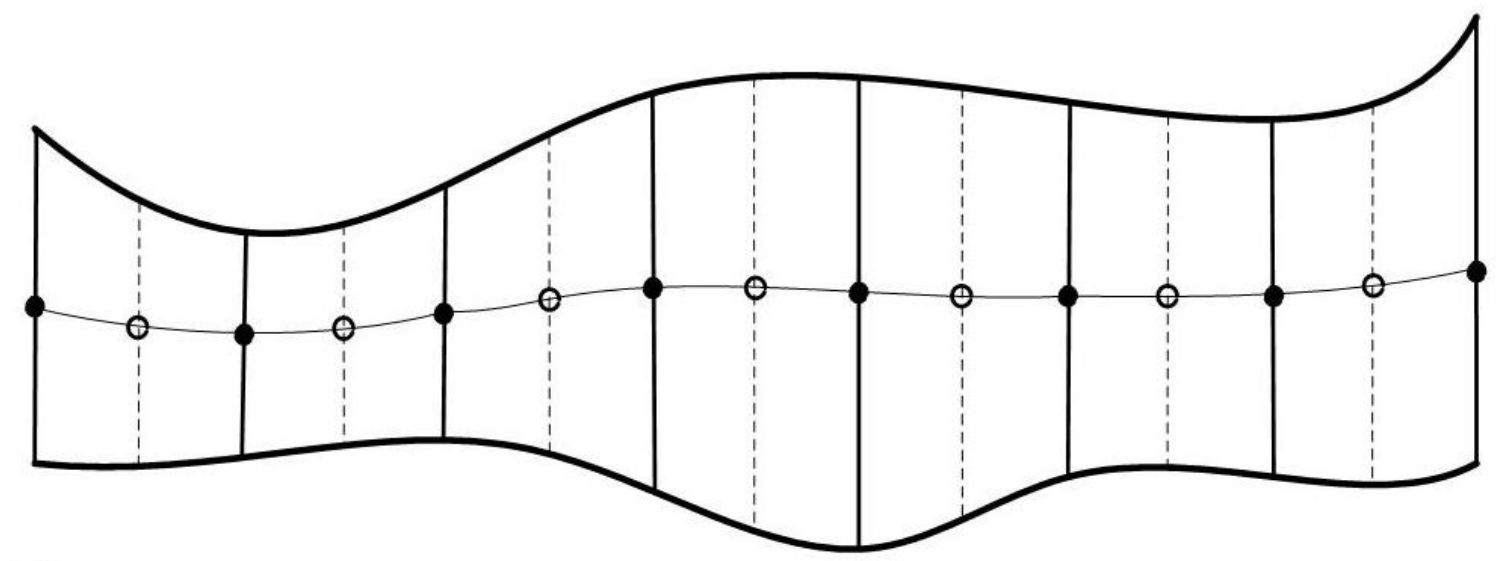

Figure 3-1 Diagram of staggered grid for generic duct cross-section; solid circles refer to main nodes and open circles refer to velocity nodes.
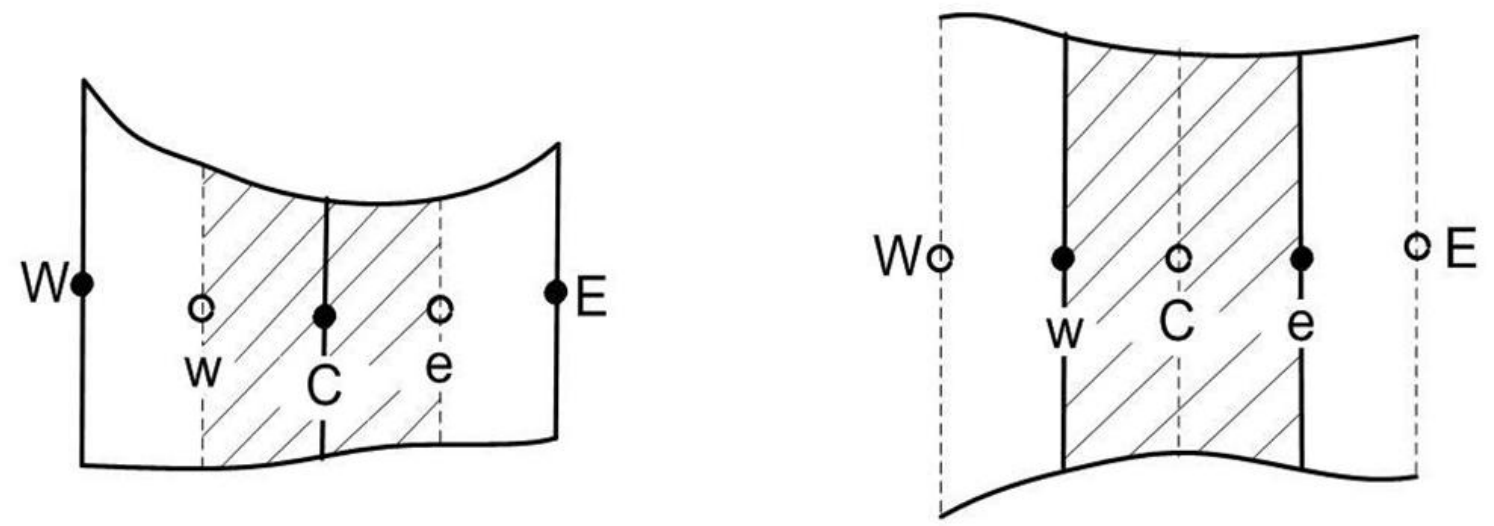

Figure 3-2 Typical cells for (a) main nodes, and (b) velocity nodes; solid circles refer to main nodes and open circles refer to velocity nodes.

\subsection{Minor Losses within the Duct}

For ducts with sudden contractions, minor losses within the duct must be accounted for due to the development of a vena contracta. In order to accurately model a vena contracta loss, a minor loss coefficient was assumed which was greatest at the 
location of the sudden contraction, and slowly decreased with distance from the contraction in a smooth manner:

$$
\begin{aligned}
& K_{\text {loss }}= K_{o} e^{-\alpha x} \\
& \text { where } \mathrm{K}_{\mathrm{o}}=\text { contraction loss coefficient at } \mathrm{x}=0 \\
& \alpha=\text { contraction loss relaxation coefficient }
\end{aligned}
$$

$\mathrm{K}_{\text {loss }}$ was then used in accordance with the minor loss term derived in equation (3-26) and used in the momentum equation (3-4).

The loss coefficient for flow through a diffuser, as suggested by White [5] was approximated by making use of the pressure coefficient:

$$
\begin{aligned}
C_{\text {press }} \equiv \frac{P_{e}-P_{w}}{P_{o_{w}}-P_{w}} & =\frac{P_{e}-P_{w}}{\frac{1}{2} \rho u_{w}^{2}} \\
\text { where } P_{\mathrm{e}} & =\text { Pressure at exit (east) of cell } \\
\mathrm{P}_{\mathrm{w}} & =\text { Pressure at entrance (west) of cell } \\
\mathrm{P}_{\mathrm{o}} & =\text { stagnation pressure }=P+\frac{1}{2} \rho u^{2} \\
\mathrm{u}_{\mathrm{w}} & =\text { axial velocity at entrance (west) of cell } \\
\mathrm{u}_{\mathrm{e}} & =\text { axial velocity at exit (east) of cell }
\end{aligned}
$$

By assuming ideal (inviscid) conditions, locally (nearly) incompressible flow, and making use of the Bernoulli relationship, the inviscid pressure coefficient can be calculated from

$$
C_{\substack{\text { press } \\ \text { inviscid }}}=1-\left(\frac{d_{w}}{d_{e}}\right)^{4}
$$

where $d_{w}=$ local entrance (west) diameter for the cell $\mathrm{d}_{\mathrm{e}}=$ local exit (east) diameter for the cell

An approximate loss coefficient can be calculated as the difference between the inviscid (3-35) and actual (3-34) pressure ratios:

$$
K_{\text {loss }}=C_{\substack{\text { press } \\ \text { inviscid }}}-C_{\text {press }}=1-\left(\frac{d_{w}}{d_{e}}\right)^{4}-\frac{P_{e}-P_{w}}{\frac{1}{2} \rho u_{w}^{2}}
$$

This diffuser loss coefficient (3-36) was used in conjunction with the minor loss term derived in equation (3-26) and used in the momentum equation (3-4). 


\subsection{MacCormack Method and the FORTRAN Code}

In order to make use of the mathematical model created, a FORTRAN code was written utilizing the MacCormack method and the staggered grid arrangement. For discretized equations such as (3-4) and (3-10) the time derivative on the left-hand side of the equations dictates that they be evaluated at velocity nodes. However, the convection term on the right-hand side shows that a value (velocity, mass flow rate, or kinetic energy) is needed at the east (e) and west (w) cell faces. The MacCormack remedy to this situation is to use a backward difference in the predictor step and a forward difference in the corrector step. This amounts to evaluating the ' $\mathrm{e}$ ' quantity (velocity, mass flow, or kinetic energy) at the $\mathrm{C}$ velocity node in the predictor step and the ' $\mathrm{w}$ ' quantity at the ' $W$ ' node. Then in the corrector step, the ' $e$ ' quantity is evaluated at the ' $E$ ' node while the ' $w$ ' quantity is evaluated at the $C$ node. The MacCormack technique was used because it is a simple approach which is second-order in both time and space [4].

A stiff system of equations is one in which the transients of the dependent variables change over a time scale which is much smaller than the time scale for the solution of interest. Because of the quick-changing nature of such systems, the stability of the numerical method used is an issue, and explicit solution techniques often become unstable. Even if an explicit numerical solution method can be used for a stiff system, the accuracy of the solution may lack fidelity in the quick-changing regions of the dependent variables. Additionally, if an explicit method can remain stable for a stiff system, it usually does so at the cost of using a very small time step (in comparison with an implicit numerical solution method).

The system of equations presented to model the one-dimensional duct flow is stiff in nature, and therefore the stability of the numerical method used was an issue. In order to make the code stable, in the numerical solution a semi-implicit procedure was used with the MacCormack method. In this procedure as soon as the predicted or new values were calculated in the predictor or corrector step respectively, these quantities were used in the solution of the other equations in the same predictor or corrector step. For example, in the predictor step the pressure at the next time level was solved for first using equation (3-30) with the values on the right-hand side evaluated at the old time level. 
However, when the momentum equation (3-4) was then solved in the predictor step, the predicted pressure at the next time level (just solved for from (3-30)) was used along with the other quantities for velocity, mass flow, etc. from the old time level. Note that in the FORTRAN code written, the conservative momentum equation (3-4), pseudocompressible continuity equation (3-30), and occasionally the non-conservative kinetic energy equation (3-10) were solved.

In order to model the wall shear stress term in the momentum, kinetic energy and thermal energy equations, the dimensionless friction factor was utilized:

$$
C_{f}=\frac{\tau_{w}}{\frac{1}{2} \rho u^{2}}
$$

where $\mathrm{C}_{\mathrm{f}}=$ dimensionless friction factor

For fully-developed laminar pipe flow the friction factor can be calculated from the analytical solution $C_{f}=16 / \operatorname{Re}_{D}$, where $\operatorname{Re}_{\mathrm{D}}$ is the Reynolds number based on the diameter of the pipe:

$\operatorname{Re}_{D}=\frac{\rho u D_{h}}{\mu}=\frac{4 \dot{m}}{\pi D_{h} \mu}$

For turbulent fully-developed pipe flow the friction factor is a function of not only the Reynolds number but also the roughness of the pipe. In the turbulent regime an appropriate friction factor can be taken from the famous Moody diagram. In the FORTRAN program, the friction factor was based on an assumed pipe roughness to diameter ratio $(\varepsilon / D)$ of approximately 0.02 , leading to a $C_{f}$ value in the fully turbulent regime of 0.0125 . In order to smoothly connect the laminar and fully turbulent regimes, the following piecewise curve fit was used. In the laminar regime (assumed to be $\mathrm{Re}_{\mathrm{D}}<$ $2 \times 10^{3}$ ), the $C_{f}=16 / \mathrm{Re}_{\mathrm{D}}$ relationship was used. In the transition region (assumed to be $2 \times 10^{3}<\operatorname{Re}_{\mathrm{D}}<4 \times 10^{3}$ ), a third order polynomial was fit which matched the slope and the value of $\mathrm{C}_{\mathrm{f}}$ at the two neighboring sections. In the range between the transition region and the fully-turbulent regime (assumed to be $4 \times 10^{3}<\operatorname{Re}_{\mathrm{D}}<1 \times 10^{5}$ ), an exponential curve was fit that mimicked the slowly decreasing behavior of the curve corresponding to 
an $\varepsilon / \mathrm{D}$ ratio of 0.012 in the Moody diagram. This curve smoothly moved into the fully turbulent regime with increasing $\mathrm{Re}_{\mathrm{D}}$ where the $\mathrm{C}_{\mathrm{f}}$ value of 0.01 was reached at approximately $\operatorname{Re}_{\mathrm{D}}=1 \times 10^{5}$. Figure 3-3 shows the results of this curve fit. It should be noted that this particular friction factor relationship was not used to model the NETL HYPER test facility; this issue is addressed in future sections.

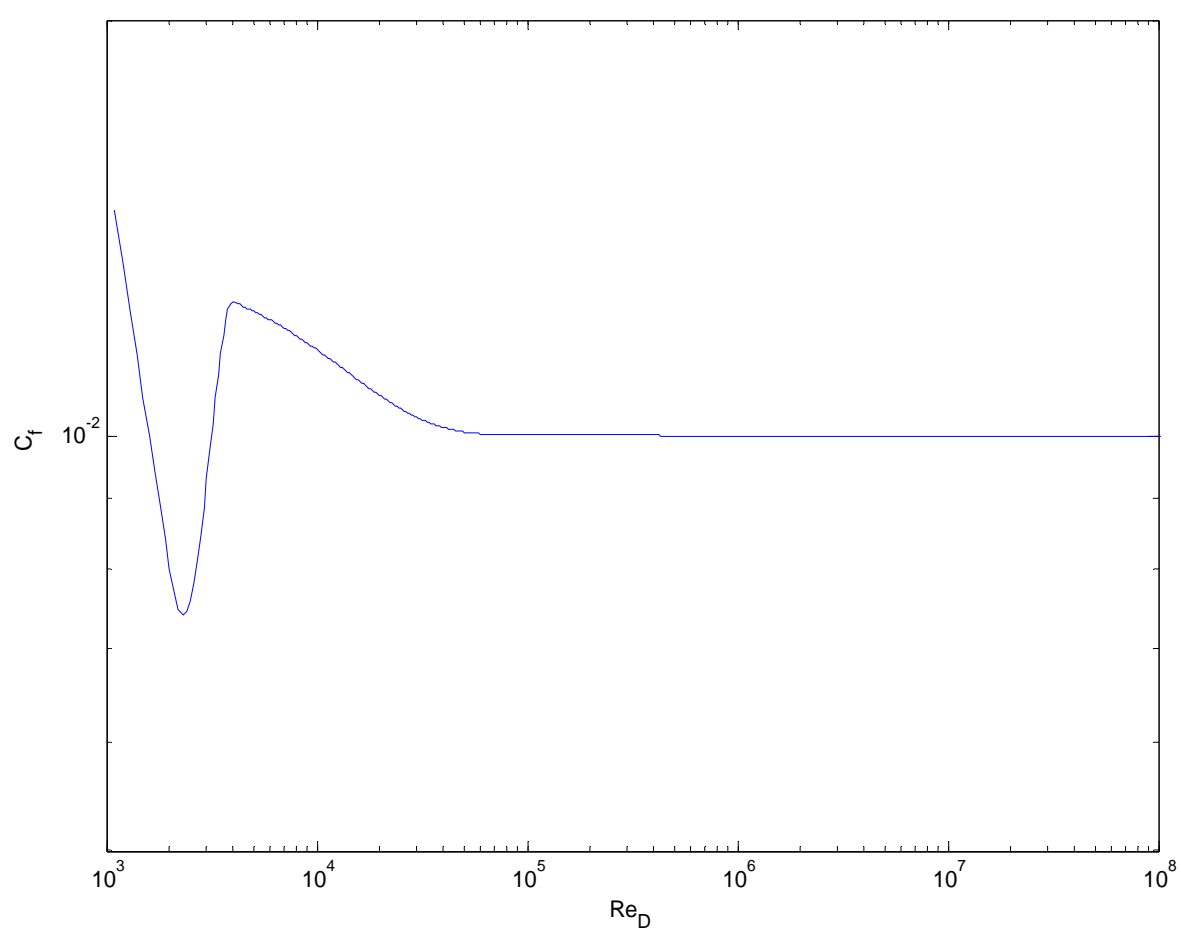

Figure 3-3 Curve fit for the dimensionless friction factor vs. $\mathrm{Re}_{\mathrm{D}}$ with an assumed $\varepsilon / \mathrm{D}$ ratio of 0.012 .

\subsection{Simulink Models}

For the Simulink workspace, plenum, tee and elbow models were created to simulate the junction of several ducts in the system. These models were very similar in methodology, but varied slightly in detail. The following four sections explain how the tee, plenum, and elbow models were created, how the duct model was implemented in Simulink, and how the different pieces were combined in the Simulink workspace. 


\subsubsection{Plenum model}

Using a control volume analysis, the continuity equation was applied to the plenum and used to model the amount of mass in the plenum at any given time:

$$
\left.\frac{d m}{d t}\right|_{\text {plenum }}=\sum_{\text {in }} \dot{m}-\sum_{\text {out }} \dot{m}
$$

where $\dot{m}=$ mass flow rate into or out of the plenum

in $=$ inlet port

out $=$ outlet port

In (3-39) the inlet and outlet mass flows are in the assumed positive directions of the flow as the system was set up. The volume for the plenum was assumed to be fixed in time (rigid tank), and the initial mass inside of the plenum was assumed to be equal to the reference density times the plenum volume. At each time step, (3-39) was integrated numerically with respect to time in Simulink to determine the mass inside of the plenum.

Further using a control volume First Law analysis on the plenum, the following equation was derived to model the temperature of the gas within the plenum:

$$
\begin{aligned}
& \frac{d T_{\text {plenum }}}{d t}=\frac{1}{m_{\text {plenum }}}\left[-T_{\text {plenum }}\left[\sum_{\text {in }} \dot{m}-\sum_{\text {out }} \dot{m}\right]+\kappa\left[\sum_{\text {in }}(\dot{m} T)-\sum_{\text {out }}(\dot{m} T)\right]-\frac{\dot{Q}_{\text {loss }}}{C_{v}}\right] \\
& \text { where } \mathrm{T}_{\text {plenum }}=\text { temperature of the gas within the plenum } \\
& \mathrm{m}_{\text {plenum }}=\text { mass of gas within the plenum } \\
& \mathrm{C}_{\mathrm{v}}=\text { specific heat of fluid } \\
& \kappa=\mathrm{C}_{\mathrm{p}} / \mathrm{C}_{\mathrm{v}}=\text { ratio of specific heats } \\
& \dot{Q}_{\text {loss }}=\text { rate of heat escaping from the plenum through its walls }
\end{aligned}
$$

In the derivation of (3-40), the continuity equation (3-39) was substituted into the energy equation in order to account for the mass change in time. The fluid exiting the plenum was assumed to be at the same temperature as the calculated plenum temperature. Making this substitution gave the following version of the plenum temperature model:

$$
\frac{d T_{\text {plenum }}}{d t}=\frac{1}{m_{\text {plenum }}}\left[-T_{\text {plenum }}\left[\sum_{\text {in }} \dot{m}-\sum_{\text {out }} \dot{m}\right]+\kappa\left[\sum_{\text {in }}(\dot{m} T)-T_{\text {plenum }} \sum_{\text {out }} \dot{m}\right]-\frac{\dot{Q}_{\text {loss }}}{C_{v}}\right]
$$

The mass flows in and out of the plenum were taken from the boundary values of connecting duct models, and the temperature of the fluid entering the plenum was 
likewise taken from the duct models' last cell values. Equation (3-41) was integrated numerically in Simulink to calculate the temperature of the fluid within the plenum. With the mass (from (3-39)) and volume of the plenum known at any given time step, the density was calculated by dividing the mass by the volume. The temperature of the gas within the plenum was calculated using (3-41) and with the density inside the plenum known, the pressure was then calculated using the ideal gas relationship (3-31).

Since the pseudo-compressibility (3-30) and momentum (3-4) equations were set up to be solved using boundary values of pressure at the duct inlet and outlet, the pressures at the duct/plenum interfaces had to be determined at all ports, i. One way to approximate these boundary values of pressure is to simply assume that the pressure at the boundary is the same as the pressure in the plenum. However, this fails to take into account the fact that (1) there is flow at the plenum/duct interface, which makes the pressure less than that in the nearly stagnant plenum, and (2) there are minor losses between the plenum and the interface due to a sudden expansion or contraction depending on whether the flow is in or out of the plenum, respectively. Therefore, in order to accurately model the plenum, the following relationship was used to determine the pressures at the plenum/duct interfaces based on the plenum pressure:

$$
\begin{aligned}
& P_{i}=P_{\text {plenum }}-\frac{1}{2} \rho_{i} u_{i}^{2}+K_{\text {loss }} \frac{1}{2} \rho_{i} u_{i}^{2} \\
& \text { where } \mathrm{P}_{\text {plenum }}=\text { plenum pressure } \\
& \mathrm{P}_{\mathrm{i}}=\text { pressure at the } \mathrm{i}^{\text {th }} \text { interface (plenum port) } \\
& \mathrm{K}_{\text {loss }}=\text { minor loss for sudden contraction or sudden expansion }
\end{aligned}
$$

If the flow is into the plenum, the loss can be considered to occur downstream of the interface and upstream of the plenum. For this situation $\mathrm{K}_{\text {loss }}$ will have a positive sign and take the value for a sudden expansion. Likewise, if the flow is out of the plenum the loss can be considered to occur downstream of the plenum and upstream of the interface. In this case $\mathrm{K}_{\text {loss }}$ will have a negative sign and take the value for a sudden contraction. White [5] gives approximate $\mathrm{K}_{\text {loss }}$ values for a sudden expansion and a sudden contraction as $\mathrm{K}_{\text {expansion }}=1.0$ and $\mathrm{K}_{\text {contraction }}=0.4$ where the ratio of the diameter of the smaller pipe to the diameter of the larger pipe is below approximately 0.1. Figure 3-4 shows a sketch of a generic plenum with three ports with the assumed positive direction of each port 
indicated. Figure 3-4 also illustrates the general locations of the calculated plenum and interface pressures.

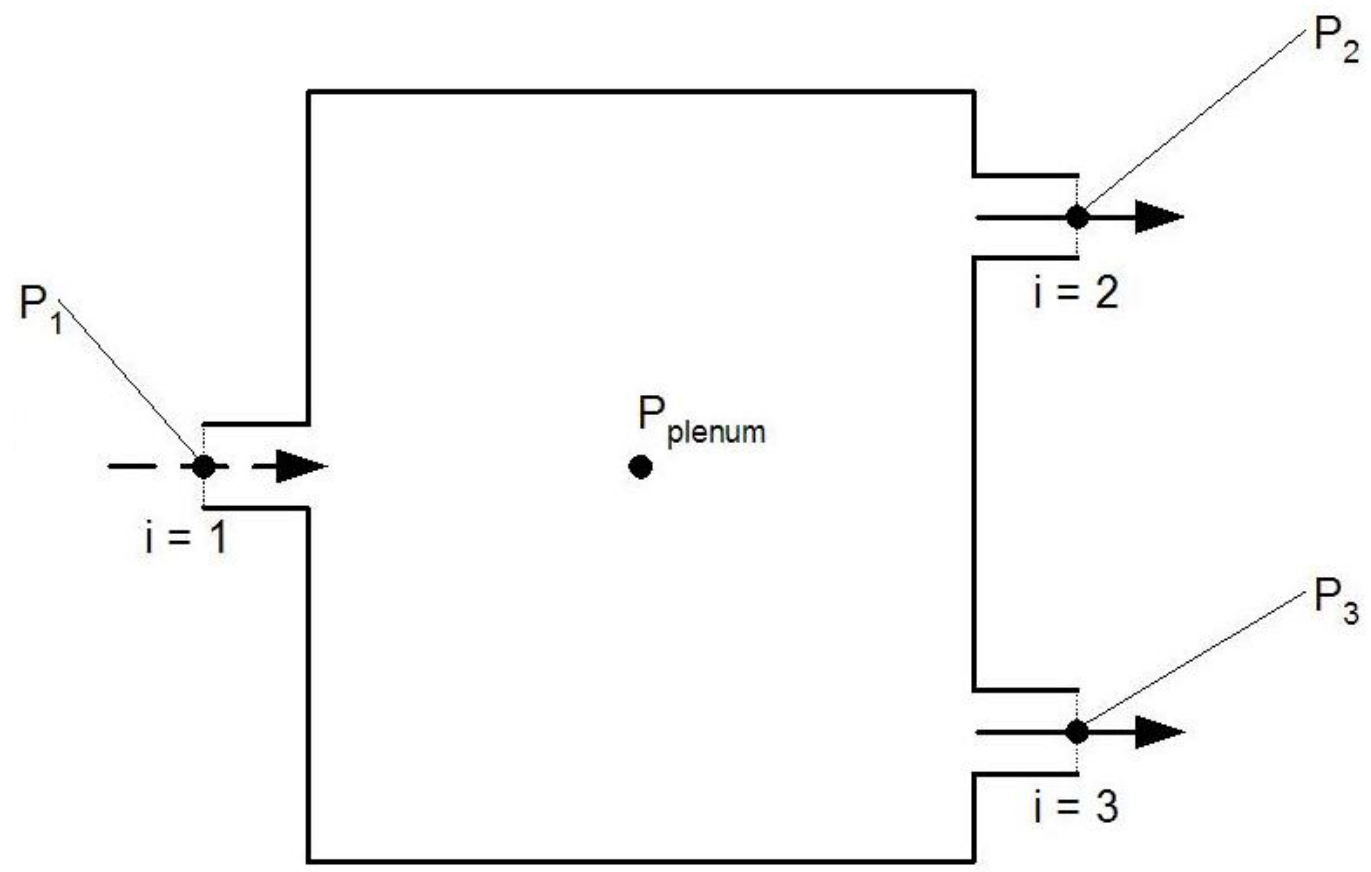

Figure 3-4 Typical plenum showing location of plenum/duct interfaces as thin dashed lines with port numbers $i=1$ through $i=3$. Note that the thick dashed arrow represents a port where the flow is assumed positive into the plenum and the thick solid arrow represents a port where the flow is assumed positive out of the plenum.

Figure 3-5 shows the block diagram of the plenum model in the Simulink workspace. Figure 3-6 illustrates the temperature and pressure models that lie inside of the plenum block (Figure 3-5). Figures 3-7 and 3-8 show the insides of the temperature and pressure models shown in Figure 3-6. Figure 3-7 gives the Simulink representation of the mathematical model given by (3-41), while Figure 3-8 shows the model for (3-39) and the minor losses calculated with (3-42). 


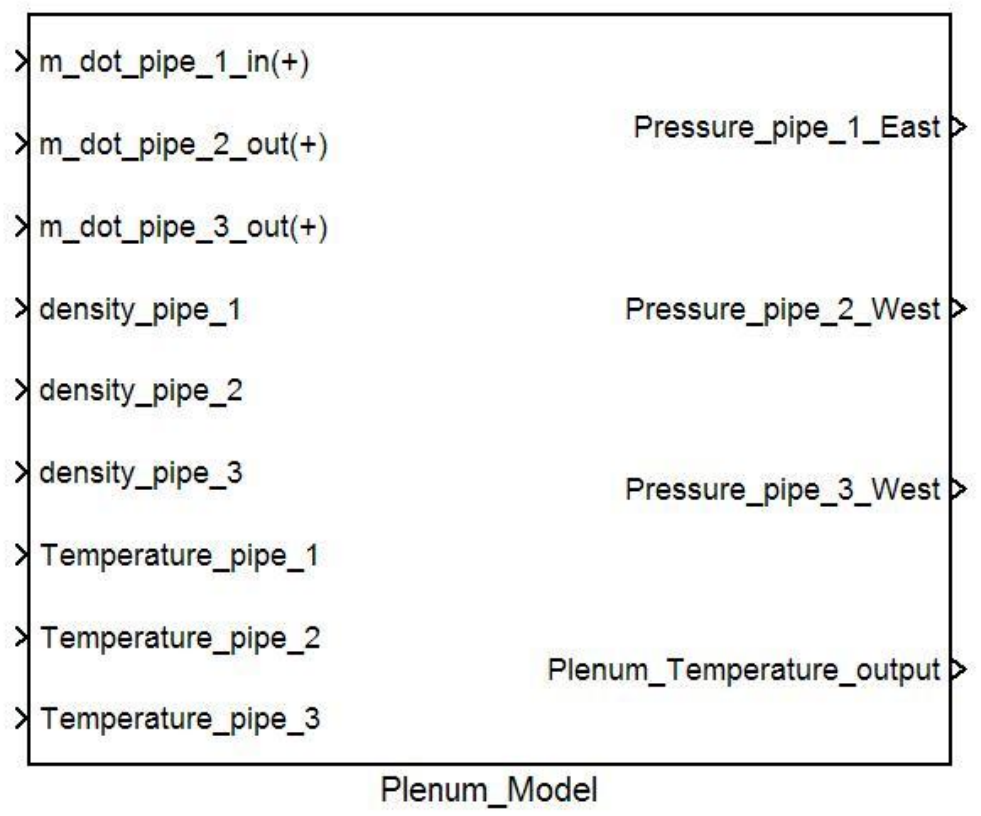

Figure 3-5 Simulink plenum block diagram for connection with three ducts.

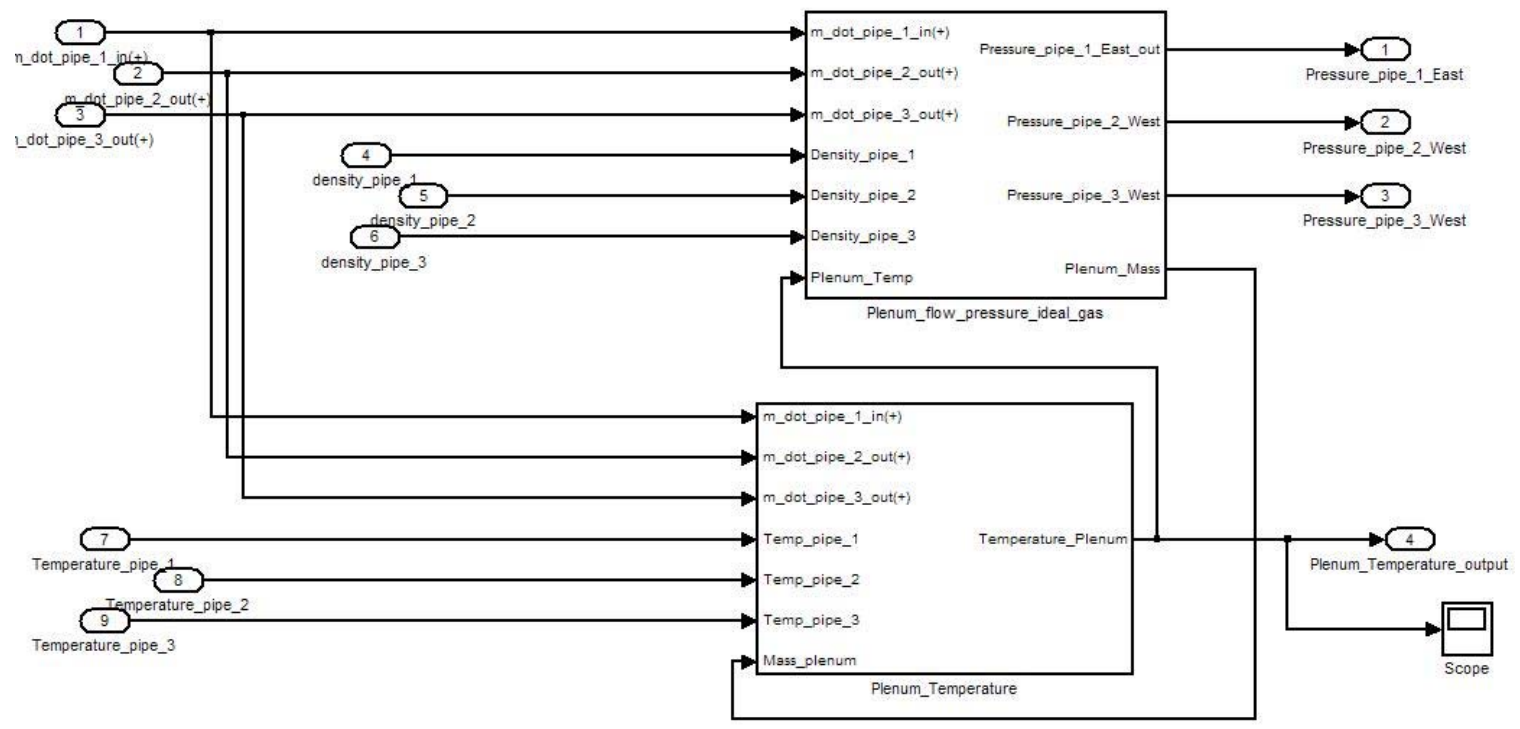

Figure 3-6 Simulink plenum model interior showing both temperature and pressure model blocks. 


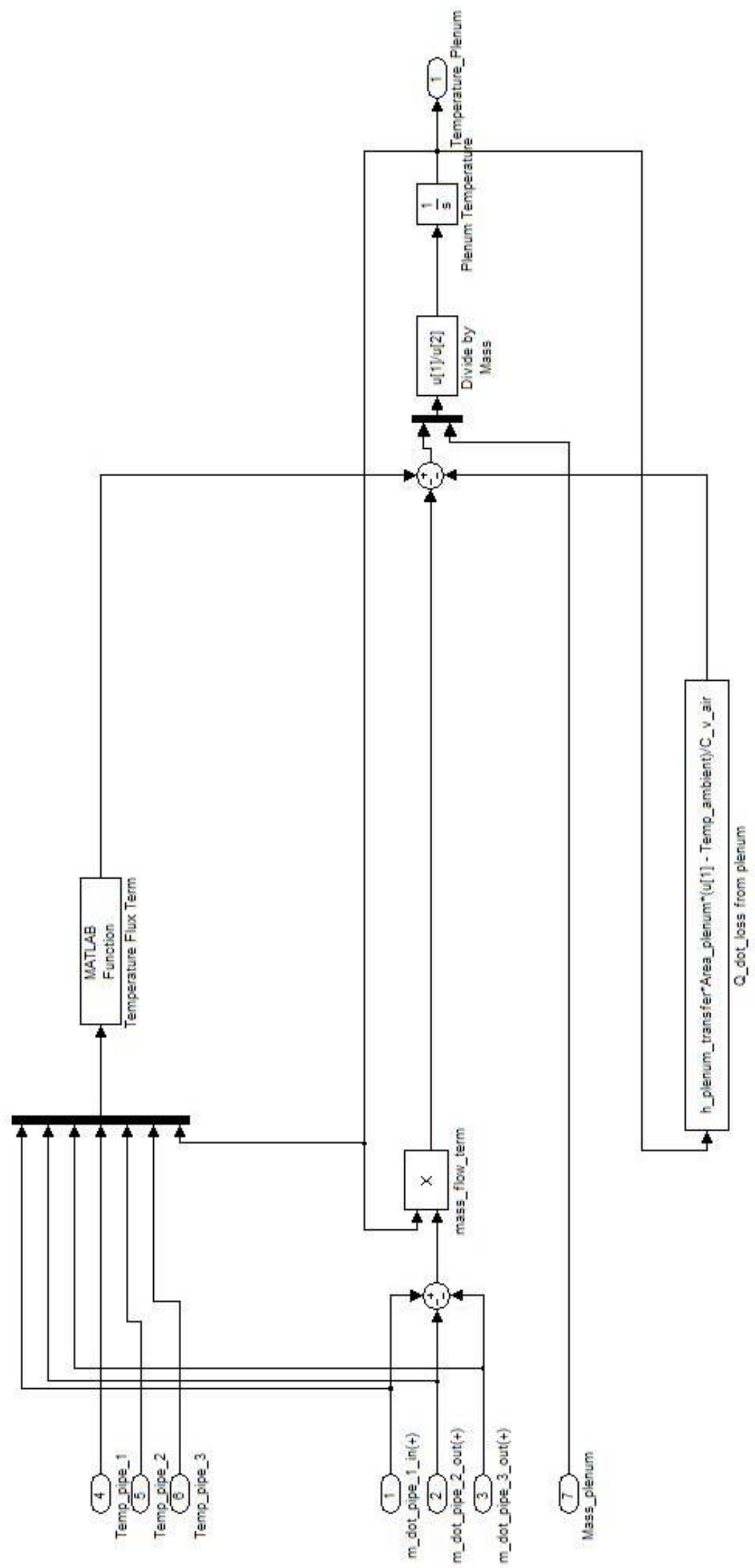

Figure 3-7 Simulink plenum temperature model. 


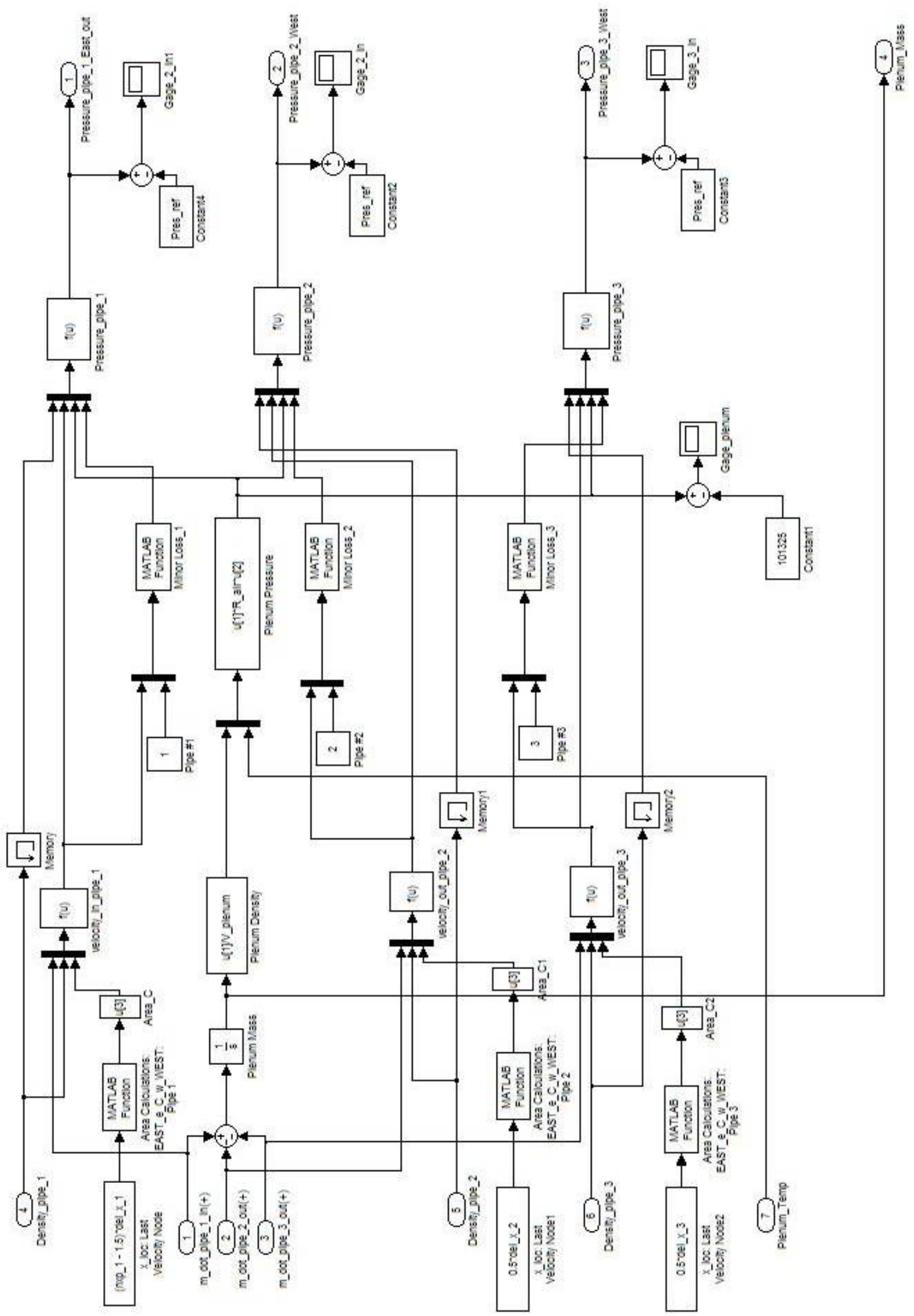

Figure 3-8 Simulink plenum pressure and minor loss model. 


\subsubsection{Tee junction model}

The derivation of equation (3-41) was also valid for the modeling of the temperature of the fluid inside of the tee. Since the heat loss or addition for the entire tee was taken into account in the derivation, the average temperature of the fluid exiting the tee should be close to the calculated tee temperature. Therefore, the exit temperature was again assumed to be the same as the tee temperature. The time integration of equation (3-39) was also used to model the mass inside of the tee junction at any given point in time, as the derivation of this equation is valid for the tee as well as the plenum. In the case of the tee however, the volume was approximated as the value of the three connecting duct diameters multiplied together. As was done with the plenum, the density inside the tee was determined by dividing the mass by the volume, and with the temperature calculated from (3-41) the ideal gas relationship (3-31) was again used to estimate the pressure inside the tee. For flow loss calculations, the velocity inside the tee was approximated by calculating the total mass flow in and then dividing by the calculated tee density and area. Here the area was based on the average of the diameters of the pipes connected to the tee, and calculated as if it were a circular cross-section.

The tee/duct interface pressures and loss terms in the tee were calculated in a slightly different manner than the plenum. Essentially the same equation as (3-42) was used to determine the pressure at the tee/duct interfaces, but since in a tee there is no sudden expansion loss when the flow enters, there is always a negative sign in front of the loss term, and $\mathrm{K}_{\text {loss }}$ is taken as zero when i refers to an inlet port:

$$
P_{i}=P_{\text {tee }}+\frac{1}{2} \rho_{\text {tee }} u_{\text {tee }}^{2}-\frac{1}{2} \rho_{i} u_{i}^{2}-K_{\text {loss }} \frac{1}{2} \rho_{i} u_{i}^{2}
$$

In (3-43) the $\mathrm{K}_{\text {loss }}$ value is used in conjunction with the velocity of the flow through the $\mathrm{i}^{\text {th }}$ exit port in question. However, approximate loss coefficients across the tee for line flow (straight path) and branch flow (bent path) are given by Munson[7] based on the velocity of the inlet port as $\mathrm{K}_{\text {line }}=0.2$ and $\mathrm{K}_{\text {branch }}=1.0$ for a flanged tee when there is a well defined flow direction with one inlet and two outlets. This scenario is depicted in Figure 3-9 with the inlet port $\mathrm{i}=2$ and the outlet ports $\mathrm{i}=1$ and $\mathrm{i}=3$. 


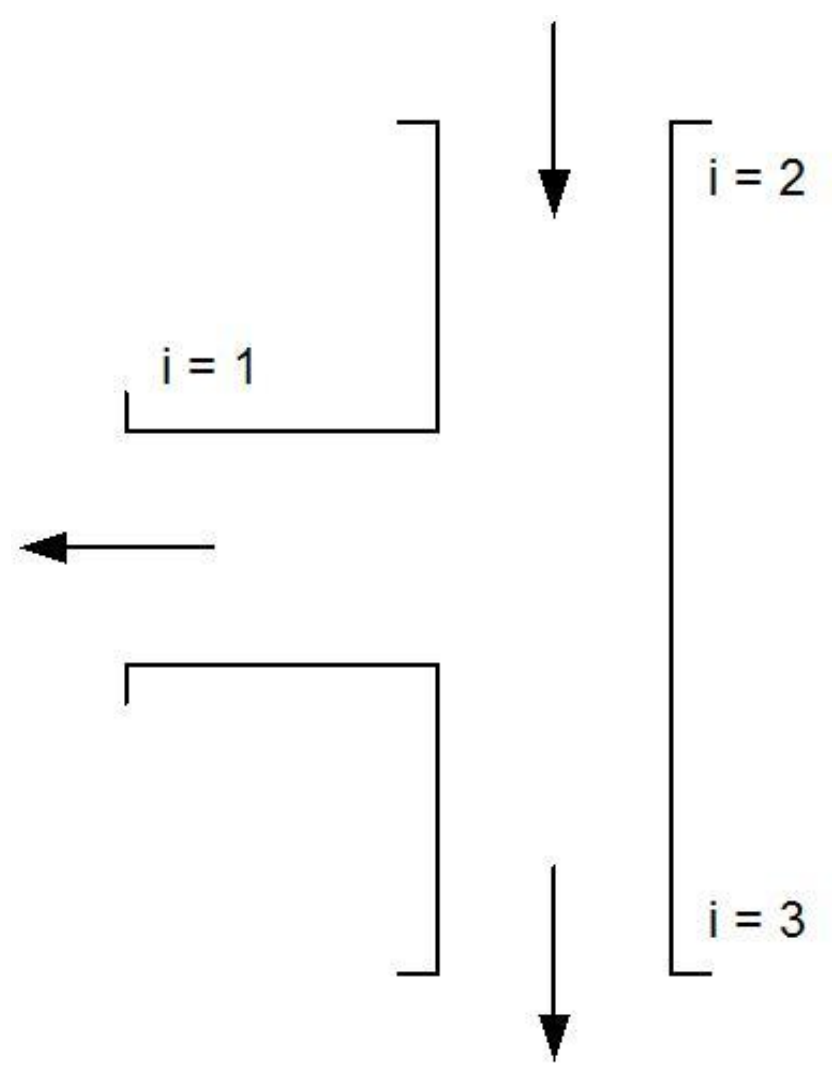

Figure 3-9 Tee with one inlet branch $(i=2)$ and two outlet branches $(i=1$ and $i=3)$.

Since in this study, there is not generally a known flow direction before hand, it should be more appropriate to use a loss coefficient for the $\mathrm{i}^{\text {th }}$ branch based on the $\mathrm{i}^{\text {th }}$ velocity value as in equation (3-43) rather than the value of the velocity in the inlet branch. Doing this avoids the situation that will occur when there is inlet flow in two branches of the tee and only one outlet branch, as depicted in Figure 3-10. For this scenario the loss of the $\mathrm{i}^{\text {th }}$ outlet branch should not be based on the velocity of some arbitrary inlet branch (remember in this case there are now two inlet branches), but rather the velocity of the flow in its own branch. This is because in this scenario the inlet flow into one branch may be very small while the inlet flow through the other branch may be very large. If the loss for the outlet branch were based on the inlet velocity of the branch with very little flow, it would give a poor estimation of the flow loss through the tee. Furthermore, the loss coefficient ( $K_{\text {loss }}$ ) for the outlet branch (branch $i=3$ in Figure 3-10) in a double inflow, single outflow scenario was taken as the velocity averaged values of 
branch flow and line flow. For example, in Figure 3-10 the $\mathrm{K}_{\text {loss }}$ value for the outlet branch $\mathrm{i}=3$ was calculated as

$$
K_{\substack{\text { loss } \\ i=3}}=\left(\frac{u_{1}}{u_{1}+u_{2}}\right) K_{\text {branch }}+\left(\frac{u_{2}}{u_{1}+u_{2}}\right) K_{\text {line }}
$$

where the subscripts refer to the branches as depicted in Figure 3-10 with inflow branches $\mathrm{i}=1$ and $\mathrm{i}=2$ and outflow branch $\mathrm{i}=3$.

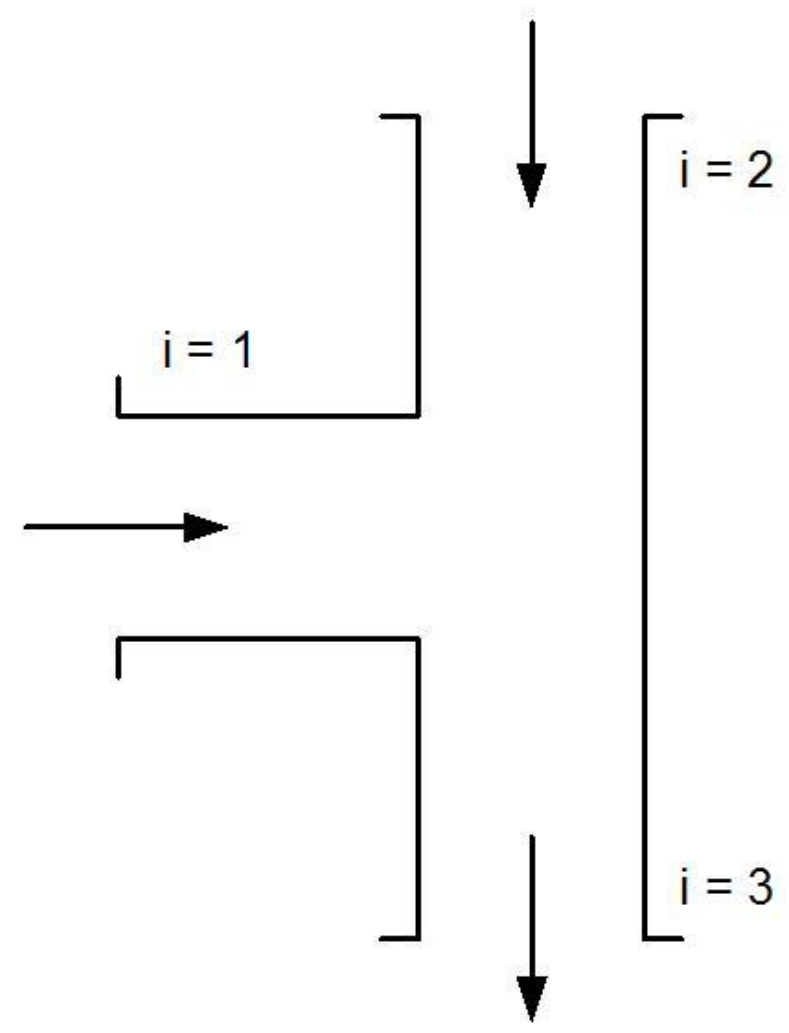

Figure 3-10 Tee with two inlet branches $(i=1$ and $i=2)$ and one outlet branch $(i=3)$.

Since the $\mathrm{K}_{\text {loss }}$ values given by Munson [7] were based on an inlet velocity of a tee with two outlets, appropriate values of $\mathrm{K}_{\text {loss }}$ based on the respective outlet branch velocities had to be determined. This was accomplished by taking the case of a tee with two outlet flows and one inlet flow as shown in Figure 3-9 and running three different cases with the Simulink model where each had different duct inlet pressures as illustrated by Figure 3-11. Several different values of loss coefficients (for use with velocity from 
the $\mathrm{i}^{\text {th }}$ branch as per equation (3-43)) were tried and results from the model were gathered. With the velocities determined by the Simulink model, the tee/duct interface pressures were calculated based on the inlet velocity and the loss terms given by Munson[7]:

$$
P_{i}=P_{\text {inlet }}+\frac{1}{2} \rho_{\text {inlet }} u_{\text {inlet }}^{2}-\frac{1}{2} \rho_{i} u_{i}^{2}-K_{\text {loss }} \frac{1}{2} \rho_{\text {inlet }} u_{\text {inlet }}^{2}
$$

where $\mathrm{K}_{\mathrm{loss}}=$ either for line or branch flow value (0.2 or 1.0) depending on port of tee as suggested by Munson[7]

$$
\mathrm{P}_{\mathrm{i}}=\text { tee/duct interface pressure of the } \mathrm{i}^{\text {th }} \text { outlet port }
$$

The tee/duct interface pressure values calculated from (3-45) were then subtracted from those determined by the Simulink model using the assumed loss coefficients and the individual branch values of velocity as per equation (3-43):

$$
\Delta P_{i}=\left.P\right|_{i-\text { Simulink }}-\left.P\right|_{i-\text { text }}
$$

where $\mathrm{P}_{\mathrm{i} \text {-Simulink }}=$ tee/duct interface pressure calculated by assumed loss coefficients and $\mathrm{i}^{\text {th }}$ branch velocity as per (3-43)

$\mathrm{P}_{\mathrm{i} \text {-text }}=$ tee/duct interface pressure calculated by textbook loss coefficients given by Munson[7] and inlet branch velocity as per (3-45)

In order to get an idea of how good the assumed $\mathrm{K}_{\text {loss }}$ values were, the difference in pressure given in (3-46) was divided by the loss term given by the textbook calculation:

$\%$ Error $_{i}=\frac{\Delta P_{i}}{K_{\text {loss }} \frac{1}{2} \rho_{\text {inlet }} u_{\text {inlet }}^{2}}(100)$

After some trial and error, the optimal values for branch and line loss coefficients based on flow through the ith outlet branch were determined to be $\mathrm{K}_{\text {branch-i }}=8.0$ and $\mathrm{K}_{\text {line-i }}=$ 0.45. Table 3-1 shows the calculated errors for the three test cases described in Figure 3-11 with $K_{\text {branch-i }}=8.0$ and $K_{\text {line-i }}=0.45$ used in conjunction with (3-43) and $K_{\text {branch-text }}=$ 1.0 and $\mathrm{K}_{\text {line-text }}=0.2$ used in conjunction with (3-45). It should be noted that the $\mathrm{K}_{\text {branch-i }}$ $=8.0$ and $\mathrm{K}_{\text {line-i }}=0.45$ values were used every time the tee model was used in this study. 


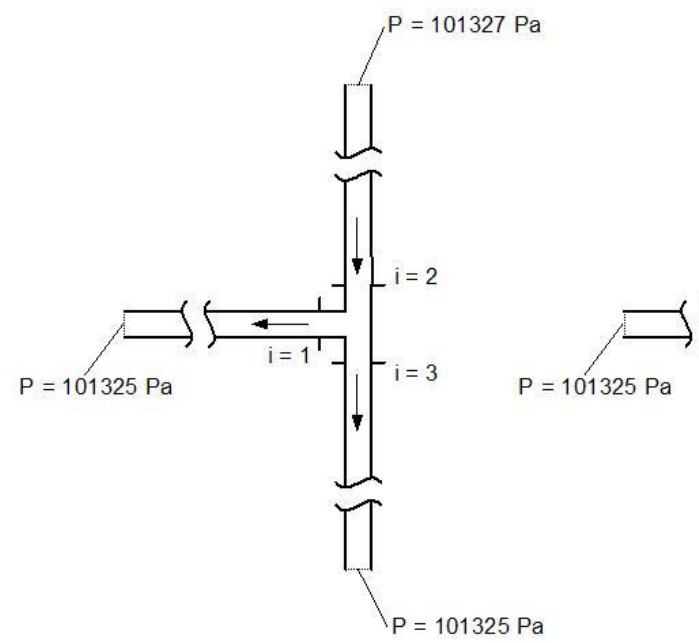

(I)

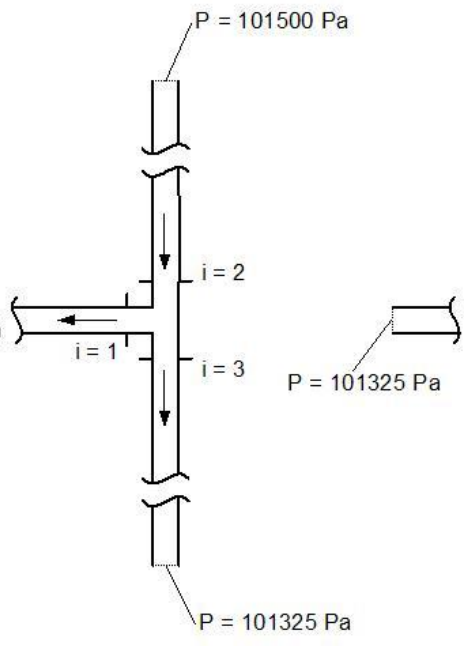

(II)

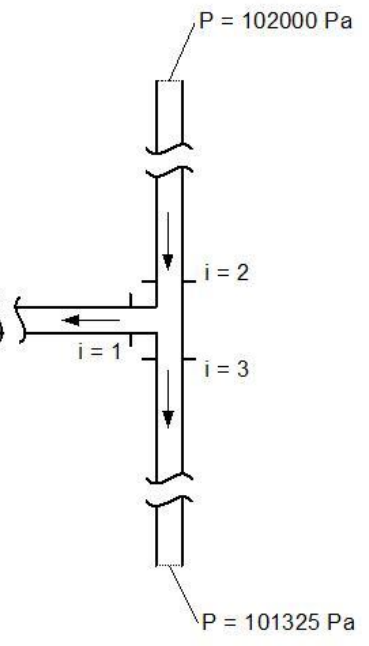

(III)

Figure 3-11 Test cases I, II, and III used to determine loss coefficients ( $\left.K_{\text {loss }}\right)$ for use with equation (3-43) based on loss coefficients given by Munson[7] for use with equation (3-45).

Table 3-1 Percent error when using assumed $K_{\text {loss }}$ values of $K_{\text {branch-i }}=8.0$ and $K_{\text {line-i }}=0.45$ for individual branch velocities with (3-43) as compared with using $K_{\text {loss }}$ inlet branch velocity and textbook values given by Munson [7] $\left(K_{\text {branch-text }}=1.0\right.$ and $\left.K_{\text {line-text }}=0.2\right)$ for the same flow rates with (3-45). Note that $i=2$ is the inlet port, and $i=1$ and $i=3$ are the outlet ports as describe in Figure 3-9.

\begin{tabular}{ccccccc}
\hline Case & $\Delta \mathrm{P}_{1}(\mathrm{~Pa})$ & $\Delta \mathrm{P}_{3}(\mathrm{~Pa})$ & $\mathrm{K}_{\text {branch-text }}(1 / 2) \rho_{2} \mathrm{u}_{2}{ }^{2}(\mathrm{~Pa})$ & $\mathrm{K}_{\text {line-text }}(1 / 2) \rho 2 \mathrm{u}_{2}{ }^{2}(\mathrm{~Pa})$ & $\%$ Error in $\mathrm{P}_{\text {1-Simulink }}$ & \% Error in $\mathrm{P}_{3 \text {-Simulink }}$ \\
\hline \hline I & 0.133 & -0.013 & 1.30 & 0.26 & 10.2 & -5.3 \\
II & 0.056 & 0.356 & 84.83 & 16.97 & 0.06 & 2.1 \\
III & 6.511 & 3.507 & 346.61 & 69.32 & 1.9 & 5.0 \\
\hline
\end{tabular}

It is evident from Table 3-1 that the calibrated values for loss coefficients based on individual branch velocity values are in good agreement with the loss values calculated with the textbook values and calculations based on the inlet velocity. This was true more or less for all three test cases as illustrated by the \%Error in the last two columns of Table 3-1. It is interesting to note that the errors with the largest magnitudes both came in case I where the mass flow through the tee was the lowest.

It should be mentioned that even the loss coefficient values given by Munson [7] are ball-park values at best. In fact White [5] gives values for loss coefficients for line flow in the flanged tee ranging from 0.24 to 0.07 and 1.0 to 0.41 for the branch flow depending on nominal diameter of the branches. White [5] also mentions that the loss values are average values for many brands and have an uncertainty of $+/-50 \%$. 
Additionally, the loss values are very geometry dependent. For example, the loss coefficients given by Munson[5] for line flow through a tee change by a factor of 4.5 (from 0.2 to 0.9 ) from a flanged tee to a threaded tee. All of these factors make one come to the conclusion that for any component, the loss values have to be determined, or known, for that particular component rather than simply taking some value from a text.

Finally, two more things should be noted about the tee model. First, the methodology used is rather general, and can be applied to y branches, and similar type junctions as long as proper $K_{\text {loss }}$ values are known or determined. Second, an equal pressure drop across both branches of this tee model will result in a symmetric split in flow (assuming the entire system is symmetric). In reality the flow split may not be symmetric because of slight imperfections in the tee geometry, minor bends in the connecting ducts, small flow disturbances, etc.

Figure 3-12 shows the block diagram of the tee model in the Simulink workspace. The interior of this block has the same breakdown of blocks as shown in Figures 3-6 through 3-8 for the plenum. The only differences are the function called to calculate the minor losses in the minor loss block, and the equation in the pressure calculation block to represent equation (3-43) instead of (3-42).

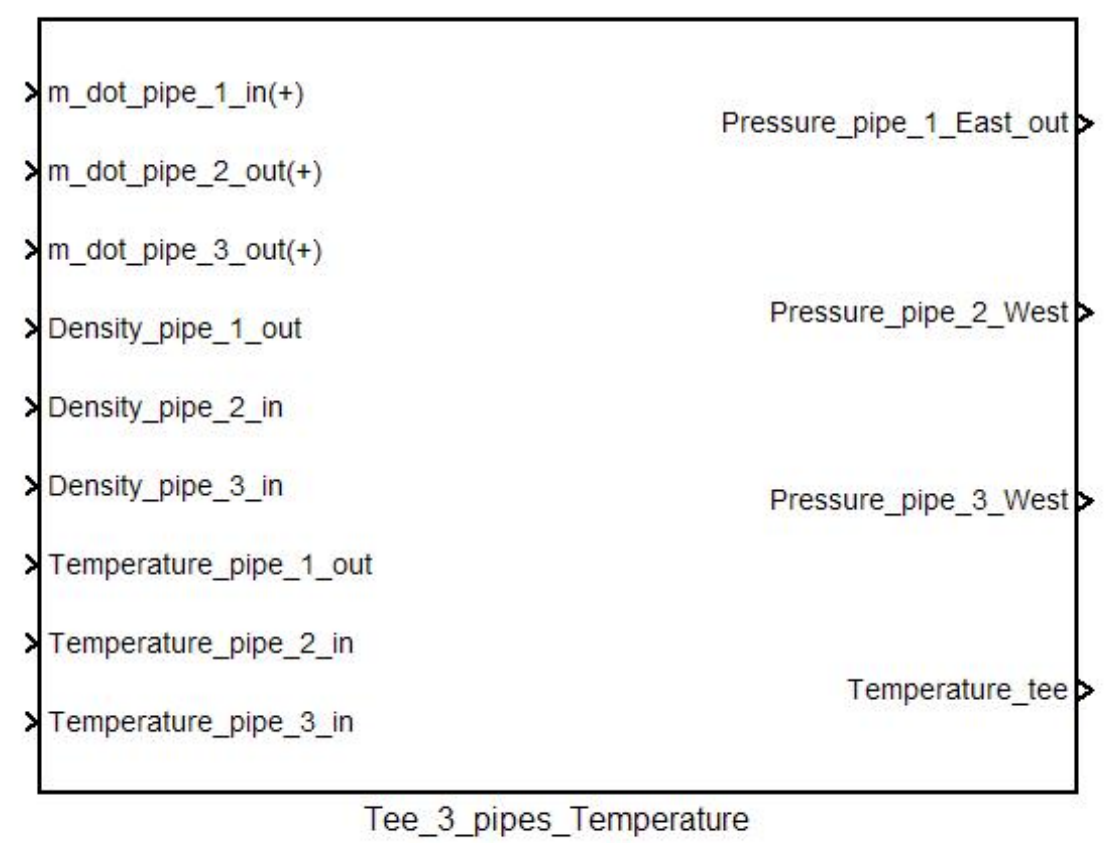

Figure 3-12 Simulink tee block diagram for connection with three ducts. 


\subsubsection{Elbow model}

As with the plenum and tee models, equation (3-41) was used to model the temperature of the fluid inside of an elbow and the exit temperature was assumed to be the calculated temperature of the elbow. Likewise, equation (3-39) was used to model the mass inside of the elbow at any given point in time, and the volume was approximated by multiplying the arc length (based on the bend radius) times the crosssectional area of the duct. The density inside the elbow was determined by dividing the calculated mass by the volume. With the temperature calculated from (3-41) the ideal gas relationship (3-31) was again used to estimate the pressure inside the elbow. The velocity inside the elbow was approximated by taking the average of the mass flow through the east and west faces of the elbow and then dividing by the calculated elbow density and cross-sectional area. Finally, the duct-elbow interface pressures were determined by the following relationships:

$$
P_{W}=P_{\text {elbow }}+\frac{1}{2} \rho_{\text {elbow }} u_{\text {elbow }}^{2}-\frac{1}{2} \rho_{W} u_{W}^{2}+K_{\text {loss }} \frac{1}{2} \rho_{\text {elbow }} u_{\text {elbow }}\left|u_{\text {elbow }}\right|
$$

and

$$
\begin{aligned}
P_{E}=P_{\text {elbow }}+\frac{1}{2} \rho_{\text {elbow }} u_{\text {elbow }}^{2}-\frac{1}{2} \rho_{E} u_{E}^{2}-K_{\text {loss }} \frac{1}{2} \rho_{\text {elbow }} u_{\text {elbow }}\left|u_{\text {elbow }}\right| \\
\text { where } \mathrm{W}=\text { west face of elbow at elbow-duct interface } \\
\mathrm{E}=\text { east face of elbow at elbow-duct interface } \\
\mathrm{K}_{\text {loss }}=\text { minor loss coefficient for elbow }
\end{aligned}
$$

The elbow minor loss coefficient was calculated using the empirical correlation for smooth-walled pipes given by White [5] as

$$
\begin{gathered}
K_{\text {loss }}=(0.388) \alpha\left(\frac{R_{\text {bend }}}{D}\right)^{0.84} \operatorname{Re}_{D}^{-0.17} \\
\text { where } \mathrm{R}_{\text {bend }}=\text { bend radius of elbow } \\
\mathrm{D}=\text { diameter of pipe } \\
\operatorname{Re}_{\mathrm{D}}=\text { Reynolds number } \\
\alpha=0.95+4.42\left(\frac{R_{\text {bend }}}{D}\right)^{-1.96}
\end{gathered}
$$

Note that in these equations the flow at the west face of the elbow is considered positive into the elbow and the flow at the east face of the elbow is considered positive out of the elbow. 
Figure 3-13 shows the Simulink block diagram for the elbow model. Once again, the interior of this block has a similar breakdown of blocks as shown in Figures 3-6 through 3-8 for the plenum. The differences are that for the elbow there are only two ducts with which to connect, the function called to calculate the minor losses in the minor loss block is different, and the equation in the pressure calculation blocks represent equations (3-48) and (3-49) instead of (3-42).

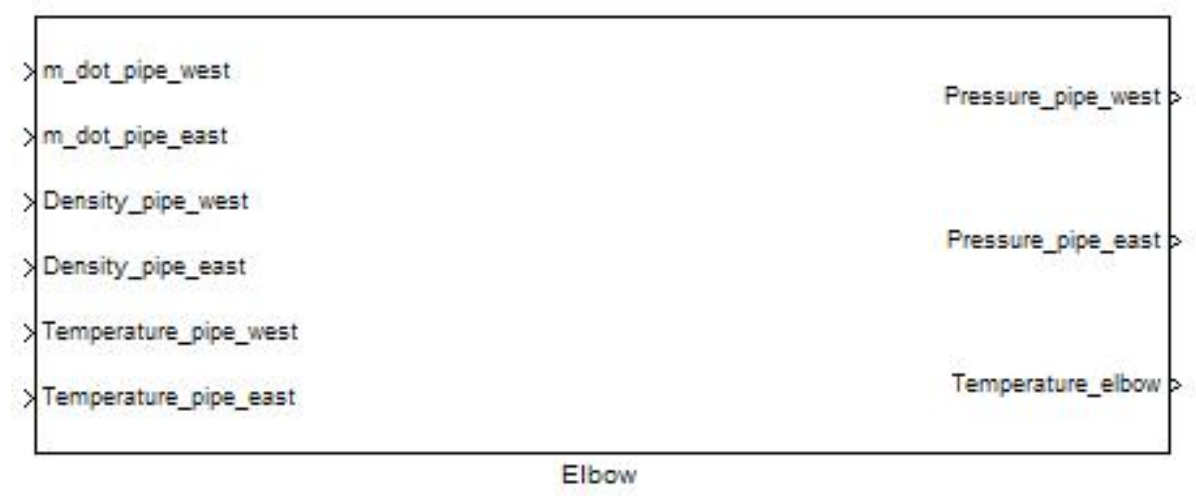

Figure 3-13 Simulink elbow block diagram.

Note that there is a difference in the way the minor losses are accounted for in Section 3.5 for the vena contracta and diffuser and Sections 3.7.1 to 3.7.3 with the plenum, tee, and elbow models. These methods are different because the diffuser and vena contracta losses as modeled in Section 3.5 are considered to take place within the geometry of the duct while the minor losses due to sudden contraction, branch flow, etc. in the plenum, tee, and elbow models of Sections 3.7.1 to 3.7.3 are accounted for within the plenum, tee, and elbow respectively. Because the losses for the plenum, tee, and elbow are modeled within these junction components, the duct/plenum, duct/tee, and duct/elbow interface pressures are located in the duct after the losses (e.g. vena contracta for contraction loss from the plenum). For example, the vena contracta that occurs with a sudden contraction is considered to occur within the plenum geometry, with the interface with the duct downstream of this location. Therefore, the duct model does not have any minor losses included within its Simulink model block accounting for its connection to a tee or plenum. 


\subsubsection{Duct model incorporation into Simulink}

The momentum (3-4), pseudo-compressibility (3-30), thermal energy (3-16), and ideal gas (3-31) equations were solved in Simulink on a staggered grid. This was accomplished by creating subsystems in Simulink for each equation representing a main or velocity node. These blocks were then connected to each other in a sequential fashion to create a duct with the desired number of nodes. Figure 3-14 shows a typical duct Simulink block diagram. The inside of a typical Simulink duct block with only three interior velocity nodes and two interior main nodes is shown in Figures 3-15, 3-16, 3-17, and 3-18 for the upper left, upper right, lower left, and lower right portions of the block interior. Note that in general more nodes were used, however in order to legibly shrink the figure to a reasonable size, fewer nodes are shown here.

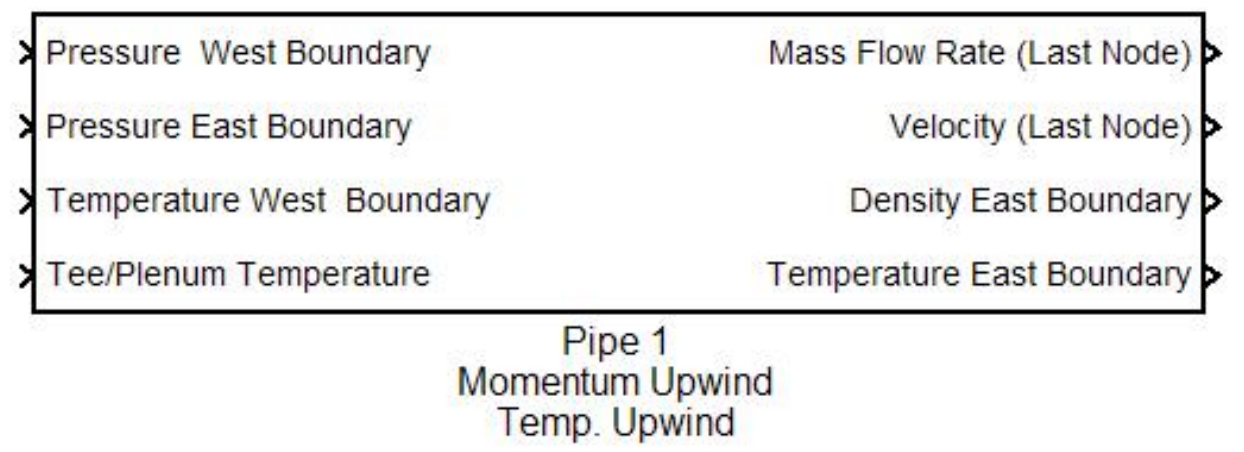

Figure 3-14 Typical Simulink duct model block diagram. 


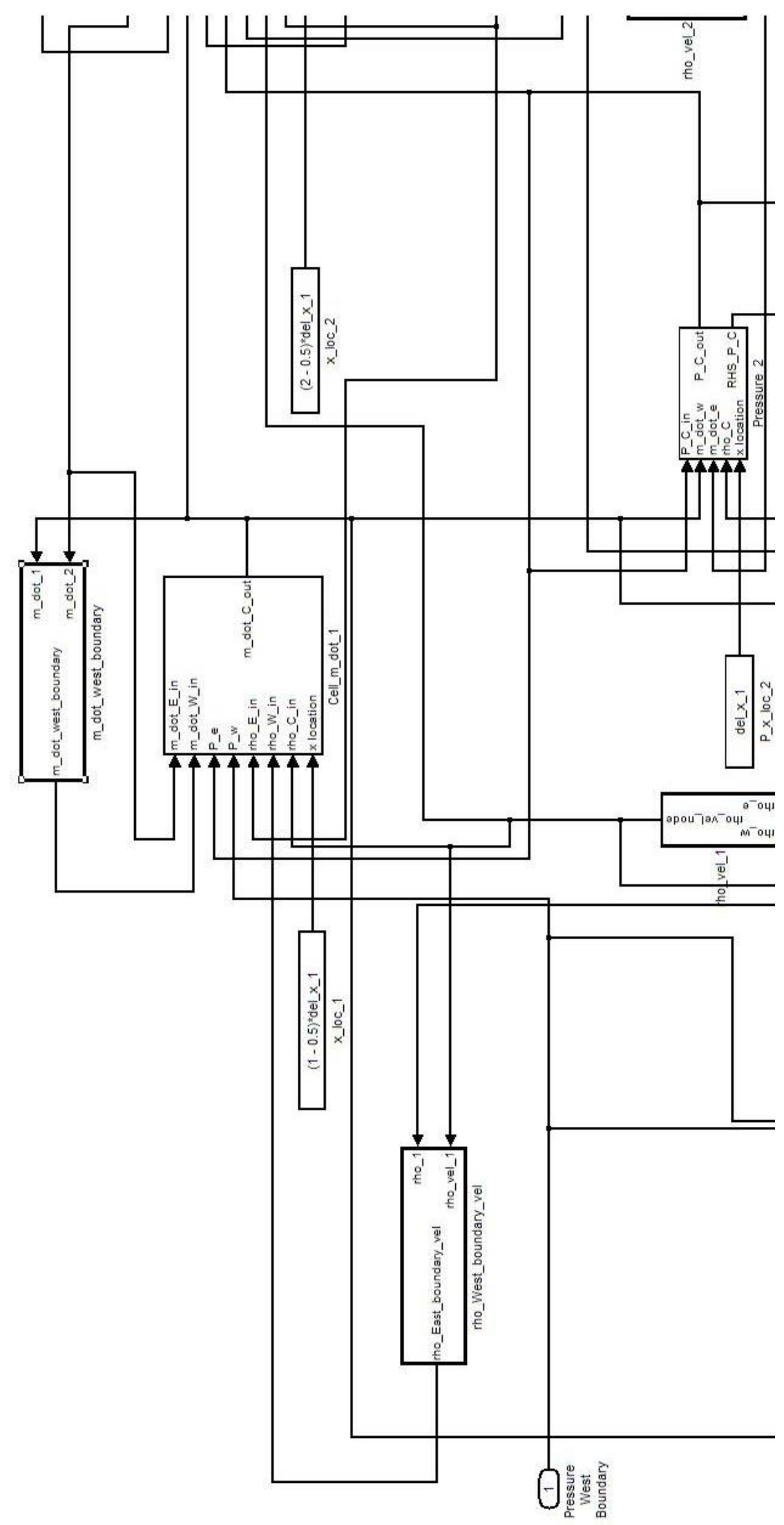

Figure 3-15 Upper left corner of inside of Simulink duct model block diagram. 


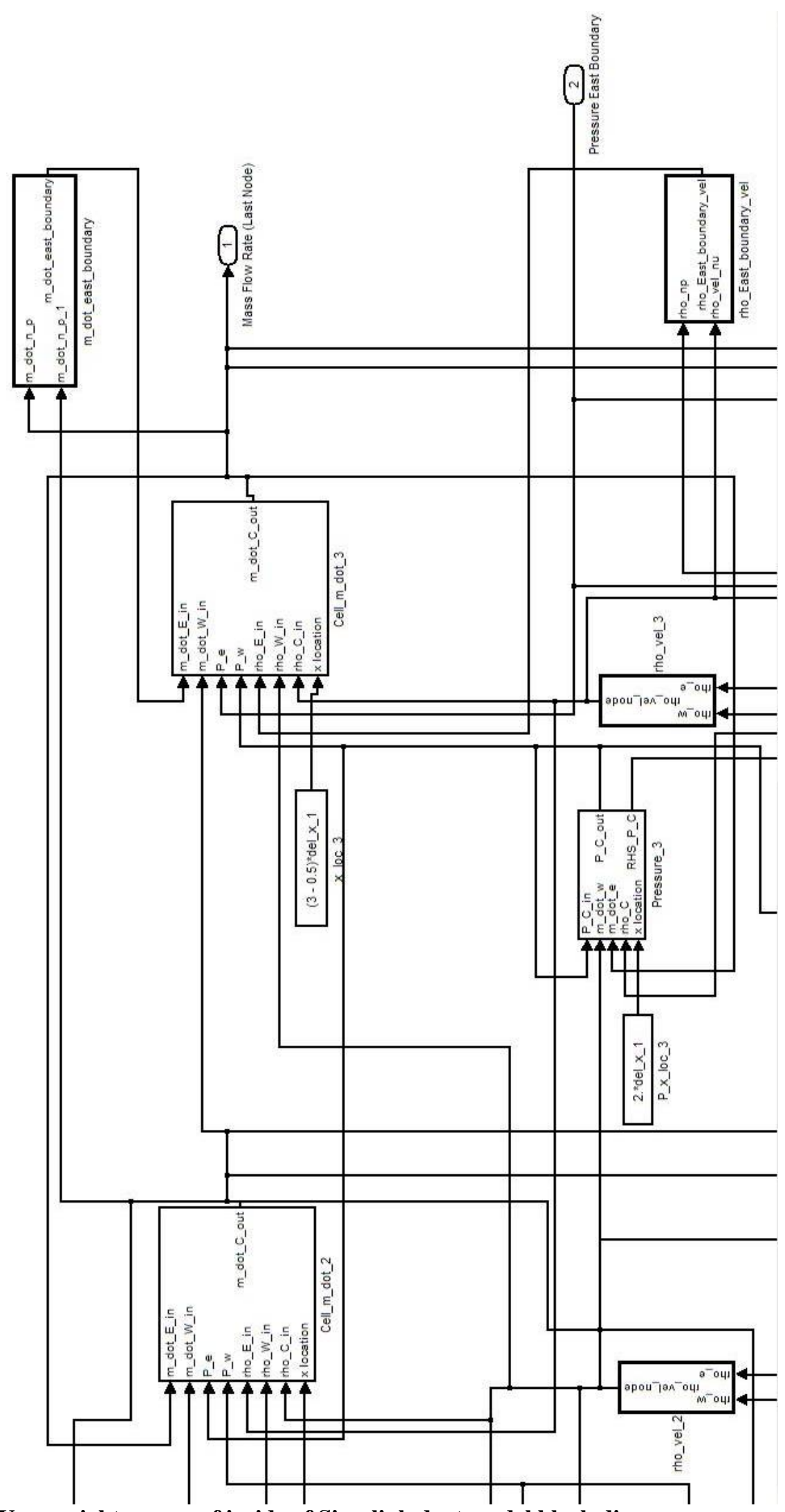

Figure 3-16 Upper right corner of inside of Simulink duct model block diagram. 


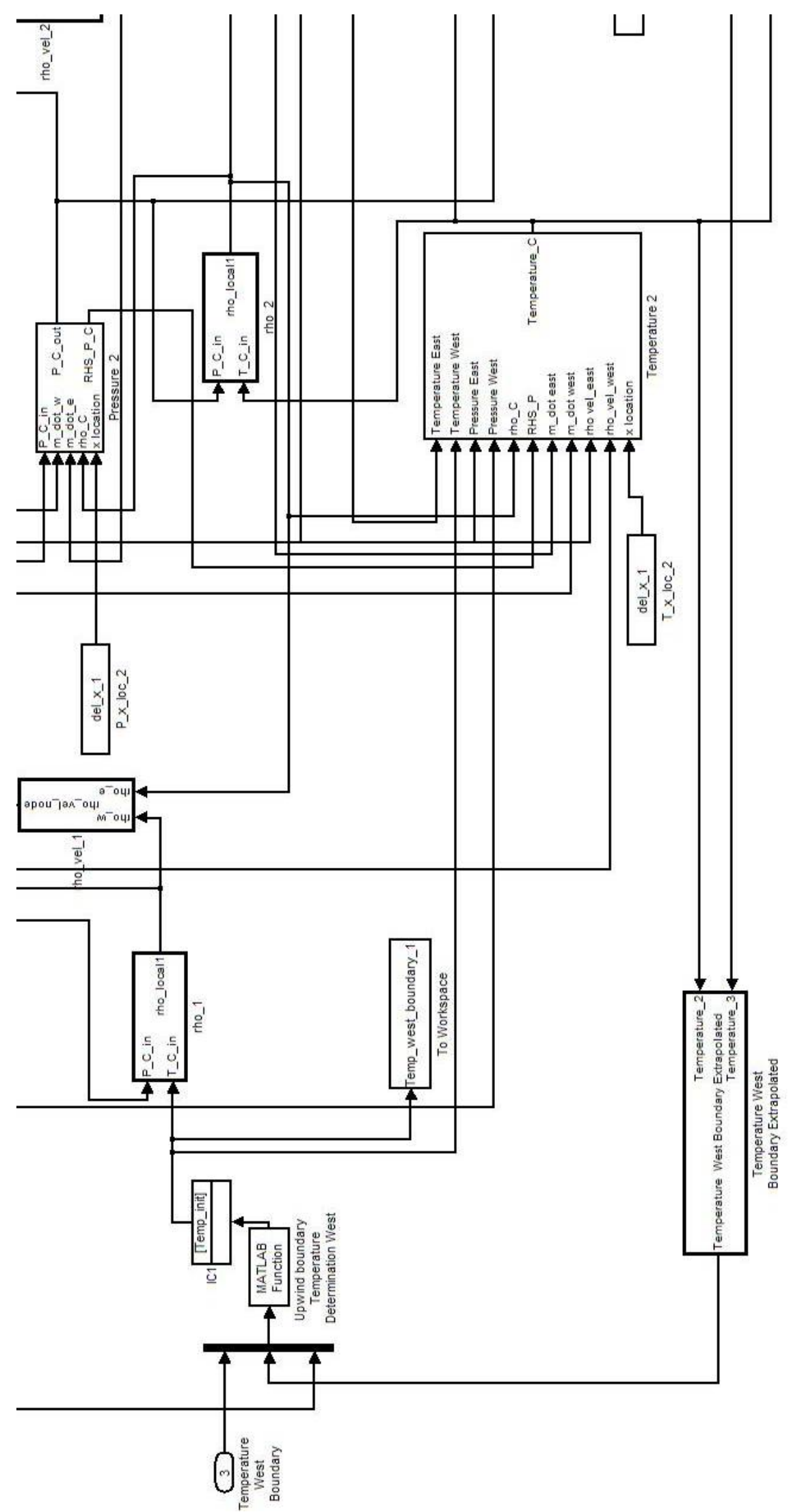

Figure 3-17 Lower left corner of inside of Simulink duct model block diagram. 


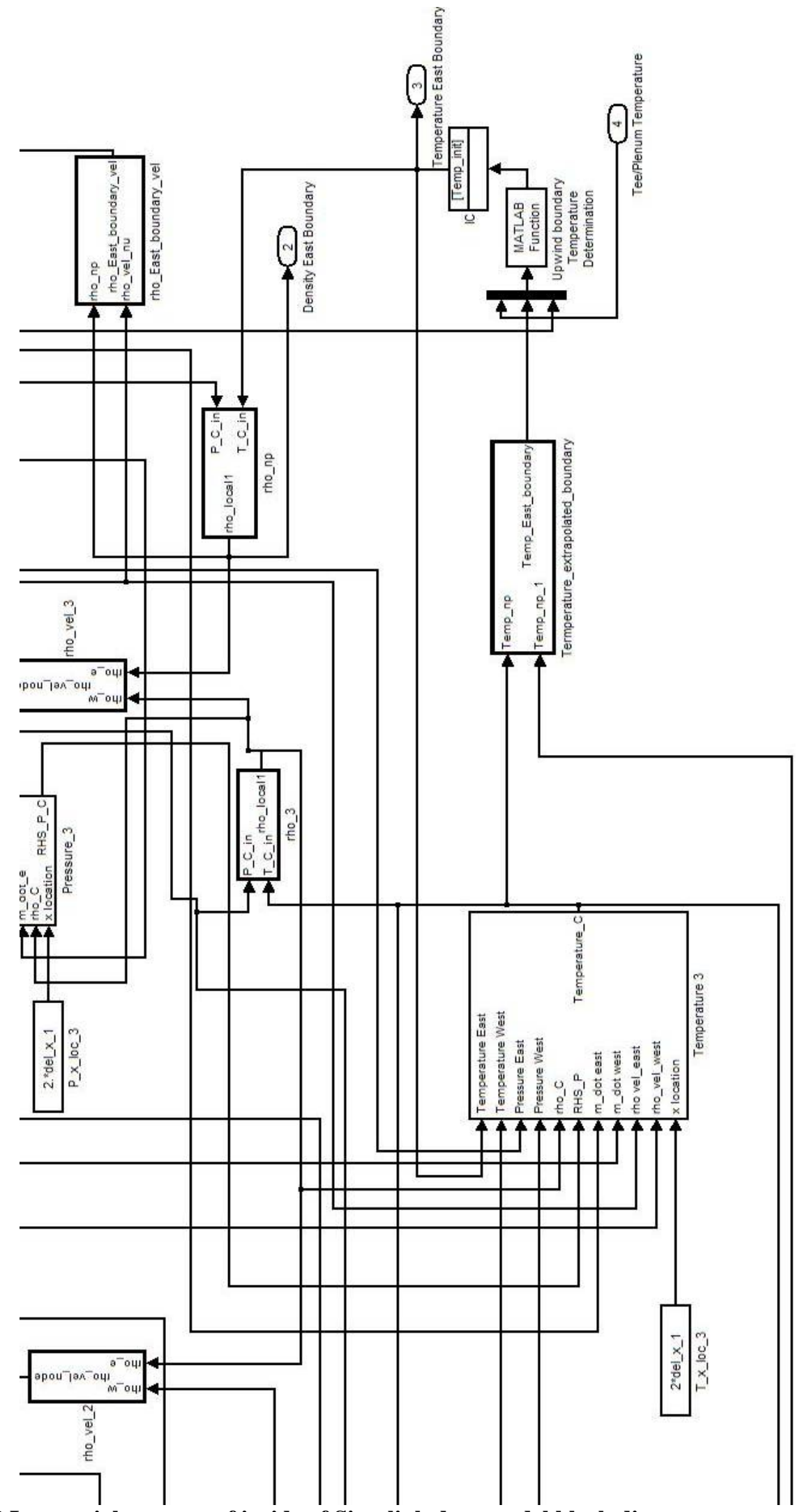

Figure 3-18 Lower right corner of inside of Simulink duct model block diagram. 
Figure 3-19 shows a typical momentum subsystem referred to as "Cell_m_dot" blocks in Figures 3-15 through 3-18. This figure illustrates the use of additional subsystem blocks to calculate each term in equation (3-4). The momentum subsystem blocks were solved on the velocity nodes as shown in Figure 3-2(b). Note that this particular momentum block uses upwinding for the convection transport term in (3-4). In the calculation of the convection transport term a MATLAB function was called where the $\mathrm{u}_{\mathrm{e}}$ and $\mathrm{u}_{\mathrm{w}}$ are evaluated at the ' $\mathrm{E}$ ', ' $\mathrm{C}$ ', or ' $\mathrm{W}$ ' velocity nodes depending on the flow direction of the mass flow at the ' $\mathrm{C}$ ' node. If the mass flow at the ' $\mathrm{C}$ ' node was positive (flowing from west to east), then $\mathrm{u}_{\mathrm{e}}$ was evaluated at the ' $\mathrm{C}$ ' velocity node and $\mathrm{u}_{\mathrm{w}}$ at the ' $W$ ' velocity node. On the other hand, if the mass flow was negative (flowing from east to west), then $\mathrm{u}_{\mathrm{e}}$ was evaluated at the ' $\mathrm{E}$ ' velocity node and $\mathrm{u}_{\mathrm{w}}$ at the $\mathrm{C}$ velocity node. In addition to using upwinding, another duct model was created using central differencing for the convection transport term in the momentum equation (3-4). For central differencing, $\mathrm{u}_{\mathrm{e}}$ was always evaluated at the ' $\mathrm{E}$ ' velocity node and $\mathrm{u}_{\mathrm{w}}$ at the ' $\mathrm{W}$ ' velocity nodes and the $\Delta \mathrm{x}$ in the denominator of the convective transport term in (3-4) was replaced with $2 \Delta x$. The only difference between the momentum subsystem blocks for upwinding and central differencing is the convection transport block.

The physics of the flow should be modeled better using the upwinding scheme for the convective transport term. Therefore, all of the results reported in this study were performed using the upwinding model. It should also be noted that the friction factor, Reynolds number relationship developed for the FORTRAN code (see Figure 3-3) was also used in all of the simulations performed with the Simulink duct model with the exception of the comparison with experimental data, as will be discussed later. 


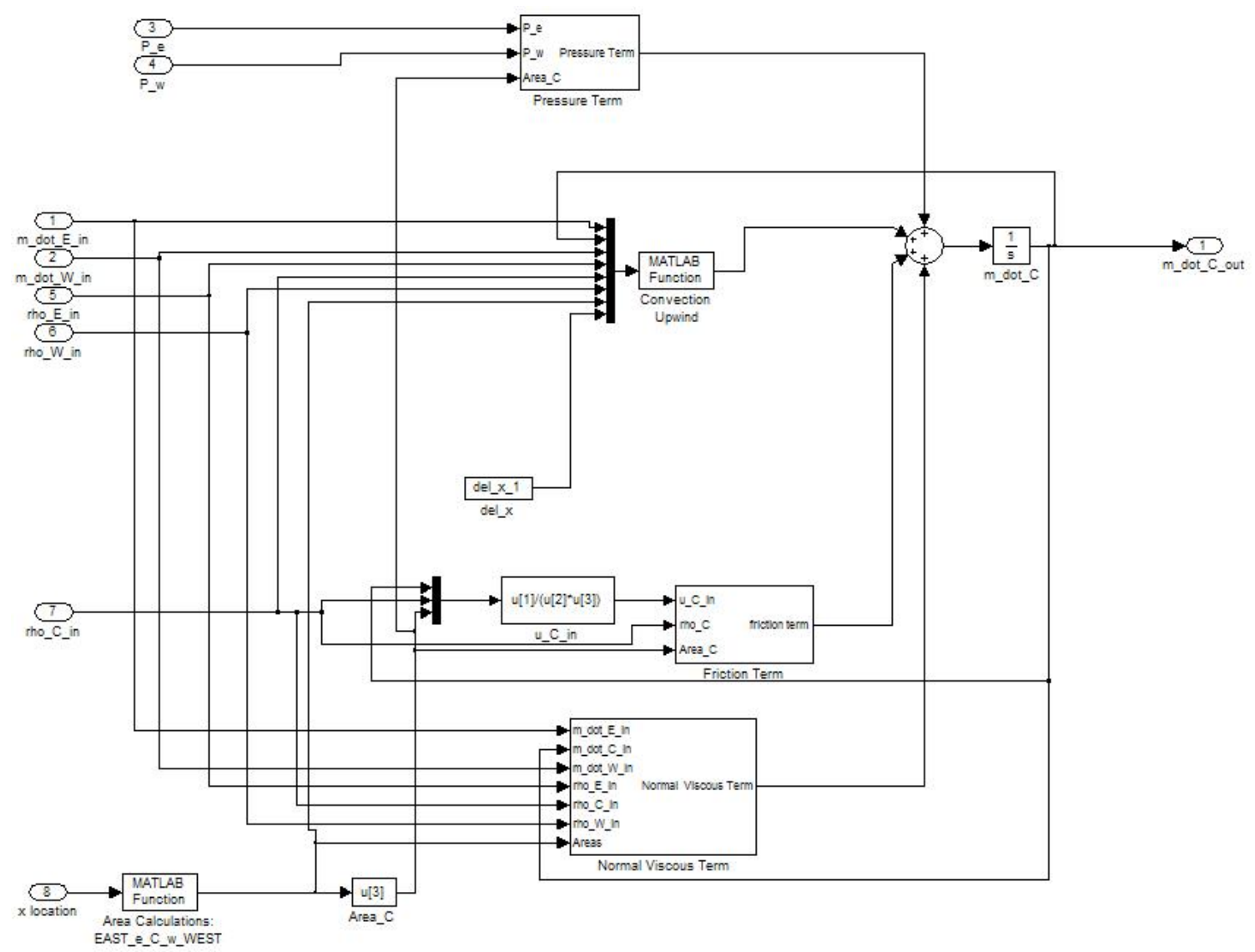

Figure 3-19 Simulink momentum subsytem model block diagram for upwinding scheme.

Figure 3-20 shows the inside of a typical Simulink pressure subsystem block used to model the pseudo-compressibility equation (3-30). These pressure blocks were contained in the duct model block as shown in Figures 3-15 through 3-18 and were solved at the main nodes as shown in Figure 3-2(a). Figures 3-21 and 3-22 give the inside of a Simulink thermal energy subsystem block used to model the thermal energy equation (3-16), showing the top and bottom half of the block diagram respectively. The thermal energy subsystem blocks were likewise contained in the duct block model and solved on the main nodes. As was done with the velocity in the momentum equation, the $\mathrm{T}_{\mathrm{e}}$ and $\mathrm{T}_{\mathrm{w}}$ temperature values in the convective transport term of equation (3-16) were upwinded using a MATLAB function block as is shown in Figure 3-21. The evaluation location of $\mathrm{T}_{e}$ and $\mathrm{T}_{\mathrm{w}}$ was exactly analogous with the $\mathrm{u}_{\mathrm{e}}$ and $\mathrm{u}_{\mathrm{w}}$ of the momentum equation, however this time based on the value of the mass flow rate at the neighboring 
velocity nodes. Finally, the density subsystem blocks visible in Figures 3-15 through 3-18 simply contain one block which calculates the density of the fluid from the ideal gas equation (3-31).

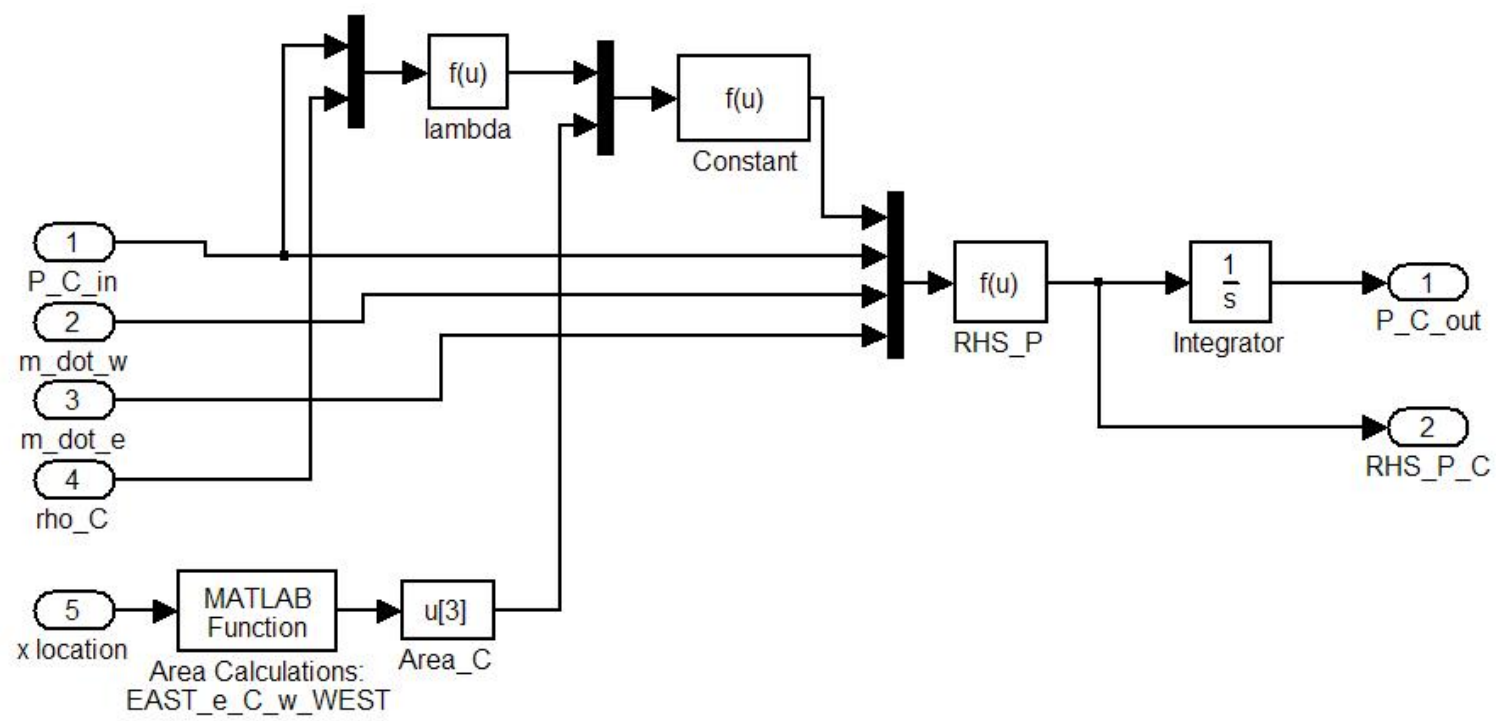

Figure 3-20 Simulink pressure subsytem model block diagram.

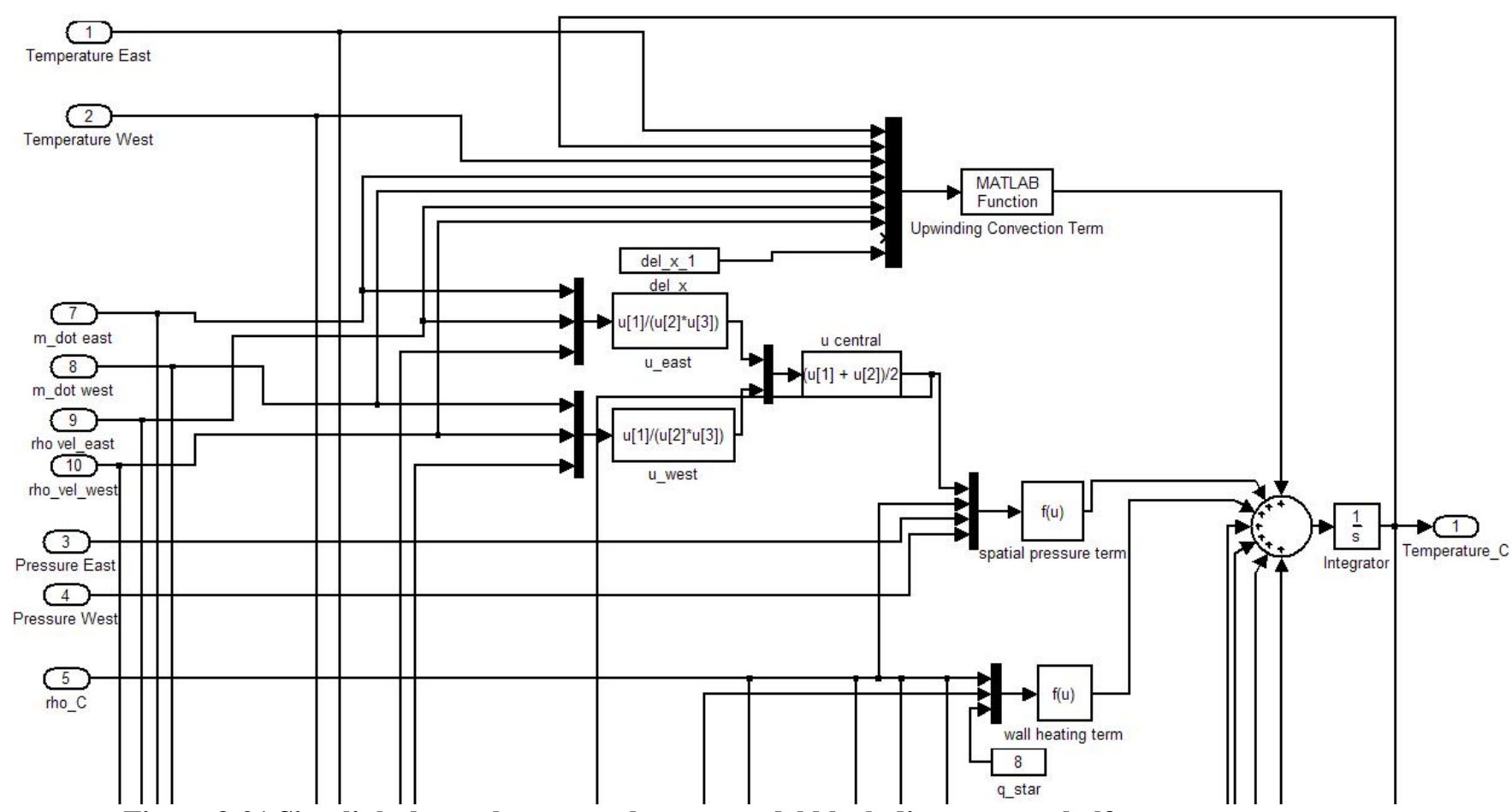

Figure 3-21 Simulink thermal energy subsytem model block diagram: top half. 


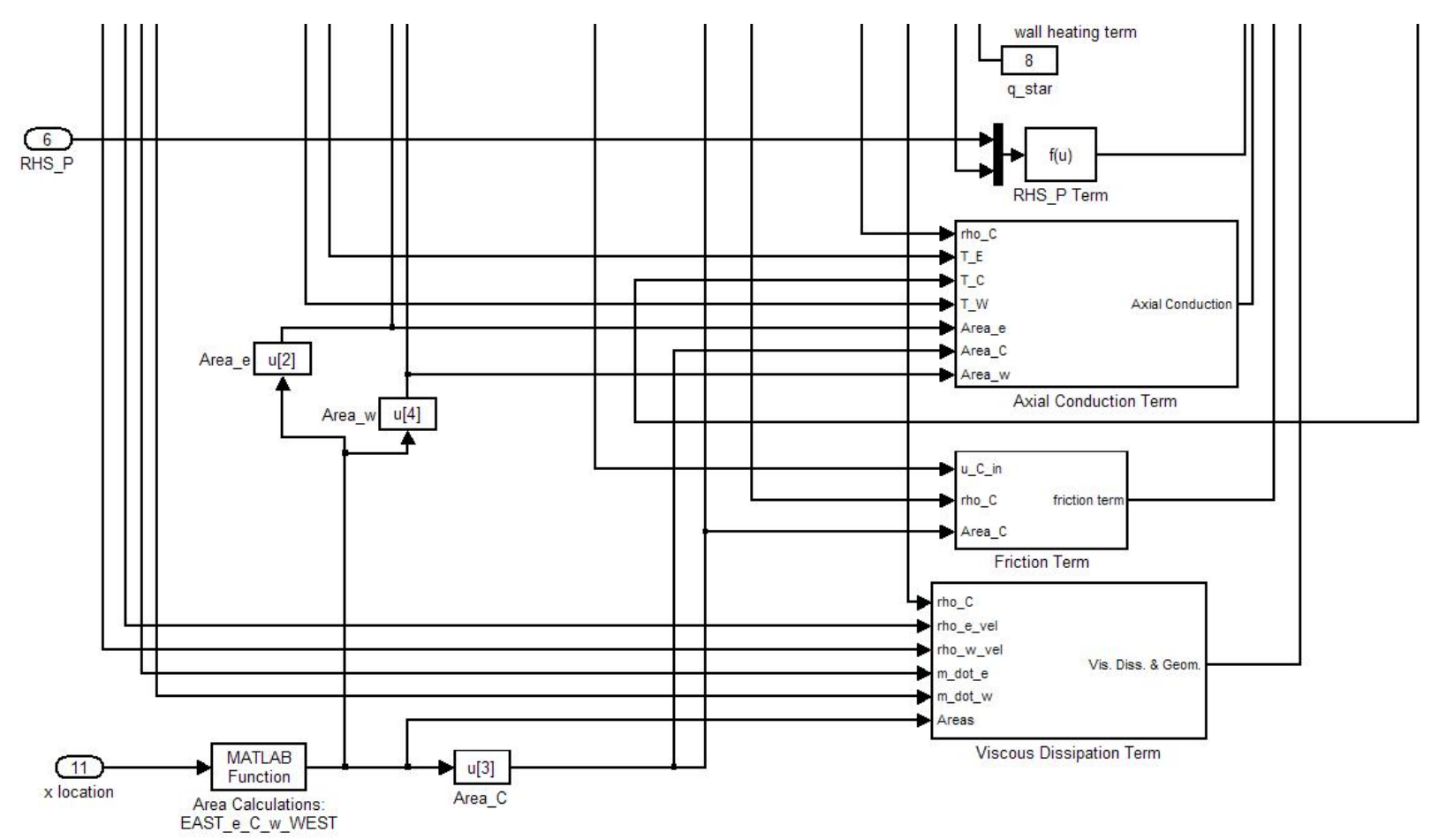

Figure 3-22 Simulink thermal energy subsytem model block diagram: bottom half.

After the duct, plenum, tee, and elbow model blocks were created in Simulink, they were connected together to form a flow system as shown in Figure 3-23. The interaction between these blocks was described in the previous four sections. While many different connection configurations are possible, Figure 3-23 gives only one typical case as an example. 


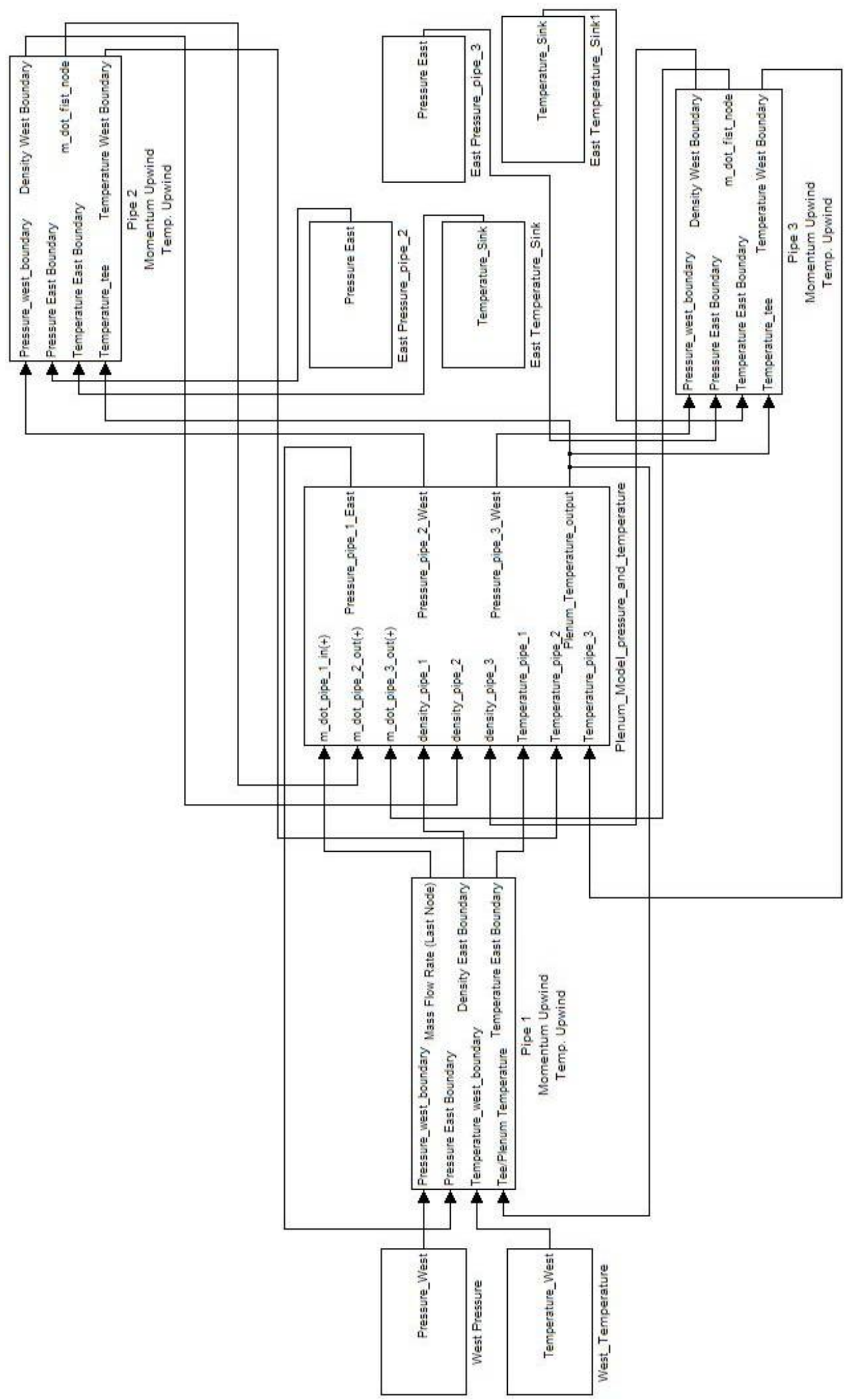

Figure 3-23 Typical Simulink block diagram illustrating connection of components. 


\subsection{Boundary Conditions}

In both the FORTRAN and Simulink models, a Dirichlet boundary condition (dependent variable specified) was used for the pressure at the duct entrance and exit. The duct boundary pressure was either specified or if the duct was connected to a plenum, tee, or elbow, the duct/plenum, duct/tee, or duct/elbow interface pressure was calculated via the pressure in the plenum, tee, or elbow and the accompanying minor losses. For the mass flow rate, the following Neumann boundary condition was used again for both FORTRAN and Simulink models:

$$
\left.\frac{\partial \dot{m}}{\partial x}\right|_{n x p}=\left.\frac{\partial \dot{m}}{\partial x}\right|_{n x p-1}
$$

As illustrated in Figure 3-24 a central difference approximation was applied to (3-51) resulting in the following relationship for the east boundary:

$$
\frac{\dot{m}_{\text {ghost }}-\dot{m}_{n x u}}{\Delta x}=\frac{\dot{m}_{n x u}-\dot{m}_{n x u-1}}{\Delta x}
$$

Rearranging (3-52) gives the following expression for the mass flow value of the ghost node:

$$
\dot{m}_{\substack{\text { ghost } \\ \text { east }}}=2 \dot{m}_{n x u}-\dot{m}_{n x u-1}
$$

In a similar manner for the west boundary:

$$
\dot{m}_{\substack{\text { ghost } \\ \text { west }}}=2 \dot{m}_{1 u}-\dot{m}_{2 u}
$$


Pressure and

Pressure and

Temperature Boundary

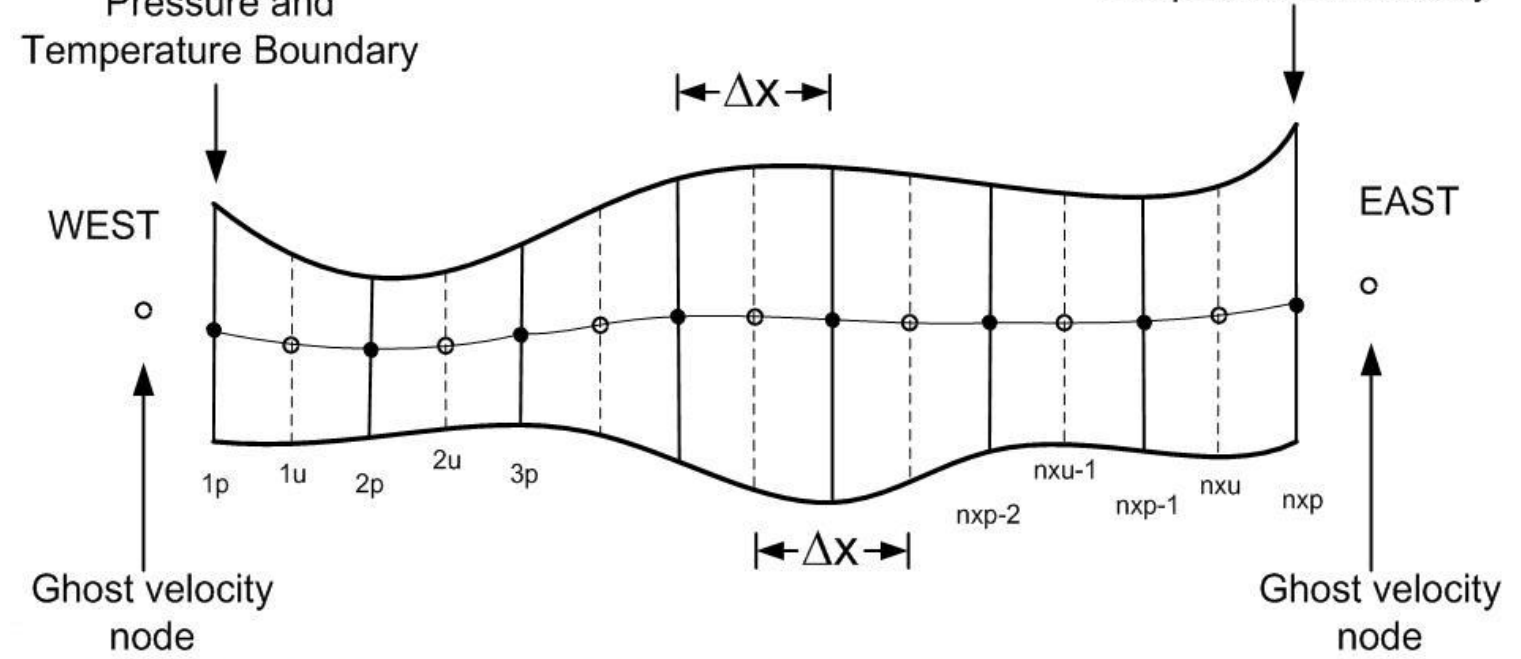

Figure 3-24 Schematic of staggered grid and boundary value locations.

In the FORTRAN model, only isothermal flows were studied and therefore the thermal energy equation was not solved. For this case the density at the boundary was determined by using the polytropic relationship (3-28) with $\gamma=1$, which is equivalent to using the ideal gas relationship with the reference temperature. In the Simulink model where the thermal energy equation was solved, the temperature boundary conditions were treated by assuming a Dirichlet boundary condition at a boundary at which the flow entered the duct and a Neumann boundary condition at an exit. At the inlet of the duct, the Temperature at the boundary was either specified, or if connected to a tee or plenum taken as the temperature within the tee or plenum. At the outlet boundary of the duct, the following Neumann boundary condition was used:

$$
\left.\frac{\partial T}{\partial x}\right|_{n x p}=\left.\frac{\partial T}{\partial x}\right|_{n x p-1}
$$

Applying a backward difference to (3-55) gave the following expression for calculation of the outflow boundary condition:

$\frac{T_{n x p}-T_{n x p-1}}{\Delta x}=\frac{T_{n x p-1}-T_{n x p-2}}{\Delta x}$ 
Solving (3-56) for the boundary temperature:

$T_{n \times p}=2 T_{n \times p-1}-T_{n \times p-2}$

Note that equations (3-55) through (3-57) represent the Neumann boundary condition assuming that the east boundary is the exit of the duct. When the west boundary is the exit of the duct, following the same procedure the following relationship was derived for the boundary value of temperature:

$T_{1 p}=2 T_{2 p}-T_{3 p}$

With the boundary temperature either known or calculated and the boundary pressure known, the density was determined by simply applying the ideal gas law (3-31).

Note that this temperature boundary treatment essentially assumes that flow through the pipe is generally fast enough that the convection of temperature in the duct is dominant over the axial conduction, i.e. the temperature of the duct is much more dependent on the temperature upstream than that downstream. An alternative to this boundary treatment would be to take a weighted average of the temperature in the exiting device (plenum, tee, etc.) with the values calculated above for the Neumann boundary condition. The weighted average could be based on the calculated values of the axial conduction and convection terms in the thermal energy equation.

The velocity value at the east and west ghost nodes were calculated by dividing the mass flow values calculated by (3-53) and (3-54) by the area of the duct and the density. Likewise, when the kinetic energy equation was used, its boundary value was determined by using this boundary value of velocity and the relationship $K=u^{2} / 2$.

\subsection{Application Issues and Limitations of Model}

In theory, using the kinetic energy equation instead of the momentum equation has the advantage that a scalar is being solved for rather than a directional vector quantity. Thus, by including a curvature effect term in the kinetic energy equation, it could be used for wavy ducts, etc. However, in practice, the mechanical energy equation is difficult to use for several reasons. 
First, there is the difficulty of how to determine the flow direction. The velocity magnitude of the flow can be found by simply using the relationship $u=\sqrt{2 K}$, but the flow direction still must be found. A second issue using the kinetic energy arises when the flow changes direction. Physically the kinetic energy must always be positive. However, if the kinetic energy decreases very quickly and a rather large time step is used, the kinetic energy can be calculated as a negative value using equations (3-7) through (3-10). Hence when the $u=\sqrt{2 K}$ relationship is used to calculate the velocity, the code blows up due the attempted square root of a negative number. Finally, if the kinetic energy equation is to be applied to a duct for which the axis significantly changes directions, proper loss terms must still be determined. These loss terms are necessary because in such cases, the flow often separates, forms secondary flows, etc.

Therefore, although solving the kinetic energy has some advantages, the only place it was used in this thesis was in the case of a straight, fully-developed, isothermal, laminar, pipe flow where the flow direction was known before hand, thereby minimizing the complications. In all other cases and models, the momentum equation (3-4) was solved in conjunction with the pseudo-compressibility model (3-30) and, in the Simulink model, the thermal energy equation (3-16).

The equations used to model the pressure relationships between the components and component connecting parts (equations (3-42), (3-43), (3-48) and (3-49)) are truly only valid for steady, incompressible flow. However, since these relationships are being applied locally to a small region of the system for the tee and elbow components, these assumptions should not generally induce a great amount of error. Additionally, since the velocity through the plenum is much less than in the other parts of the system, and the density at each port is being used in conjunction with the velocity at each port, these assumptions likewise should not generally create an overwhelming amount of error. However, in the case of surge or stall in the system due to the compressor and turbine, the flow though the system will rapidly change rates. In this scenario these relationships will most likely cause an appreciable amount of error in the results. 


\subsection{Comparison with Experimental Data}

In order to validate the flow model, experimental data was taken from a section of the NETL HYPER test facility and compared with simulation results. Figure 3-25 gives a schematic of the section modeled including the location of the probes used in the comparison. Air drawn in from outside constituted the gas flowing through this section of the system. Temperature and pressure data were taken from the west and east boundary probes, mass flow data was taken from the probe between the tee and the plenum, and the plenum pressure was recorded. It should be noted that no air flowed through the "third" branch of the tee because a valve downstream was closed during this simulation. The Simulink model created for this section included the ductwork, tee, plenum, and elbow, as shown in Figure 3-26. Note that several flanges present in the actual model were ignored in the Simulink representation.

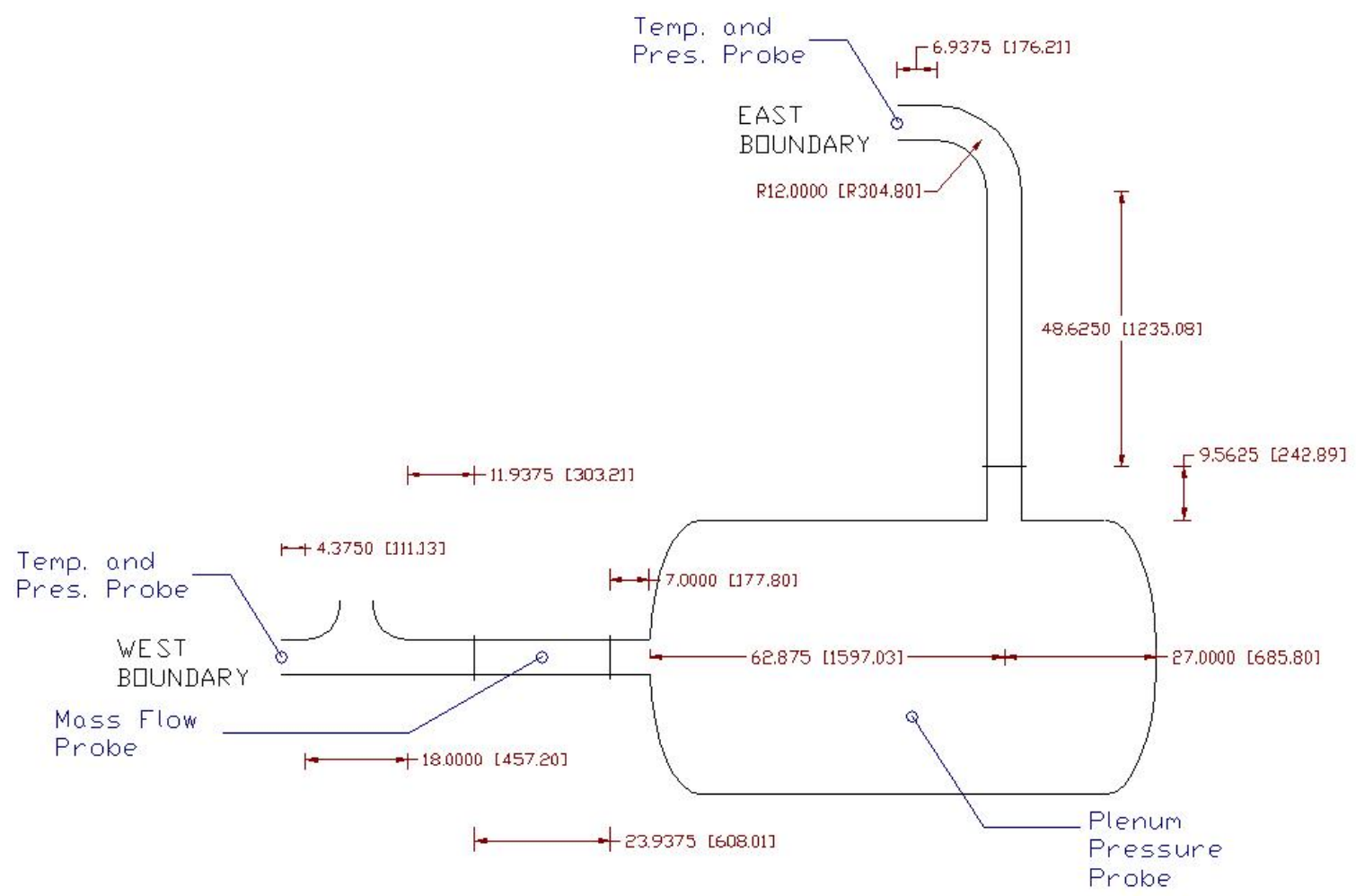

Figure 3-25 Diagram of the section of the NETL HYPER test facility used to validate the flow model. Note that dimensions are in inches and $[\mathrm{mm}]$; internal diameter of all ductwork is $154 \mathrm{~mm}$. 


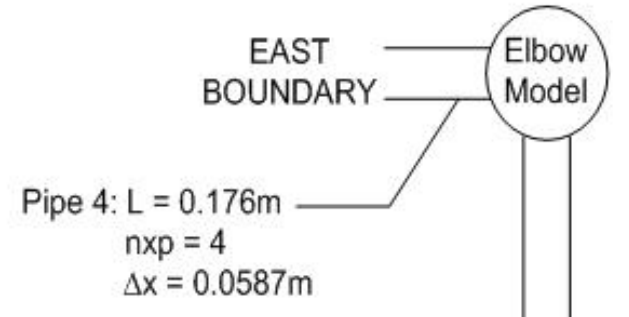

Pipe 3: $L=1.478 \mathrm{~m}$

$\mathrm{nxp}=16$

$\Delta \mathrm{x}=0.0985 \mathrm{~m}$

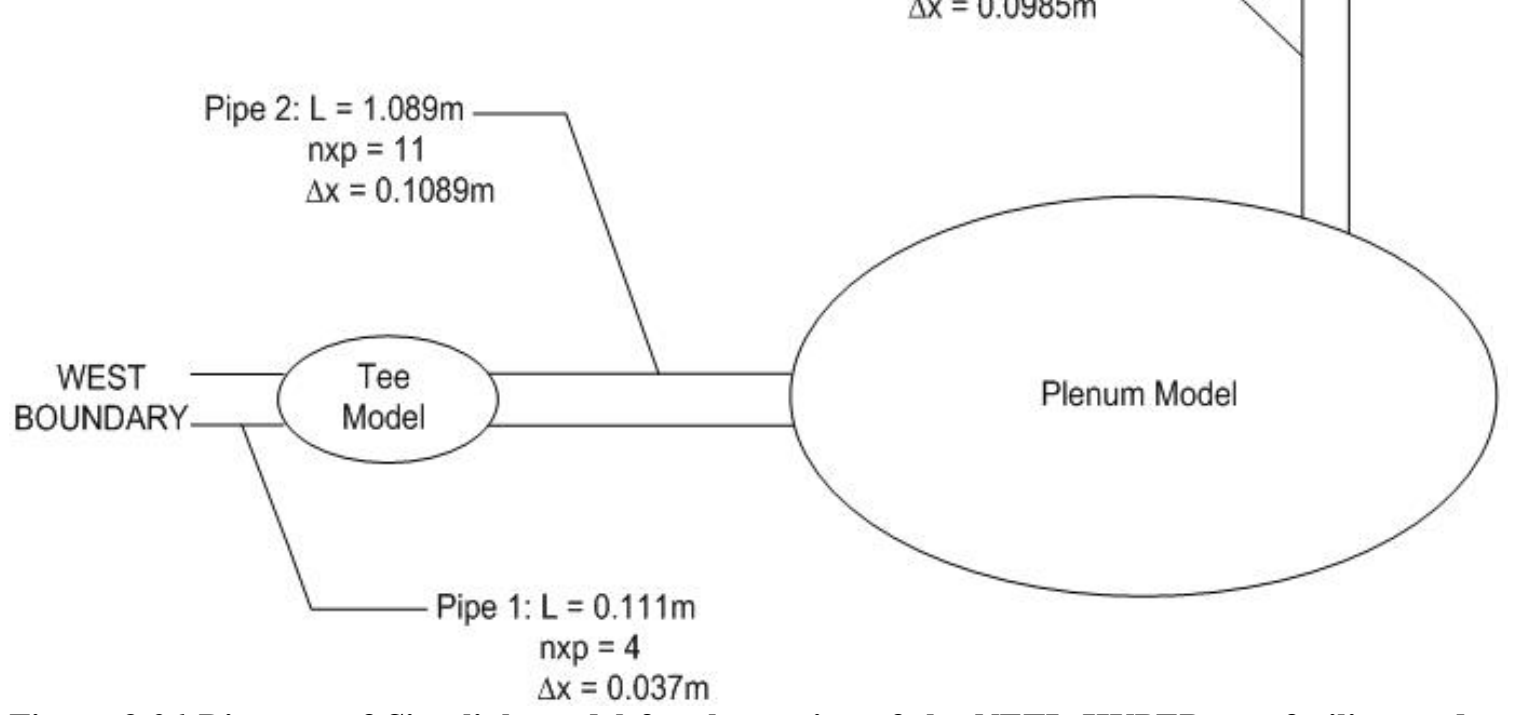

Figure 3-26 Diagram of Simulink model for the section of the NETL HYPER test facility used to validate the simulation.

In order to model the heat transfer between the air in the duct and its surroundings, the thermal capacity of the steel piping and the insulation had to be taken into account. Based on a heat transfer coefficient and temperature gradient, the following relationship was used to model this heat exchange:

$q_{\text {internal }}^{*}=-h_{\text {int-pipe }} \pi D_{h}\left(T_{\text {gas }}-T_{\text {pipe-ins }}\right)$

where $q_{\text {internal }}^{*}=$ heat transfer from gas in duct used in equation (3-16)

$\mathrm{h}_{\text {int-pipe }}=$ internal heat transfer coefficient for the pipe

$\mathrm{T}_{\text {gas }}=$ temperature of gas flowing through the duct

$\mathrm{T}_{\text {pipe-ins }}=$ lumped temperature of the surrounding pipe and insulation 
Since the temperature of the surrounding pipe and insulation also changed with changing gas temperature, the following lumped model was developed to simulate the heating of the surrounding material:

$$
\left.\frac{d T}{d t}\right|_{\text {pipe-ins }}=\frac{q_{\text {internal }}^{*}-q_{\text {external }}^{*}}{m_{\text {pipe-ins }}^{*} c_{\text {pipe-ins }}}
$$

where $\mathrm{m}^{*}$ pipe-ins $=$ mass per unit length of the surrounding pipe and insulation

$\mathrm{C}_{\text {pipe-ins }}=$ lumped heat capacity of the surrounding pipe and insulation

In equation (3-60) the lumped heat capacity was calculated as the mass average of the pipe and insulation capacities. The $\mathrm{q}_{\text {internal }}$ term was calculated from equation (3-59), but a positive sign was used instead of the negative to be consistent with heat flow direction. The $\mathrm{q}^{*}$ external term was determined using the following relationship:

$$
q_{\text {external }}^{*}=h_{\text {ext-pipe }} \pi D_{o-i n s}\left(T_{\text {pipe-ins }}-T_{\text {amb }}\right)
$$

where $q_{\text {external }}^{*}=$ heat transfer from the lumped mass to the surroundings

$\mathrm{h}_{\text {ext-pipe }}=$ external heat transfer coefficient

$\mathrm{D}_{\text {o-ins }}=$ outer diameter of the insulation

$\mathrm{T}_{\mathrm{amb}}=$ temperature of ambient surroundings

Essentially the same model was used for the heating of the metal and insulation in the tee, plenum, and elbow components. However, for these components the actual mass and actual heat transfer rates were used instead of on a per length basis due to the geometry differences between the ductwork and these components. This gave rise to the following equations:

$$
\dot{Q}_{\text {internal }}=h_{\text {int-comp }} A_{\text {int-comp }}\left(T_{\text {gas }}-T_{\text {body-ins }}\right)
$$

where $\dot{Q}_{\text {internal }}=$ rate of heat loss from the component (plenum, tee, or elbow) used with equation (3-41)

$\mathrm{h}_{\text {int-comp }}=$ internal heat transfer coefficient for the component

$\mathrm{A}_{\text {int-comp }}=$ internal surface area of the component

$\mathrm{T}_{\text {gas }}=$ temperature of the gas moving through the component

$\mathrm{T}_{\text {body-ins }}=$ lumped temperature of the body and insulation of the component

$$
\left.\frac{d T}{d t}\right|_{\text {body-ins }}=\frac{\dot{Q}_{\text {internal }}-\dot{Q}_{\text {external }}}{m_{\text {body }- \text { ins }} c_{\text {body }-i n s}}
$$

where $m_{\text {body-ins }}=$ mass of the surrounding metal body and insulation 
$C_{\text {body-ins }}=$ lumped heat capacity of the surrounding metal body and insulation

$$
\begin{gathered}
\dot{Q}_{\text {external }}=h_{\text {ext-comp }} A_{\text {ext-comp }}\left(T_{\text {body-ins }}-T_{\text {amb }}\right) \\
\text { where } \dot{Q}_{\text {external }}=\text { heat transfer from the lumped body and insulation to the } \\
\text { surroundings } \\
h_{\text {ext-comp }}=\text { external heat transfer coefficient for the component } \\
A_{\text {ext-comp }}=\text { external surface area of the component } \\
\mathrm{T}_{\text {amb }}=\text { temperature of ambient surroundings }
\end{gathered}
$$

The properties of the piping, pipe insulation, components, and component insulation used for this analysis are given in Table 3-2. The pipe, tee, and elbow insulation density and heat capacity were taken from the manufacturer literature [30], and the values used for the plenum insulation were assumed to be the same. The thickness of the pipe insulation was given in the NETL process and instrumentation diagram as 2in. The piping in the NETL HYPER system is ASTM 316 A312 TP316 6” SCH40S pipe. The actual inside and outside diameters of this pipe were looked up [32], and the density and heat capacity were found for 316 stainless steel [31]. The thickness of the 316 stainless steel in the plenum was given as $1 / 4$ ” [33]. Note that the volume and surface area of the plenum were calculated as if it were a cylinder with closed ends. In reality the plenum has elliptical ends, which will make the actual values slightly different.

In order to use a proper friction factor for the piping in the NETL system, a curve fit was created to model the relationship between the friction factor $\left(\mathrm{C}_{\mathrm{f}}\right)$ and the Reynolds number as given by the Moody diagram. First, the equivalent sand roughness value of stainless steel pipe was found to be approximately $\varepsilon=0.002 \mathrm{~mm}$ (White [5]), leading to a relative roughness ratio $(\varepsilon / \mathrm{D})$ of approximately 0.00001 . In the laminar region of the curve fit (assumed to be $\operatorname{Re}<2 \times 10^{3}$ ), the laminar relationship $C_{f}=16 /$ Re was used. In the transition region (assumed to be $2 \times 10^{3}<\operatorname{Re}<4 \times 10^{3}$ ), a third order polynomial was fit matching both the slope and value of $\mathrm{C}_{\mathrm{f}}$ on both the laminar and turbulent neighboring regions. The smooth pipe turbulent $C_{f}$ curve and the $C_{f}$ curve for a relative roughness ratio of 0.00001 are virtually equivalent for Reynolds numbers below about $1 \times 10^{6}$. Therefore, in the region $4 \times 10^{3}<\operatorname{Re}<3.861 \times 10^{4}$ the empirical relationship $C_{\mathrm{f}}=$ $0.078 \mathrm{Re}_{\mathrm{D}}{ }^{-1 / 4}$ given by Bejan [29] for smooth pipes with Reynolds number less than $8 \times 10^{4}$ 
was used. In the range $3.861 \times 10^{4}<\mathrm{Re}<1 \times 10^{6}$ the empirical relationship $\mathrm{C}_{\mathrm{f}}=$ $0.046 \mathrm{Re}_{\mathrm{D}}{ }^{-1 / 5}$ was used which was given by Bejan [29] for smooth pipes with a Reynolds number range between $2 \times 10^{4}$ and $1 \times 10^{6}$. The number $3.861 \times 10^{4}$ was taken to be the changing number because this is where the two empirical curves meet. For Reynolds numbers above $1 \times 10^{6}$ an exponential curve was fit to allow the $\mathrm{C}_{\mathrm{f}}$ versus Re curve smoothly move to its constant value of 0.00245 at an approximate Reynolds number of $6 \times 10^{7}$ as given by the Moody diagram. The resulting $C_{f}$ vs. Re curve is shown in Figure 3-27.

Table 3-2 Properties of the piping, components, and insulation in the NETL HYPER test facility used for the simulation.

\begin{tabular}{|c|c|c|}
\hline Material & Property & Value \\
\hline \multirow{2}{*}{316 Stainless Steel } & $\rho\left(\mathrm{kg} / \mathrm{m}^{3}\right)$ & 8238 \\
\hline & $c(\mathrm{~J} / \mathrm{kgK})$ - Heat Capacity & 504 \\
\hline \multirow{2}{*}{ Insulation } & $\rho\left(\mathrm{kg} / \mathrm{m}^{3}\right)$ & 320 \\
\hline & $\mathrm{c}(\mathrm{J} / \mathrm{kgK})$ & 860 \\
\hline \multirow{5}{*}{ Pipes } & D (m) - Inner Pipe Diameter & 0.1540 \\
\hline & $D_{o}(m)$ - Outer Pipe Diameter & 0.1683 \\
\hline & $\mathrm{D}_{\mathrm{o} \text {-ins }}(\mathrm{m})$ - Outer Insulation Diameter & 0.2700 \\
\hline & $\mathrm{m}_{\text {pipe-ins }}^{*}(\mathrm{~kg} / \mathrm{m})$ & 41.02 \\
\hline & $\mathrm{C}_{\text {pipe-ins }}(\mathrm{J} / \mathrm{kgK})$ & 601.2 \\
\hline \multirow{2}{*}{ Tee } & $\mathrm{m}_{\text {body-ins }}(\mathrm{kg})$ & 18.76 \\
\hline & $\mathrm{C}_{\text {body-ins }}(\mathrm{J} / \mathrm{kgK})$ & 601.2 \\
\hline \multirow{2}{*}{ Elbow } & $\mathrm{m}_{\text {body-ins }}(\mathrm{kg})$ & 19.64 \\
\hline & $\mathrm{C}_{\text {body-ins }}(\mathrm{J} / \mathrm{kgK})$ & 601.2 \\
\hline \multirow{5}{*}{ Plenum } & D (m) - Inner Steel Diameter & 1.219 \\
\hline & $D_{0}(m)$ - Outer Steel Diameter & 1.232 \\
\hline & $\mathrm{D}_{\mathrm{o} \text {-ins }}(\mathrm{m})$ - Outer Insulation Diameter & 1.334 \\
\hline & $\mathrm{m}_{\text {body-ins }}(\mathrm{kg})$ & 786.4 \\
\hline & $\mathrm{C}_{\text {body-ins }}(\mathrm{J} / \mathrm{kgK})$ & 592.2 \\
\hline
\end{tabular}




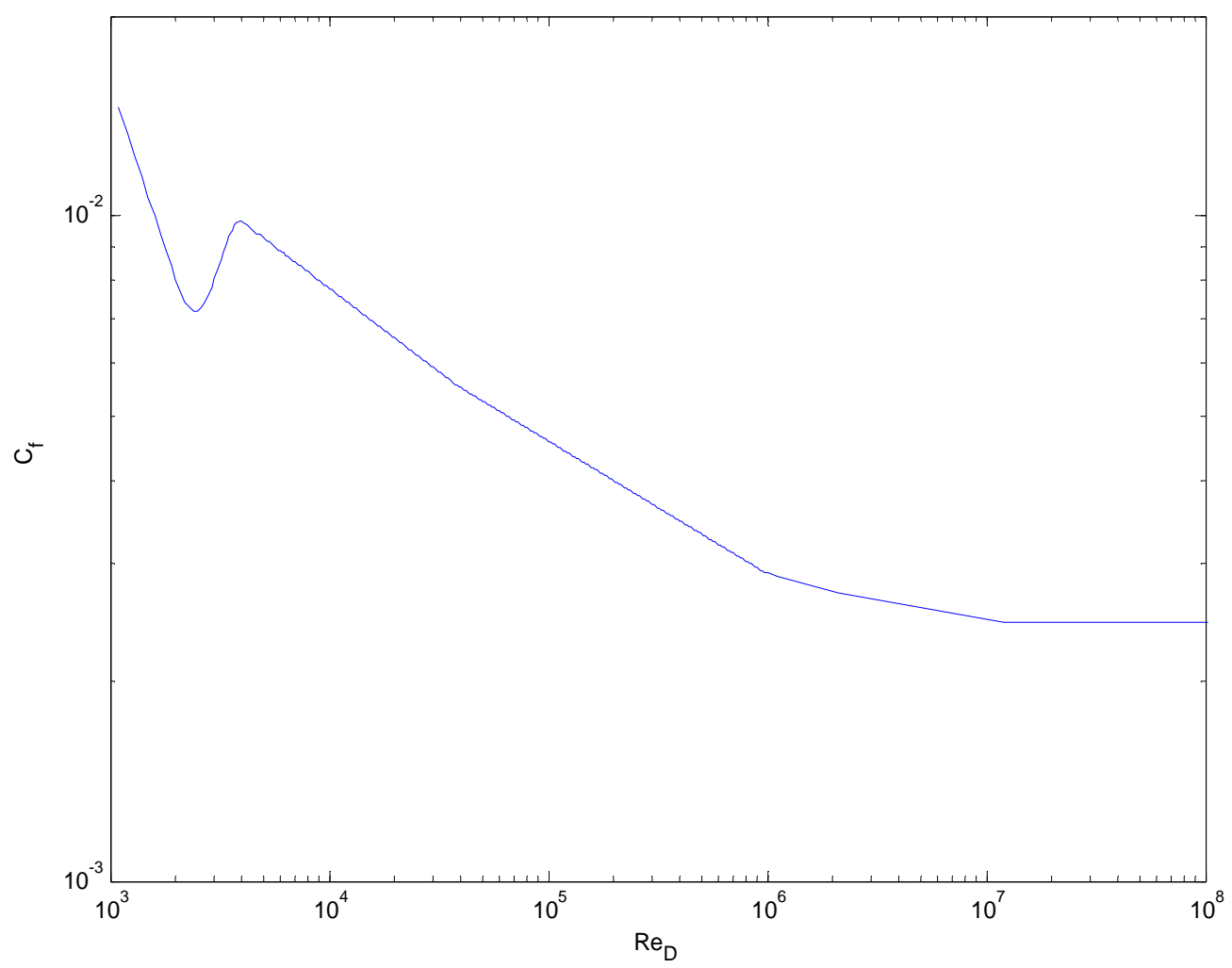

Figure 3-27 Curve fit for $C_{f}$ vs. $\operatorname{Re}_{\mathrm{D}}$ for the stainless steel pipe used in the NETL HYPER test facility.

The Reynolds number range for experimental data analyzed was approximately $1.7 \times 10^{5}$ to $7 \times 10^{5}$. In order to calculate values of internal heat transfer coefficients in equations (3-59) and (3-62), an appropriate Nusselt number $(\mathrm{Nu})$ relationship had to be determined. Bejan [29] gives the following empirical Gnielinski correlation for fullydeveloped turbulent flow through pipes:

$$
N u_{D, \text { int }}=\frac{\left(C_{f} / 2\right)\left(\mathrm{Re}_{D}-10^{3}\right) \operatorname{Pr}}{1+12.7\left(C_{f} / 2\right)^{1 / 2}\left(\operatorname{Pr}^{2 / 3}-1\right)}
$$

where $\mathrm{Nu}_{D, \text { int }}=h_{\mathrm{int}} \mathrm{D} / \mathrm{k}=$ Nusselt number for the internal heat transfer between gas and wall temperature

$\operatorname{Pr}=$ Prandtl number 
Equation (3-65) is accurate for the idealized case of full-developed, turbulent pipe flow. In the NETL HYPER system, there are flanges, tees, expansions, contractions, elbows, etc. in the flow system. Additionally, just upstream of the west boundary temperature and pressure probes there are two inlets to the duct from a heat exchanger. All of these factors generate extra turbulence in the flow, thereby improving the heat transfer and increasing the Nusselt number. It was therefore assumed that this extra turbulence could be treated as an effective increase in the wall friction, i.e., for the purpose of heat transfer the piping could be treated as if had additional wall friction. Therefore the friction factor in the Gnielinski correlation (3-65) was replaced with a scaled effective friction $\mathrm{C}_{\mathrm{f}}{ }^{*}=$ $\omega \mathrm{Cf}$, where $\omega$ is an assumed scaling factor. Making this substitution in (3-65) gives the relationship used to determine the internal Nusselt number and heat transfer coefficient (used to determine the heat transfer between the gas and the lumped pipe/insulation temperature):

$$
N u_{D, \text { int }}=\frac{\left(C_{f}^{*} / 2\right)\left(\operatorname{Re}_{D}-10^{3}\right) \operatorname{Pr}}{1+12.7\left(C_{f}^{*} / 2\right)^{1 / 2}\left(\operatorname{Pr}^{2 / 3}-1\right)}
$$

where $\mathrm{C}_{\mathrm{f}} *=\omega \mathrm{C}_{\mathrm{f}}=$ effective friction factor for heat transfer purposes caused by additional turbulence

A scale factor of $\omega=5.0$ was assumed in this study. While this may seem high, one must remember that the NETL HYPER system contained stainless steel piping which is very near the smooth-pipe limit. A five times increase in the friction factor in the fully turbulent regime still lies well within the friction factors reported for rougher pipes in the Moody diagram. However, this scale factor is a free modeling parameter and therefore must be determined appropriately for different scenarios.

Equation (3-66) was also used to estimate the Nusselt number and heat transfer coefficients for the tee and elbow components. The Reynolds numbers in these calculations were based on the assumed diameters and velocities for these parts as described in the tee and elbow model sections. The friction factor was determined using 
the straight pipe value given in Figure 3-27, and the effective friction factor scaling again assumed to be $\omega=5.0$.

The Reynolds number for the flow through the plenum was calculated to be about $2.3 \times 10^{4}$ at the lowest mass flow rate reported in the experimental data based on the inside diameter of the cylindrical part of the plenum. At this Reynolds number, even the flow inside the plenum was surely turbulent. Additionally, the effects of the expansion and contraction at the plenum entrance and exit should add to the level of turbulence within the plenum. With these factors in mind, it was assumed that once again equation (3-66) could be used to get an approximate value for the internal Nusselt number for the plenum. Finally, it should be noted that the Nusselt number given in equation (3-66) is related to the internal heat transfer coefficient given by either equation (3-59) or (3-62) in the following manner:

$$
h_{\text {int }}=\frac{N u_{D, \text { int }} k}{D}
$$

$$
\begin{aligned}
\text { where } \mathrm{k} & =\text { thermal conductivity of the gas } \\
\mathrm{D} & =\text { internal diameter of the component }
\end{aligned}
$$

No extremely good correlation was found for an external Nusselt number based on the temperature difference between the pipe wall and the ambient temperature. However, Bejan [29] gives effective Nusselt numbers for the steady-state case of a wellinsulated pipe based on the temperature difference between the mean fluid temperature and the ambient temperature of the surroundings. In steady-state with good insulation, the pipe and mean fluid temperature should be fairly close and hence these results should give a good approximate value for an external Nusselt number based on the calculated lumped temperature of the insulation pipe and the external ambient temperature. The effective Nusselt number range reported by Bejan [29] for such a case is about 0.1 to 1.0. In this study the external Nusselt number was assumed to be 0.5. It should be noted however that this external Nusselt number is dependent on many things, not the least of which is the amount of circulation of external air. An additional factor is how the ambient temperature in the room rose with the run time of the system; in this study the ambient temperature was simply taken to be $294 \mathrm{~K}$. The external heat transfer coefficient is related to the external Nusselt number in the following manner: 
$h_{\text {ext }}=\frac{N u_{D_{o-i n s}, e x t} k}{D_{o-i n s}}$

where $N u_{D, e x t}=$ external Nusselt number

$\mathrm{D}_{\text {o-ins }}=$ external diameter of the component's insulation

The temperature of the experimental data ranged from about $300 \mathrm{~K}$ to almost 800K. In this range the thermal conductivity and viscosity of air both approximately double from the lowest to the highest temperature. Additionally, the specific heat $\left(\mathrm{C}_{\mathrm{p}}\right)$ of air changes almost seven percent. In order to get accurate results, these factors had to be taken into account in the model. The viscosity and thermal conductivity variation were modeled with the Sutherland relationships given by White [3]:

$$
\frac{\mu}{\mu_{o}}=\left(\frac{T}{T_{o}}\right)^{3 / 2} \frac{T_{o}+S_{\mu}}{T+S_{\mu}}
$$

and

$$
\frac{k}{k_{o}}=\left(\frac{T}{T_{o}}\right)^{3 / 2} \frac{T_{o}+S_{k}}{T+S_{k}}
$$

$$
\text { where } \begin{aligned}
\mathrm{T}_{0} & =\text { standard temperature }=273 \mathrm{~K} \text { (air) } \\
\mu_{0} & =\text { viscosity at standard temperature }=1.716 \times 10^{-5} \mathrm{~Pa} \mathrm{~s} \text { (air) } \\
\mathrm{k}_{0} & =\text { thermal conductivity at standard temperature }=0.0241 \mathrm{~W} / \mathrm{mK} \text { (air) } \\
\mathrm{S}_{\mu} & =\text { Sutherland constant for viscosity }=111 \mathrm{~K} \text { (air) } \\
\mathrm{S}_{\mathrm{k}} & =\text { Sutherland constant for thermal conductivity }=194 \mathrm{~K} \text { (air) }
\end{aligned}
$$

The variation of the specific heat of air at constant pressure was calculated using the fourth order polynomial curve fit by Moran, et. al. [6]:

$$
\begin{gathered}
C_{p, a i r}=\left(\frac{\bar{R}}{\bar{m}_{\text {air }}}\right)\left[\alpha+\beta T+\gamma T^{2}+\delta T^{3}+\varepsilon T^{4}\right] \\
\text { where } \bar{R}=\text { universal gas constant }=8314 \mathrm{~J} / \mathrm{kmolK} \\
\bar{m}_{\text {air }}=\text { molecular weight of air }=28.97 \mathrm{~kg} / \mathrm{kmol} \\
\alpha=3.653 \\
\beta=-1.337 \times 10^{-3} \mathrm{~K}^{-1} \\
\gamma=3.294 \times 10^{-6} \mathrm{~K}^{-2} \\
\delta=-1.913 \times 10^{-9} \mathrm{~K}^{-3} \\
\varepsilon=0.2763 \times 10^{-12} \mathrm{~K}^{-4}
\end{gathered}
$$


No good curve fit was immediately found for the variation of the specific heat of air at constant volume. Therefore, a third order polynomial was fit in Excel using the data from Moran,et. al. [6]:

$$
\begin{aligned}
& C_{v, \text { air }}=A+B T+C T^{2}+D T^{3} \\
& \text { where } C_{v, \text { air }}=\text { specific heat of air in } \mathrm{J} / \mathrm{kgK} \\
& \mathrm{A}=7.5467 \times 10^{2} \mathrm{~J} / \mathrm{kgK}^{2} \\
& \mathrm{~B}=-3.2880 \times 10^{-1} \mathrm{~J} / \mathrm{kgK}^{2} \\
& \mathrm{C}=7.8971 \times 10^{-4} \mathrm{~J} / \mathrm{kgK}^{3} \\
& \mathrm{D}=-3.6116 \times 10^{-7} \mathrm{~J} / \mathrm{kgK}^{4}
\end{aligned}
$$

Before continuing, the Nusselt number relationship used to model the heat loss from the plenum is worth discussing. Since the flow and heat transfer phenomena inside the plenum is different than in a pipe, an alternative approach to obtaining an approximate Nusselt number is to simply use a powerlaw relationship incorporating the modeling parameters known to cause a change in the Nusselt number. If forced convection is expected to have the dominant influence on heat transfer, then an effective Nusselt number could be related to an effective Reynolds number and the Prandtl number:

$$
\begin{aligned}
& N u_{\text {eff }}=c_{h t} \operatorname{Pr}^{m} \operatorname{Re}_{\text {eff }}^{n} \\
& \text { where } \mathrm{Nu}_{\text {eff }}=\text { effective Nusselt number } \\
& \quad \mathrm{Re}_{\text {eff }}=\text { effective Reynolds number } \\
& \quad \mathrm{C}_{\mathrm{ht}}=\text { coefficient for effective Nusselt number relationship } \\
& \mathrm{m}=\text { Prandtl number exponent for effective Nusselt number relationship } \\
& \mathrm{n}=\text { Reynolds number exponent for effective Nusselt number relationship }
\end{aligned}
$$

In this relationship the effective Reynolds number would be calculated based an effective velocity which itself would be based on a flow-through time and the characteristic length of the plenum in question:

$$
\begin{gathered}
\operatorname{Re}_{\text {eff }}=\frac{U_{\text {eff }} D_{c h}}{v} \\
\text { where } U_{\text {eff }}=\text { effective velocity of gas through plenum } \\
D_{\text {ch }}=\text { characteristic diameter of plenum } \\
v=\text { kinematic viscosity }
\end{gathered}
$$

and 


$$
U_{\text {eff }}=\frac{L_{c h}}{\tau}
$$

where $\mathrm{L}_{\mathrm{ch}}=$ characteristic flow length through the plenum

$\tau=$ flow-through time for the plenum

and

$$
\begin{aligned}
\tau=\frac{\forall}{\dot{\forall}} & \\
& \text { where } \begin{aligned}
\forall & =\text { volume of plenum } \\
& \dot{\forall}=\text { volumetric flowrate through the plenum }
\end{aligned}
\end{aligned}
$$

The effective Nusselt number would be related to an effective heat transfer coefficient in the same manner as equation (3-67):

$$
h_{\text {eff }}=\frac{N u_{\text {eff }} k}{D_{c h}}
$$

Likewise, the calculation of the rate of heat loss from the plenum would be similar to that given by equation (3-62):

$\dot{Q}_{\text {internal }}=h_{\text {eff }} A_{\text {int-comp }}\left(T_{\text {gas }}-T_{\text {body-ins }}\right)$

If a plenum is being modeled which has a large vertical component (similar to a silo shape), and the flow-through time of the plenum is relatively large, then natural convection will become a factor in the rate of heat transfer. In this case the calculation of the effective Nusselt number would have to also be dependent on the Rayleigh number, i.e. an alternative to equation (3-73) would have to be formulated which would include the Rayleigh number. Additionally, if the influence of radiation becomes an important factor in the heat transfer (which it may at high temperatures such as in the NETL HYPER test facility), its effects should be incorporated into this effective heat transfer coefficient. The coefficient, $c_{h t}$, and exponents ' $m$ ' and ' $n$ ', in equations such as (3-73) would essentially be free modeling parameters along with the characteristic diameter $\mathrm{D}_{\mathrm{ch}}$ and length $\mathrm{L}_{\mathrm{ch}}$. This type of approach is more general than that used to model the heat transfer through the plenum given by equations (3-62) and (3-67) (used in the Results section to simulate the portion of the NETL HYPER test facility) and would be applicable to different geometries and flow situations. However, with the added 
generality comes more degrees of freedom, in particular exponents ' $m$ ' and ' $n$ ', $D_{\mathrm{ch}}, \mathrm{ch}_{\mathrm{ht}}$, etc. discussed previously. 


\section{Results and Discussion}

\subsection{Isothermal Fully-Developed Laminar Pipe Flow using the FORTRAN Code}

In order to verify the results of the equations derived and the code written, the first test case run with the FORTRAN code was of a simple straight, circular pipe. The pipe modeled had a length of $1 \mathrm{~m}$ and a diameter of $0.0254 \mathrm{~m}$, and the specified inlet and outlet pressures were $101326 \mathrm{~Pa}$ and $101325 \mathrm{~Pa}$. As illustrated in Figures 4-1 and 4-2 the steady-state pressure and velocity results from both the kinetic energy equation and the momentum equations were gathered and compared. The results from both models match identically and are consistent with the laminar Poiseuille flow solution where the pressure is expected to drop in a linear fashion and the calculated axial velocity for such a case is $\mathrm{u}$ $=1.034 \mathrm{~m} / \mathrm{s}$ from the laminar friction factor $C_{f}=16 /$ Re. Note that the calculated Reynolds number for this case is approximately 1700, which usually remains in the laminar region.

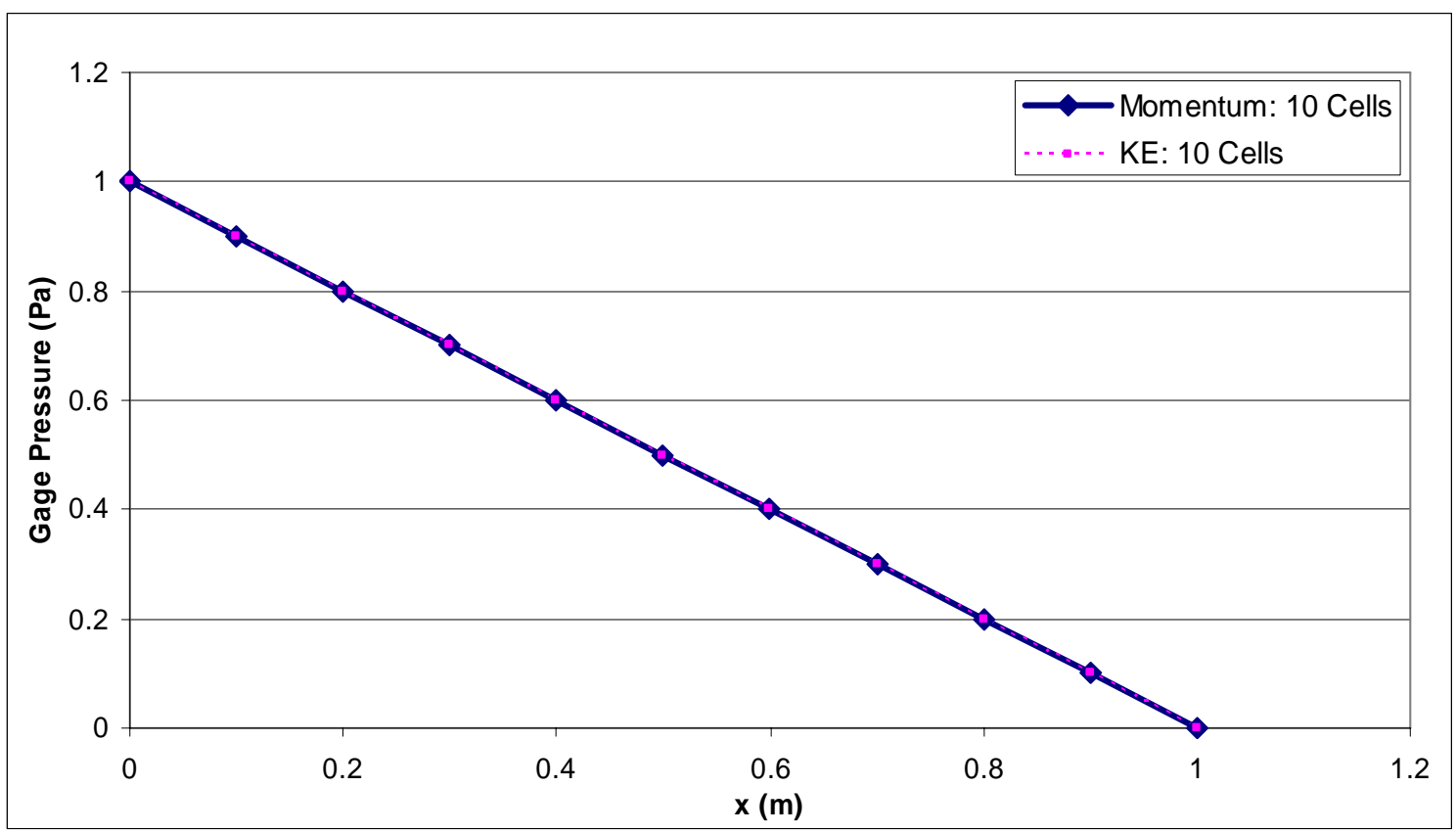

Figure 4-1 Steady-state gage pressure vs. axial length $(x)$ of straight pipe for momentum equation and kinetic energy equation; solution from Moody chart data: $u=1.034 \mathrm{~m} / \mathrm{s}$ for $\Delta \mathrm{P}=1 \mathrm{~Pa}$ for air $(\mu$ $=19.5 \times 10-6$ Pa s); pipe length $=1 \mathrm{~m}$, pipe diameter $=0.0254 \mathrm{~m}$. 


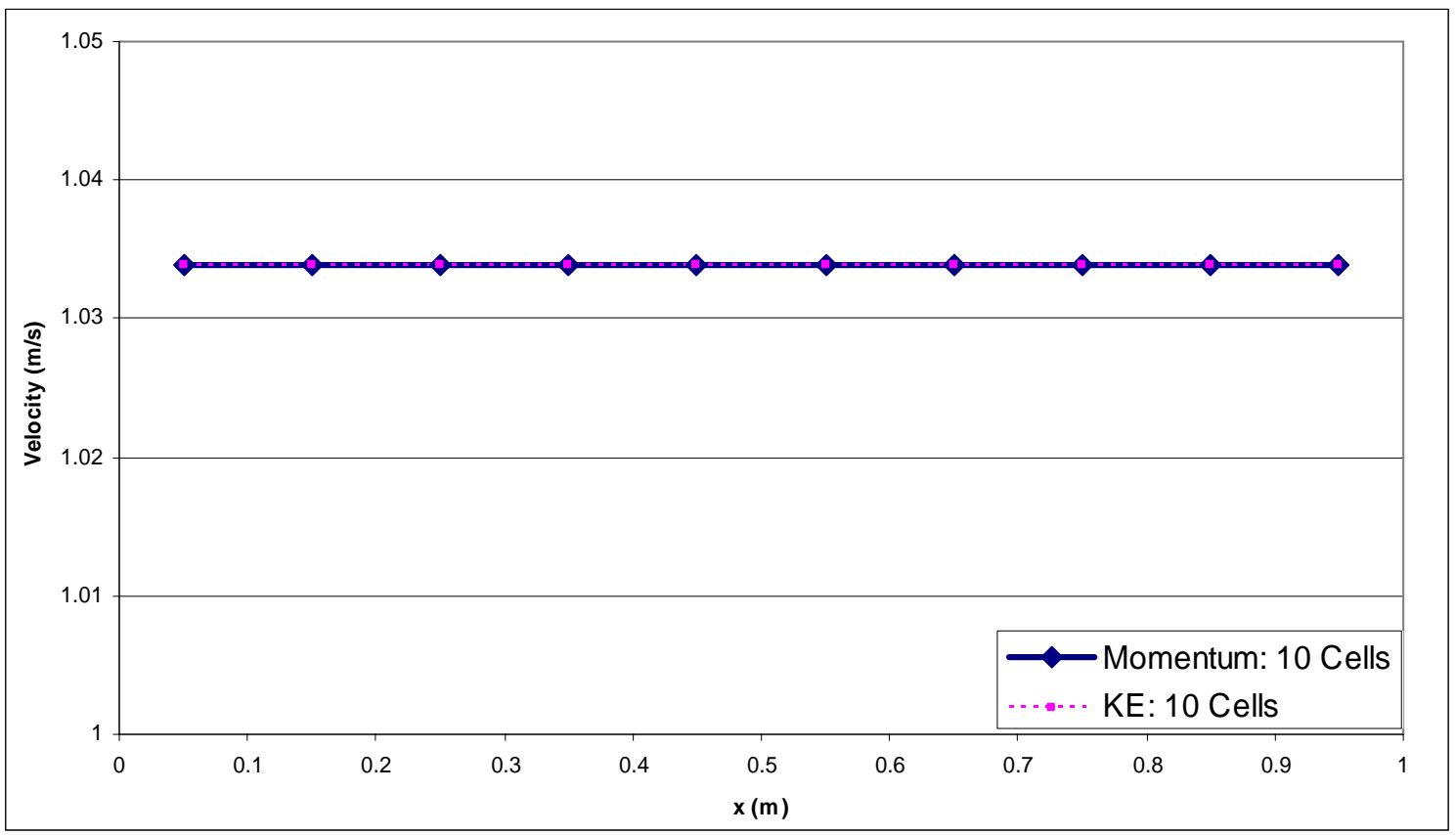

Figure 4-2 Steady-state average axial velocity vs. axial length (x) of straight pipe for momentum equation and kinetic energy equation; solution from Moody chart data: $\mathrm{u}=1.034 \mathrm{~m} / \mathrm{s}$ for $\Delta P=1 \mathrm{~Pa}$ for air $(\mu=19.5 \times 10-6$ Pa s); pipe length $=1 \mathrm{~m}$, pipe diameter $=0.0254 \mathrm{~m}$.

\subsection{Isothermal Plenum and Diffuser Flow using the FORTRAN Code}

Solving the momentum equation (3-4) along with the pseudo-compressible form of the continuity equation (3-30) gave fairly good results even for complicated geometries when the proper precautions were taken. As an example, these two equations were solved using the FORTRAN code for the case of a diffuser connected directly to a plenum, as shown in Figure 4-3. In this geometry, the length of the diffuser was 1m, and its diameter changed in a linear fashion from 1in. at the plenum to 10in. at the exit. The pressure drop from the plenum to the diffuser exit was specified as 1Pa. This was a difficult problem to solve numerically for three reasons: 1) a sudden contraction from the plenum into the diffuser causing a vena contracta, 2) possible losses in the diffuser due to flow separation caused by the adverse pressure gradient, and 3) the fact that this case appears to be on the border line between a laminar and turbulent flow. 


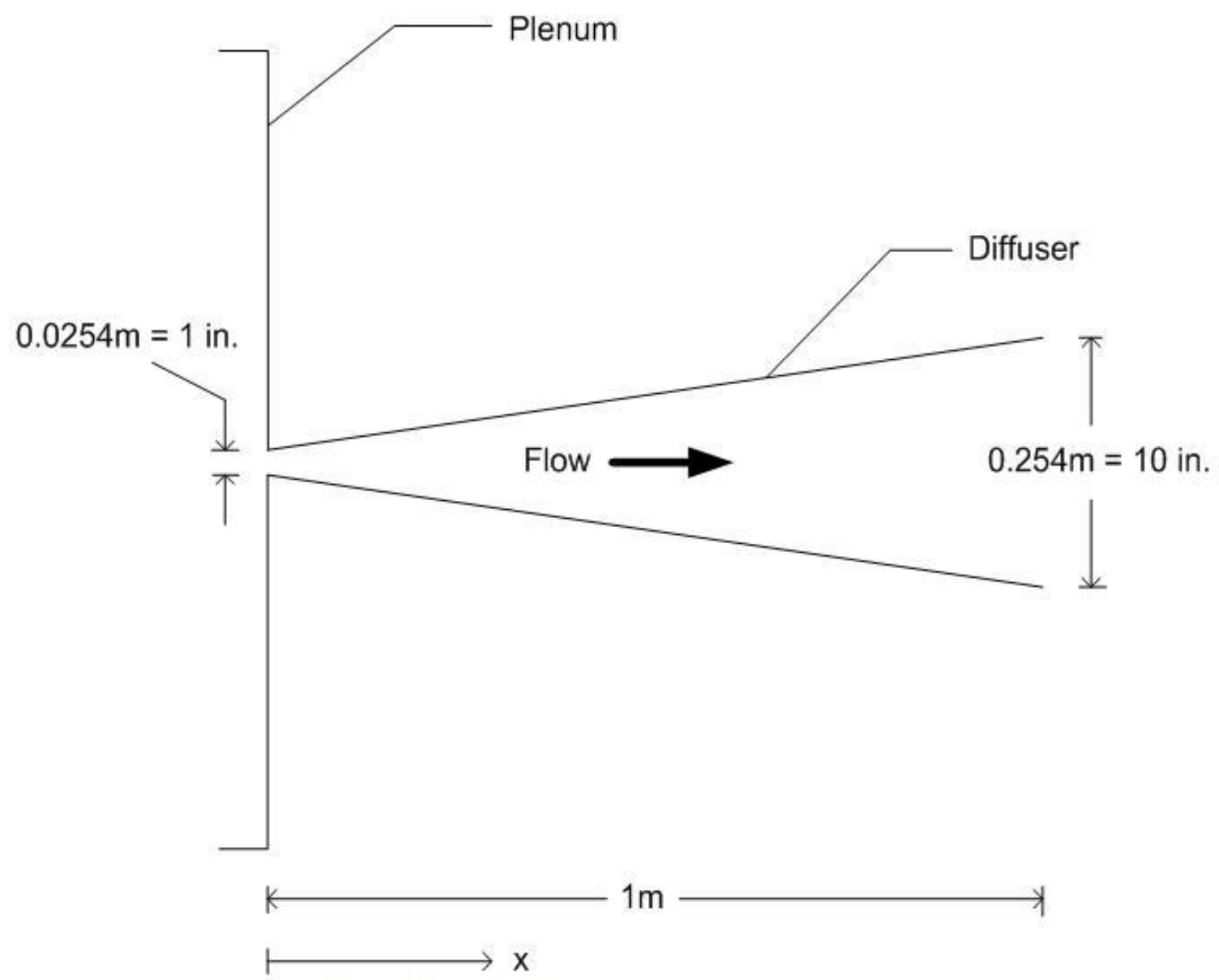

Figure 4-3 Schematic of plenum/diffuser test case.

The geometry shown in Figure 4-3 was constructed in Fluent, and a laminar model was used. The friction factor from this case was then obtained from the steadystate Fluent results and plotted against the axial coordinate x. While the laminar Fluent run did predict flow separation, the friction factor obtained from this run should still be approximately valid because the effective shear on the main flow for the same mass flow rate (and area-averaged axial velocity) is greater than the wall shear would be without flow separation. Essentially, the main flow is acted upon by an effective shear which should be roughly the same magnitude as the wall shear, as illustrated in Figure 4-4. By approximately matching the $\mathrm{C}_{\mathrm{f}}$ used in the 1-D code with the value of $\mathrm{C}_{\mathrm{f}}$ obtained from Fluent, the diffuser loss as presented in the Methodology section was not needed because it was accounted for in this $\mathrm{C}_{\mathrm{f}}$. The approximate matching of these two $\mathrm{C}_{\mathrm{f}}$ values is shown in Figure 4-5, and the steady-state pressure and axial velocity results in Figures 
4-6 and 4-7. It was determined from using this matching $C_{f}$ that appropriate values for the contraction minor loss coefficient and relaxation coefficient were $K_{0}=0.9$ and $\alpha=$ 6.0 as given by equation (3-33).

Since the $C_{f}$ obtained from Fluent is only valid for the specific Reynolds number tested, a more general approach is to approximate the friction factor using the laminar fully-developed pipe flow value ( $\mathrm{Cf}=16 / \mathrm{Re}$ ) and account for the minor loss of the flow separation using the loss coefficient as given by (3-36). This method gave good steadystate results for the pressure and axial velocity, as shown in Figures 4-8 and 4-9.

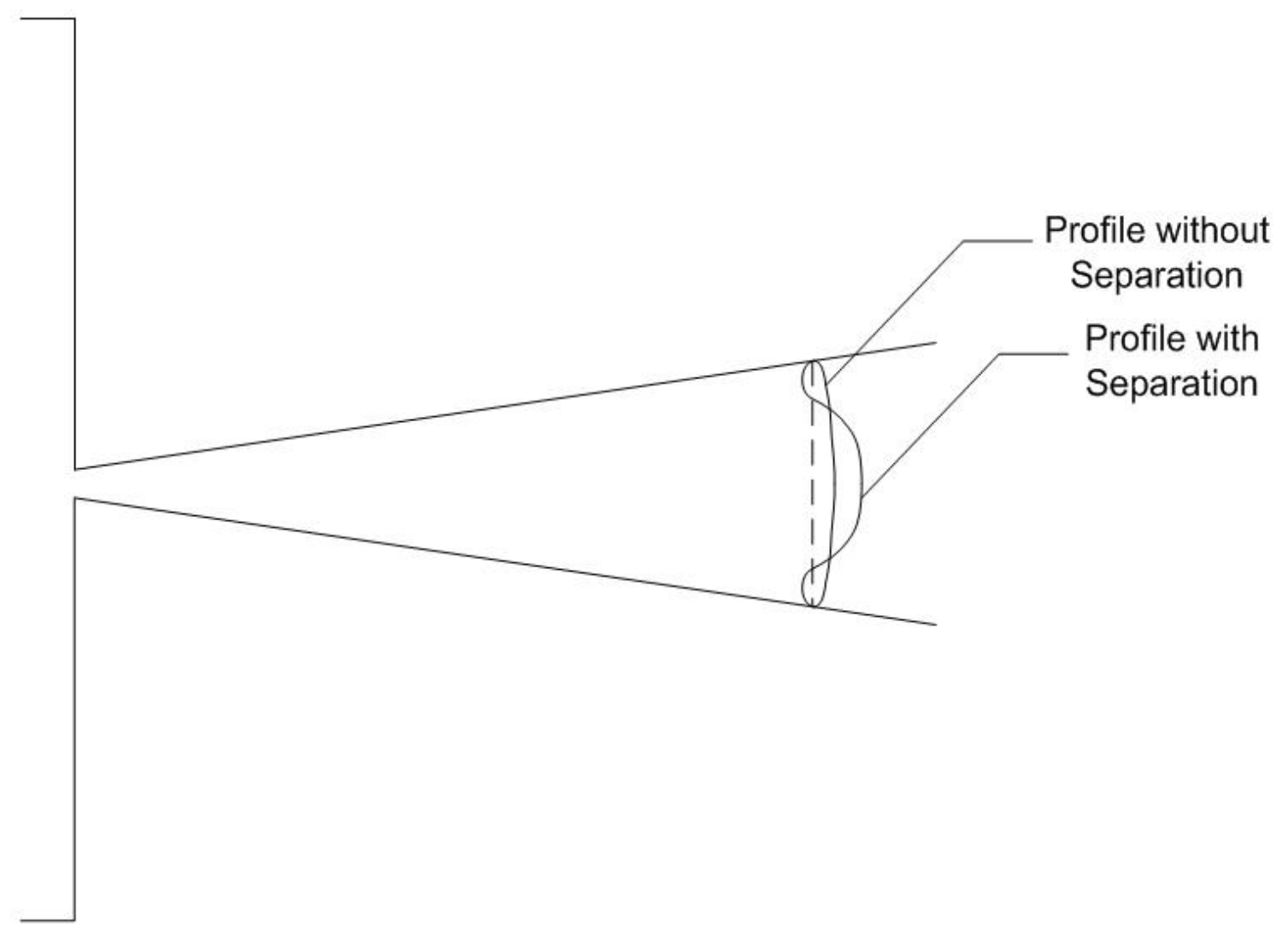

Figure 4-4 Sketch of wall shear and effective wall shear on main flow. 


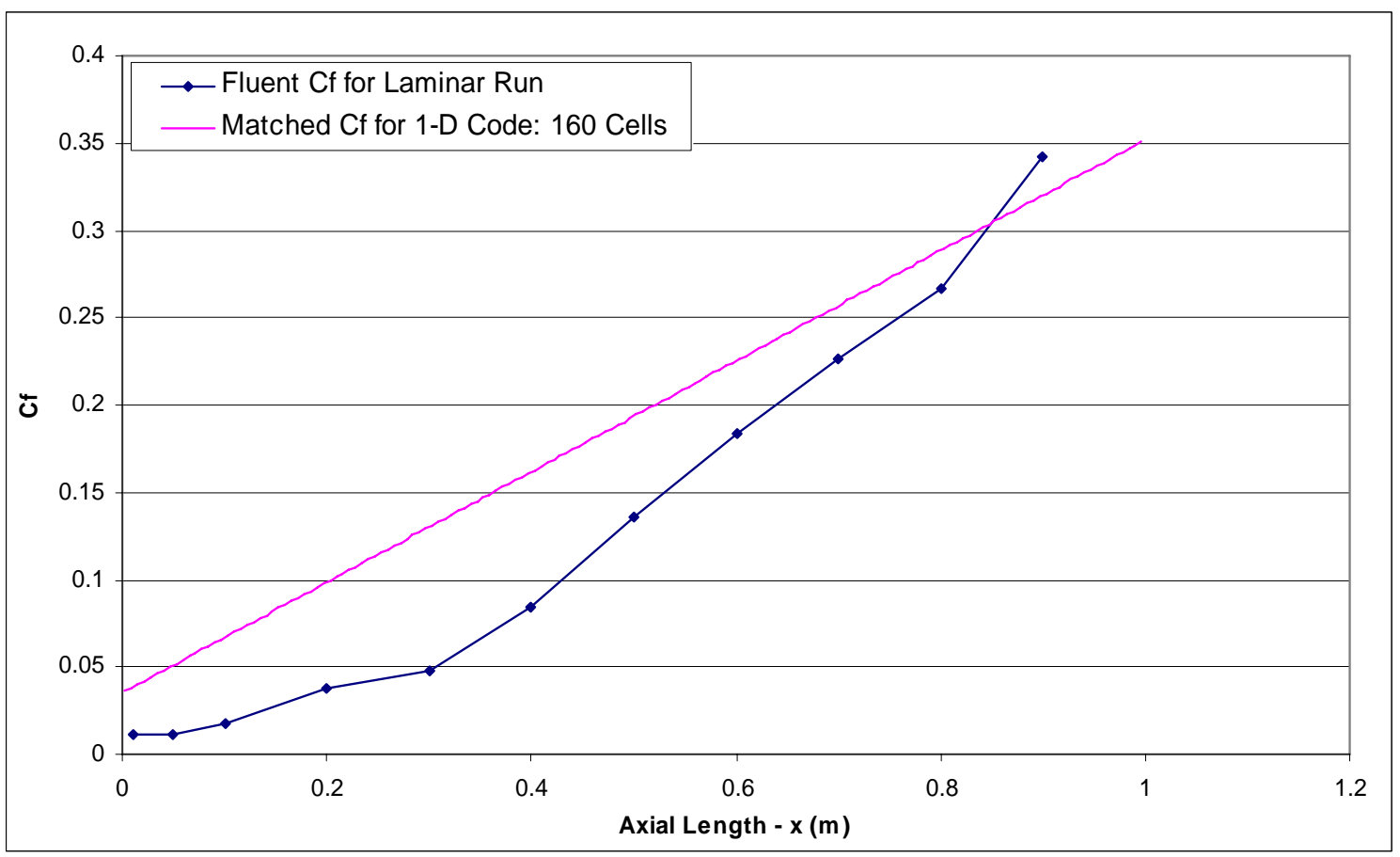

Figure 4-5 Matched $C_{f}$ for 1-D code with laminar Fluent $C_{f}$.

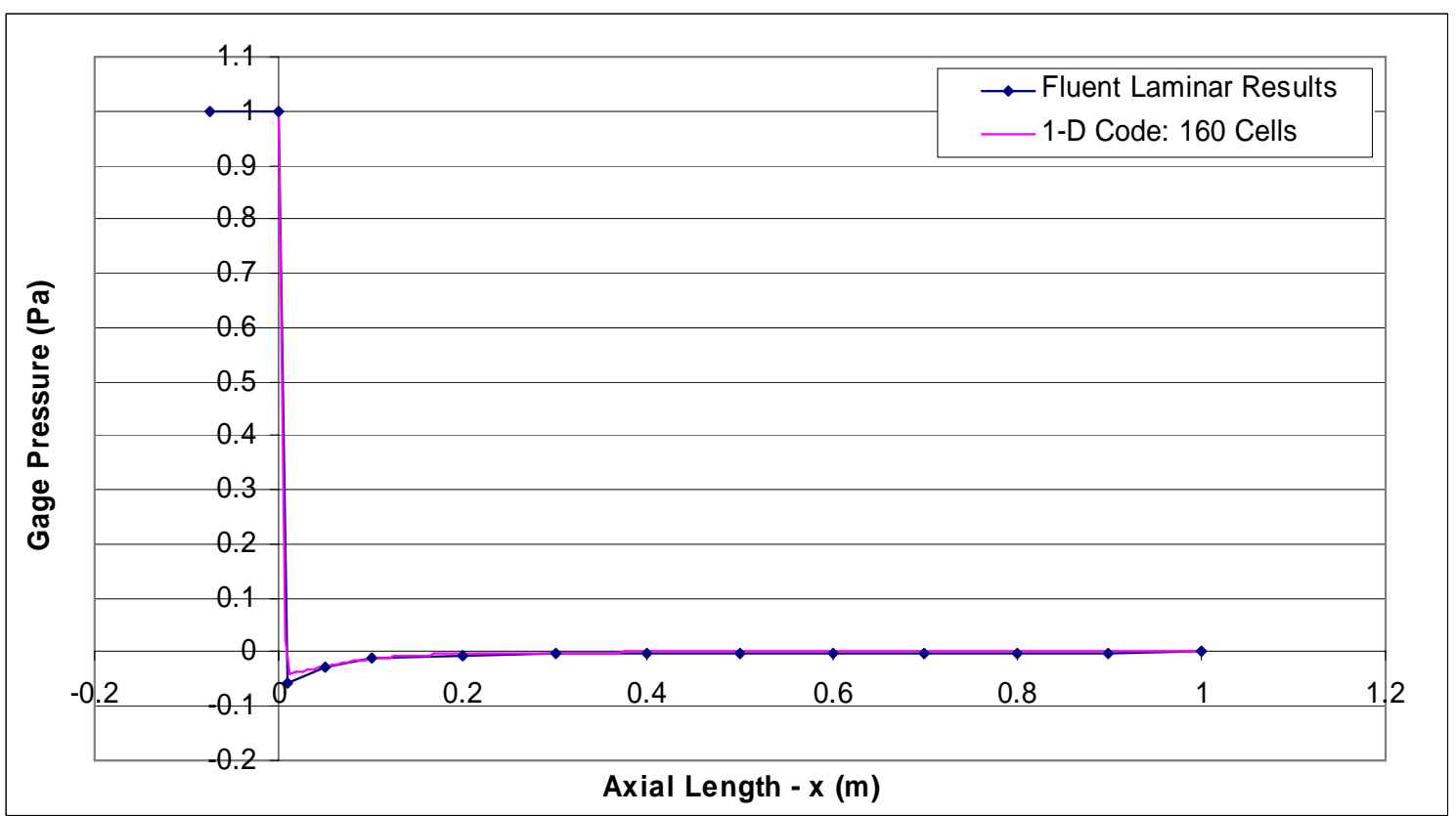

Figure 4-6 Steady-state, isothermal flow $(T=287 \mathrm{~K})$ gage pressure vs. $x$ for laminar Fluent results and 1-D code with matched laminar $C_{f}$ and minor contraction loss $\left(K_{0}=0.9, \alpha=6.0\right)$. 


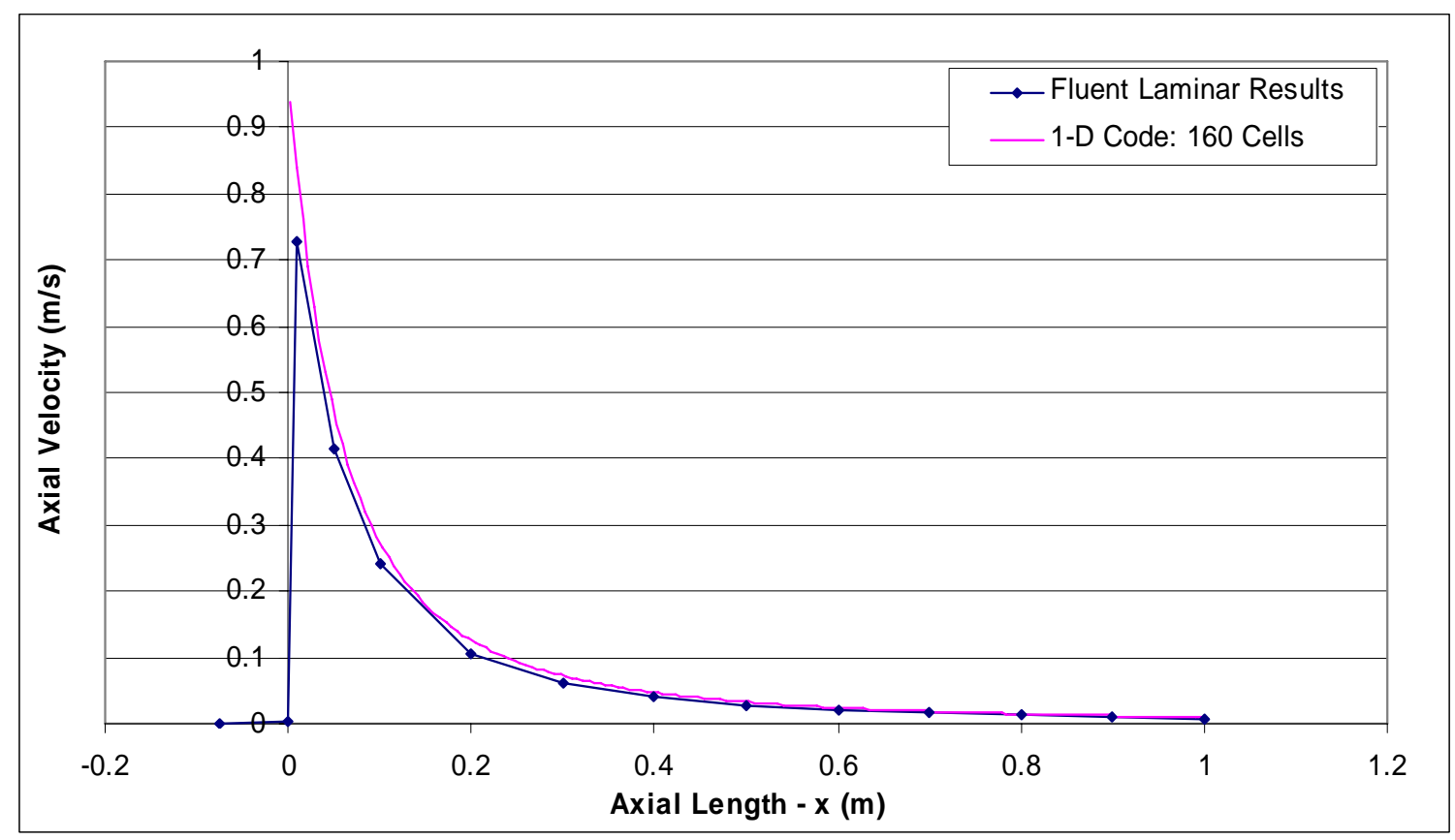

Figure 4-7 Steady-state, isothermal flow $(T=287 \mathrm{~K})$ axial velocity vs. $x$ for laminar Fluent results and 1-D code with matched laminar $C_{f}$ and minor contraction loss $\left(K_{0}=0.9, \alpha=6.0\right)$.

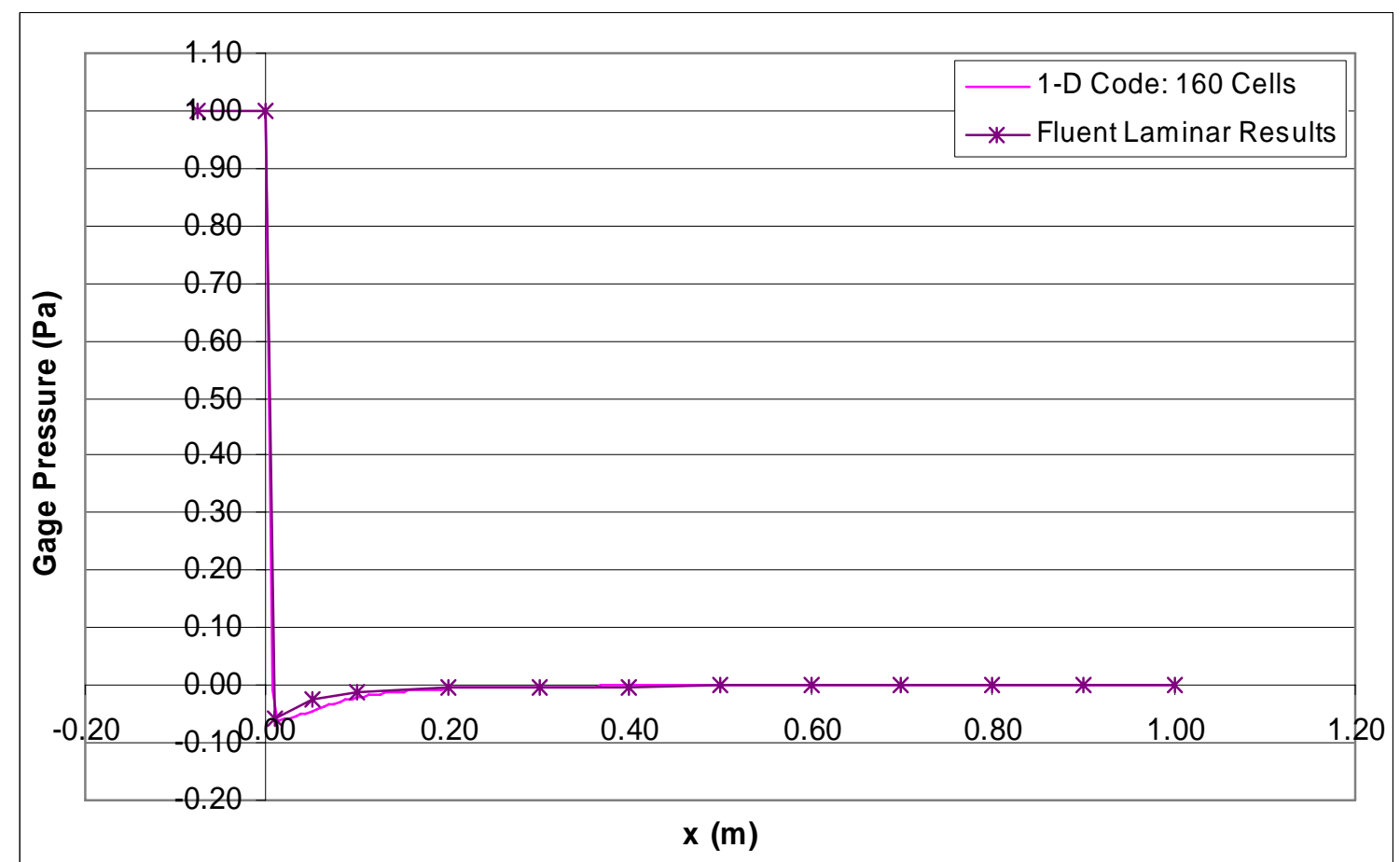

Figure 4-8 Steady-state, isothermal flow $(T=287 \mathrm{~K})$ gage pressure vs. $\mathrm{x}$ for laminar Fluent run and 1-D model with fully-developed pipe flow friction factor with diffuser and contraction minor losses $\left(K_{0}=0.9, \alpha=6.0\right)$. 


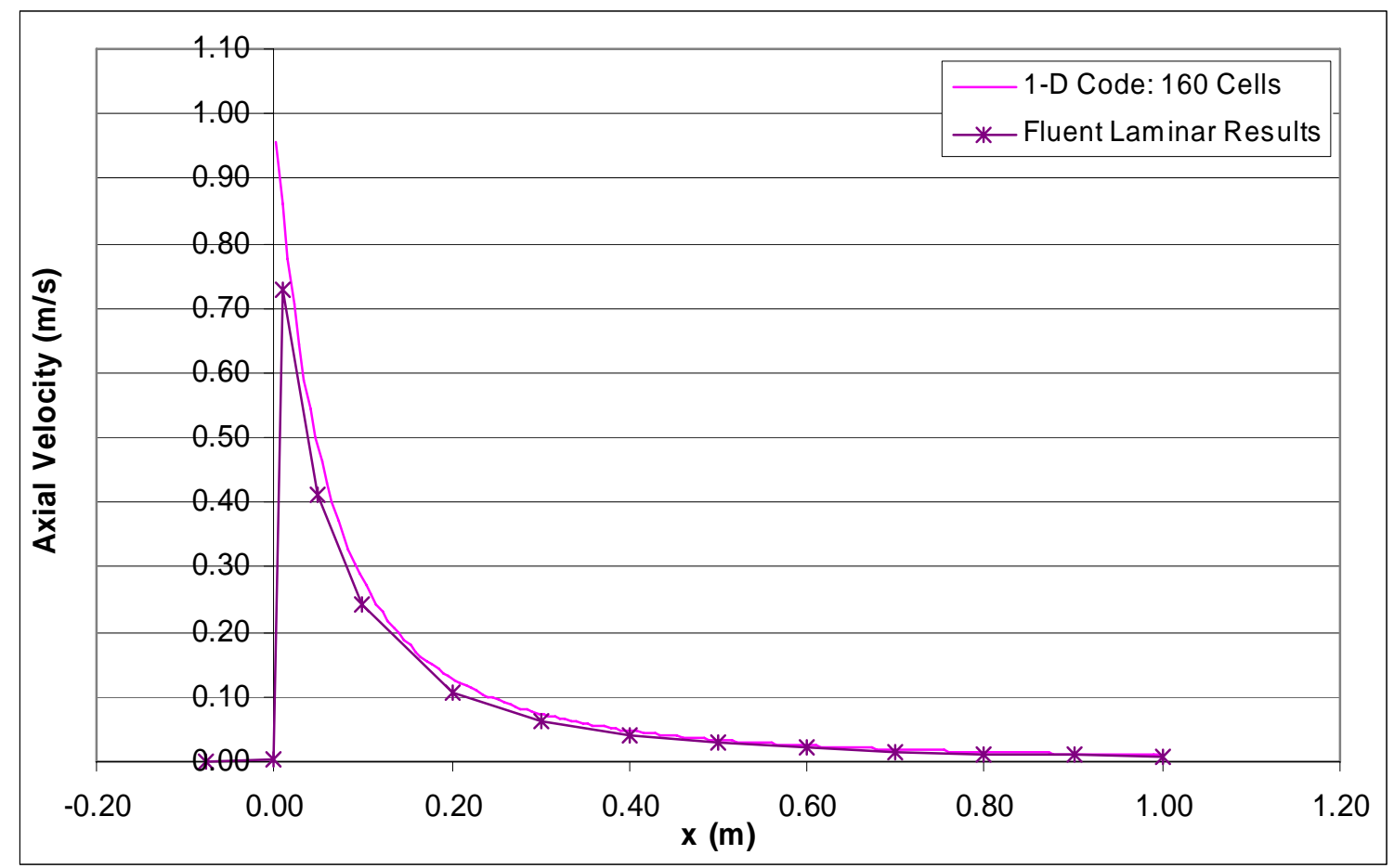

Figure 4-9 Steady-state, isothermal flow $(T=287 \mathrm{~K})$ average axial velocity vs. $x$ for laminar Fluent run and 1-D model with fully-developed pipe flow friction factor with diffuser and contraction minor losses $\left(K_{0}=0.9, \alpha=6.0\right)$.

Since it was unclear whether the diffuser flow described was laminar or turbulent, a second test run was performed in Fluent using the K- $\varepsilon$ turbulence model. The results from this run predicted no flow separation in the diffuser, presumably due to better mixing, and a smaller vena-contracta in the entrance region of the diffuser. Once again a friction factor for the 1-D code was matched with the friction factor obtained from Fluent as shown in Figure 4-10, and appropriate contraction loss coefficients were determined as $\mathrm{K}_{\mathrm{o}}=0.7$ and $\alpha=10.0$. The steady-state pressure and axial velocity results from the 1-D code and Fluent are shown in Figures 4-11 and 4-12 for the matching $C_{f}$ values. Since there was no flow separation predicted by Fluent for the turbulent case, there was no need to include a diffuser minor loss term while approximating the friction factor with the fully-developed straight pipe factor. The steady-state pressure and axial velocity results using this fully-developed $\mathrm{C}_{\mathrm{f}}$ (as described in the FORTRAN code Methodology section) along with a contraction loss are shown in Figures 4-13 and 4-14, and are also in fairly good agreement with the Fluent results. 
It should be noted that all of the results presented in this section from the onedimensional model used 160 cells $(\Delta x=0.00625 \mathrm{~m})$. Also of note are the execution times of the one-D code and Fluent. With the 160 cells used, the one-D code took approximately 10 minutes to run for the cases shown in this section. On the other hand, the Fluent runs for the diffuser cases took between about 40 minutes to around two hours,

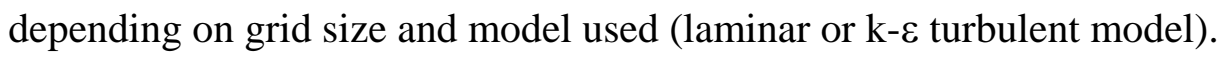

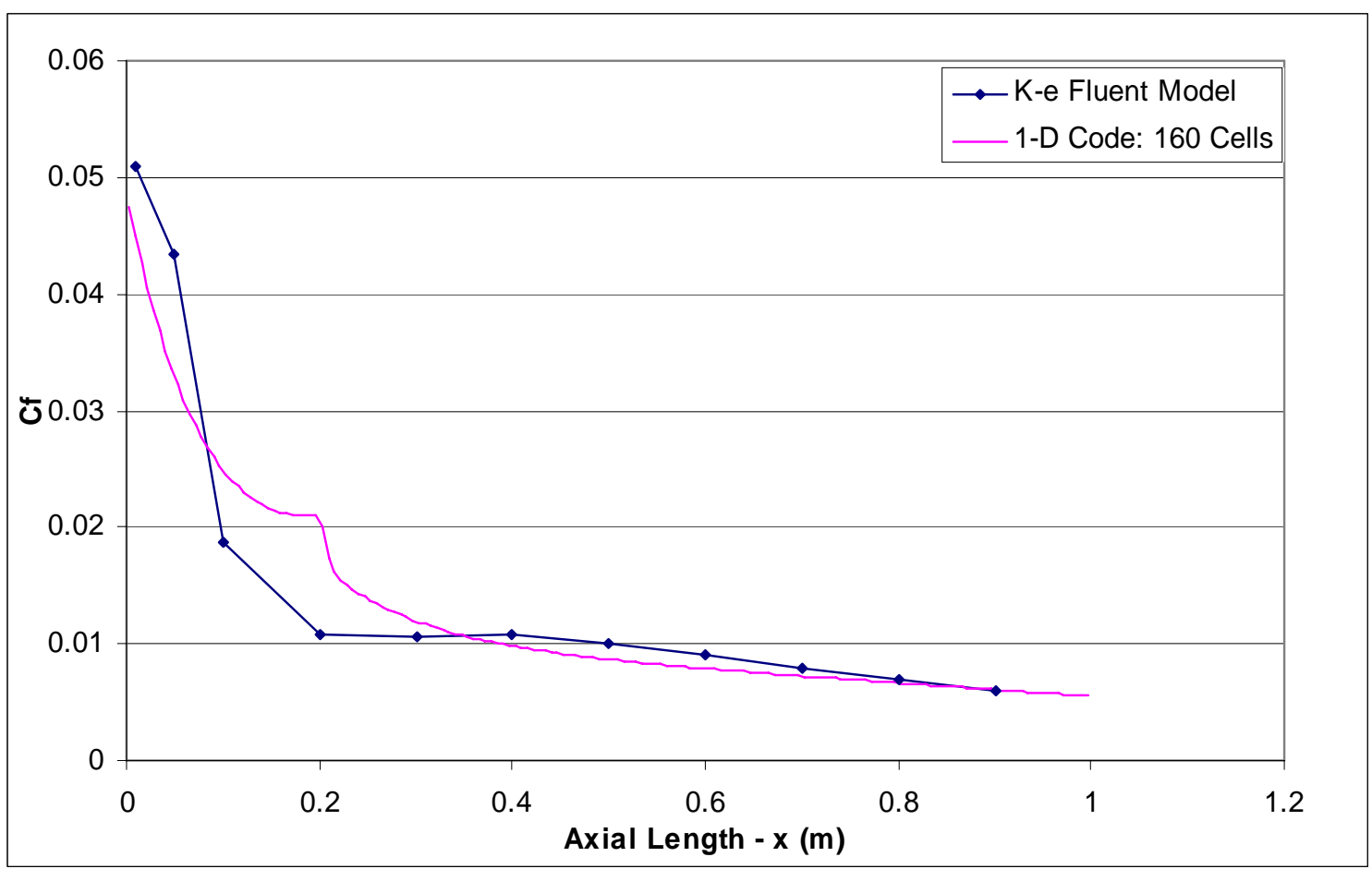

Figure 4-10 Steady-state matched $C_{f}$ for1-D code with turbulent k- $\varepsilon$ Fluent $C_{f}$. 


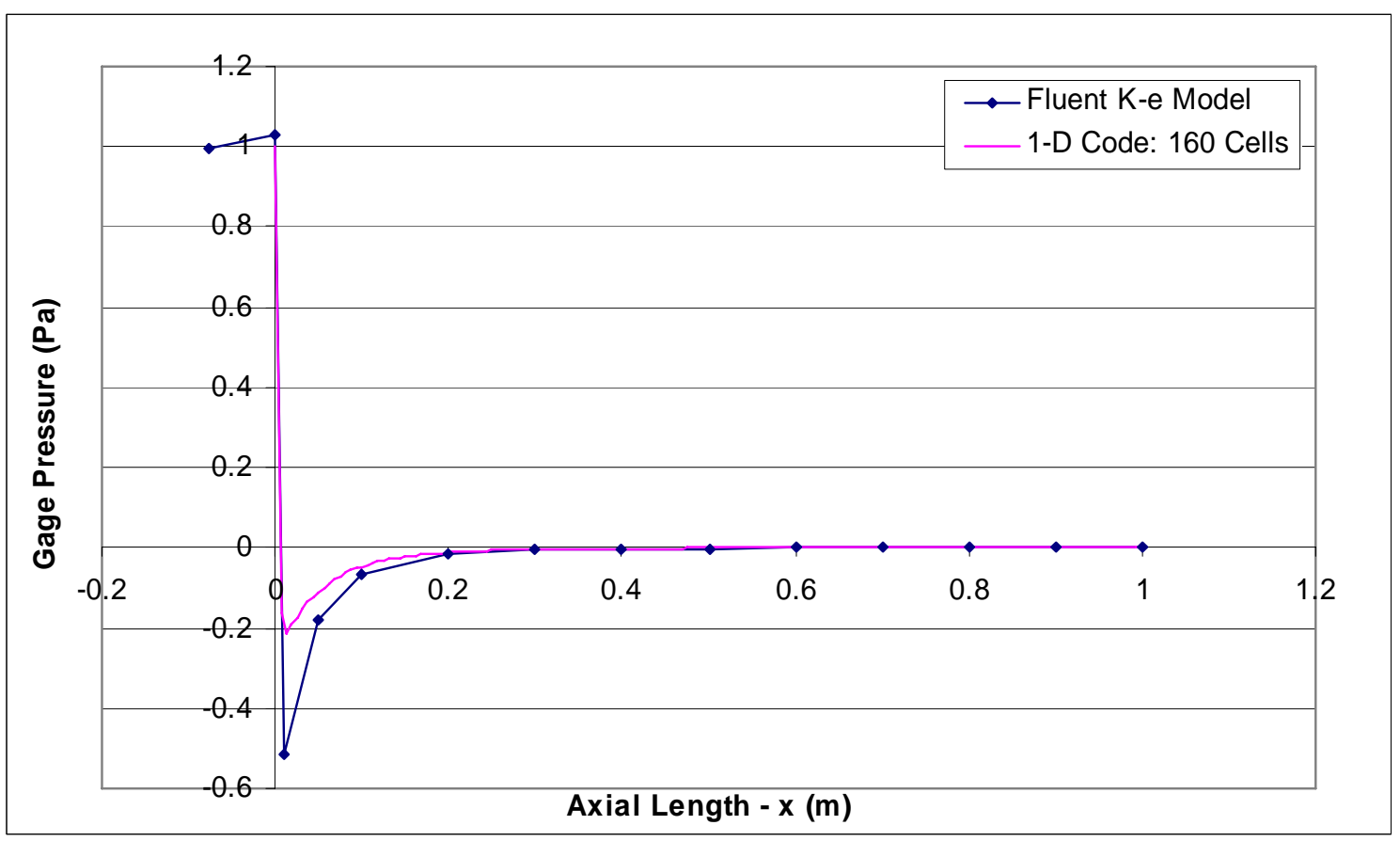

Figure 4-11 Steady-state, isothermal flow $(T=287 \mathrm{~K})$ gage pressure vs. $\mathrm{x}$ for turbulent $\mathrm{K}-\varepsilon$ Fluent results and 1-D code with matched turbulent $C_{f}$ and minor contraction loss $\left(K_{0}=0.7, \alpha=10.0\right)$.

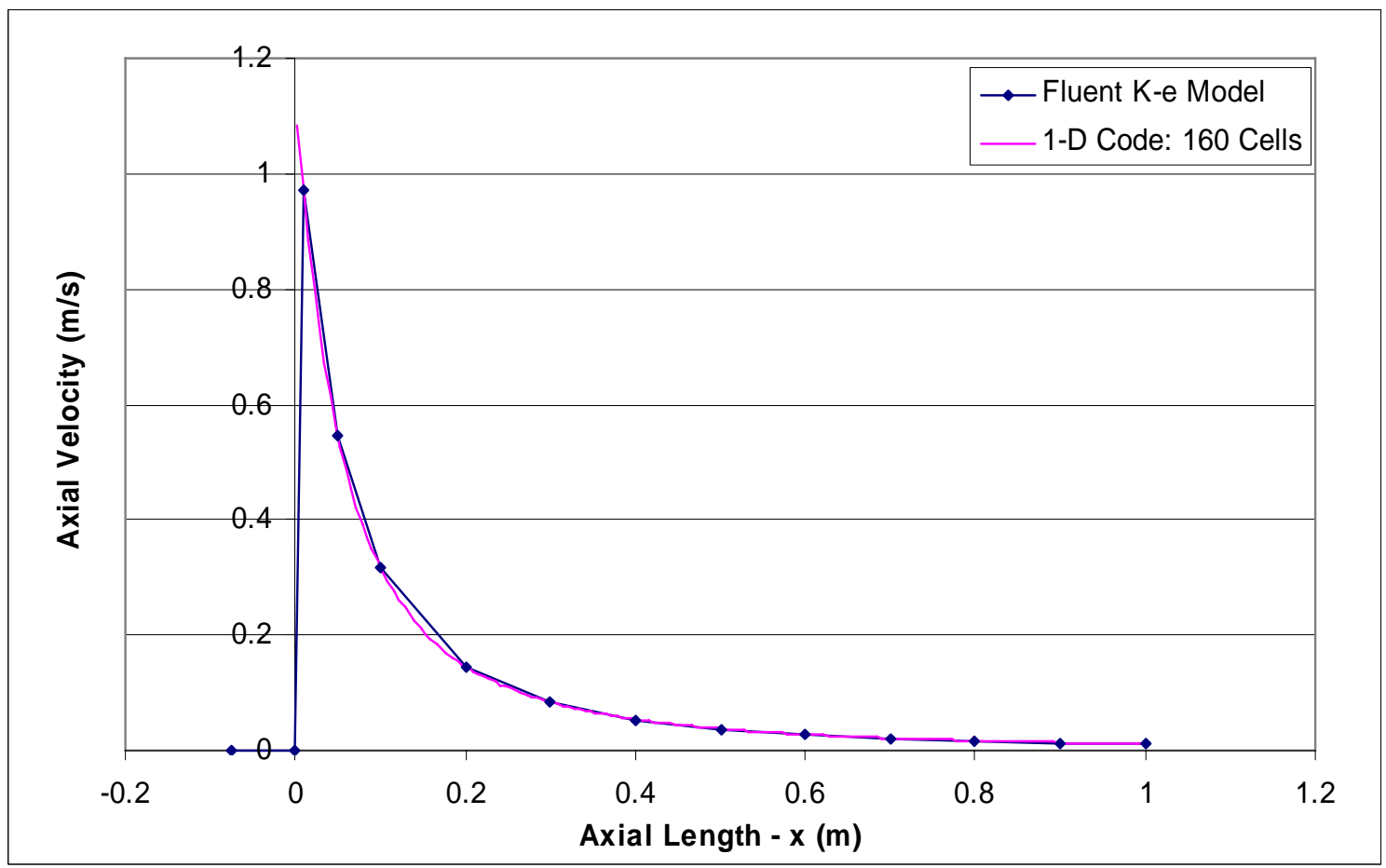

Figure 4-12 Steady-state, isothermal flow $(T=287 \mathrm{~K})$ axial velocity vs. $\mathrm{x}$ for turbulent $\mathrm{K}-\varepsilon$ Fluent results and 1-D code with matched turbulent $C_{f}$ and minor contraction loss $\left(K_{0}=0.7, \alpha=10.0\right)$ 


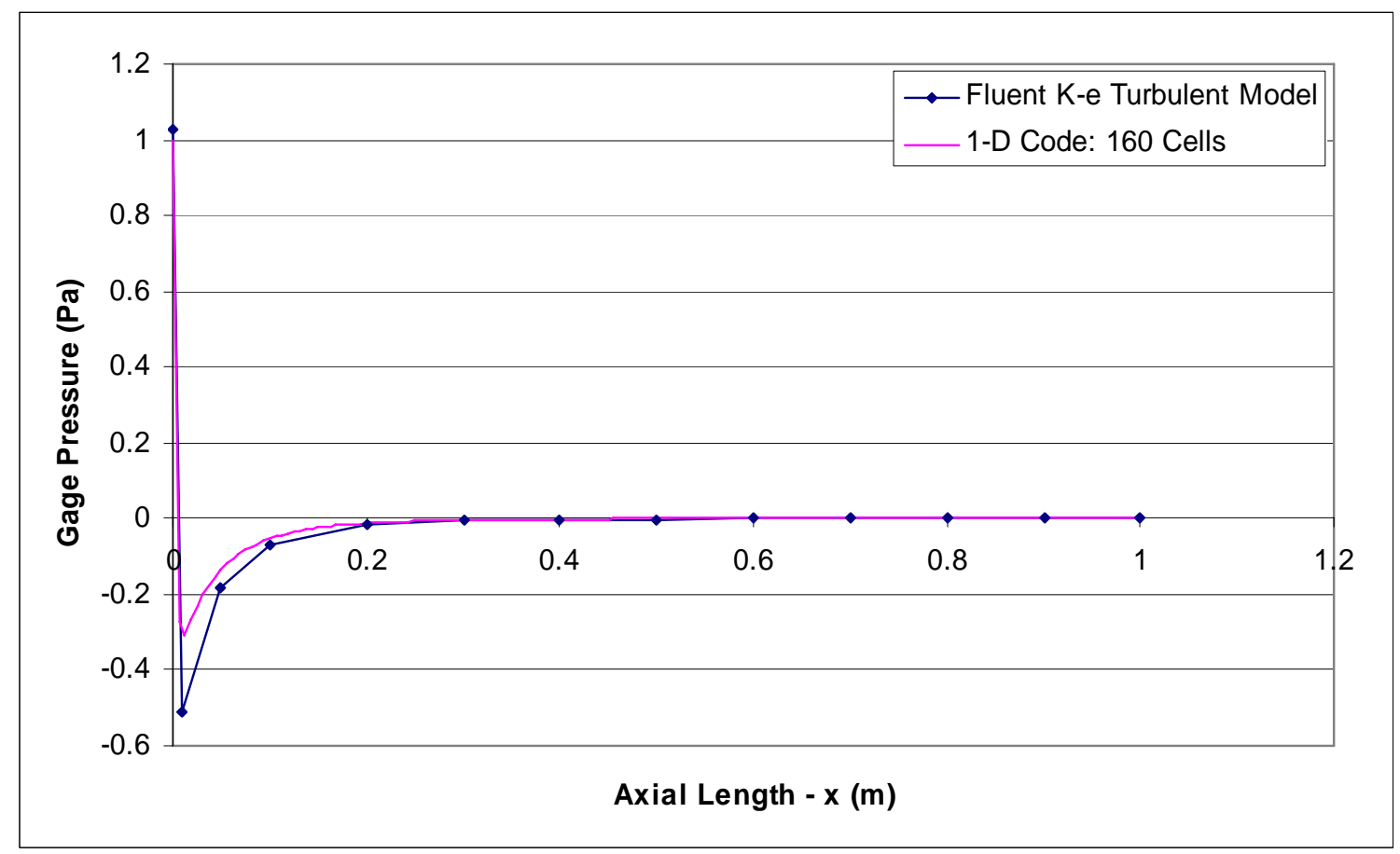

Figure 4-13 Steady-state, isothermal flow $(T=287 \mathrm{~K})$ gage pressure vs. $x$ for Fluent $K-\varepsilon$ model and 1$D$ model with fully-developed pipe flow friction factor with contraction minor $\operatorname{loss}\left(K_{0}=0.7, \alpha=\right.$ 10.0).

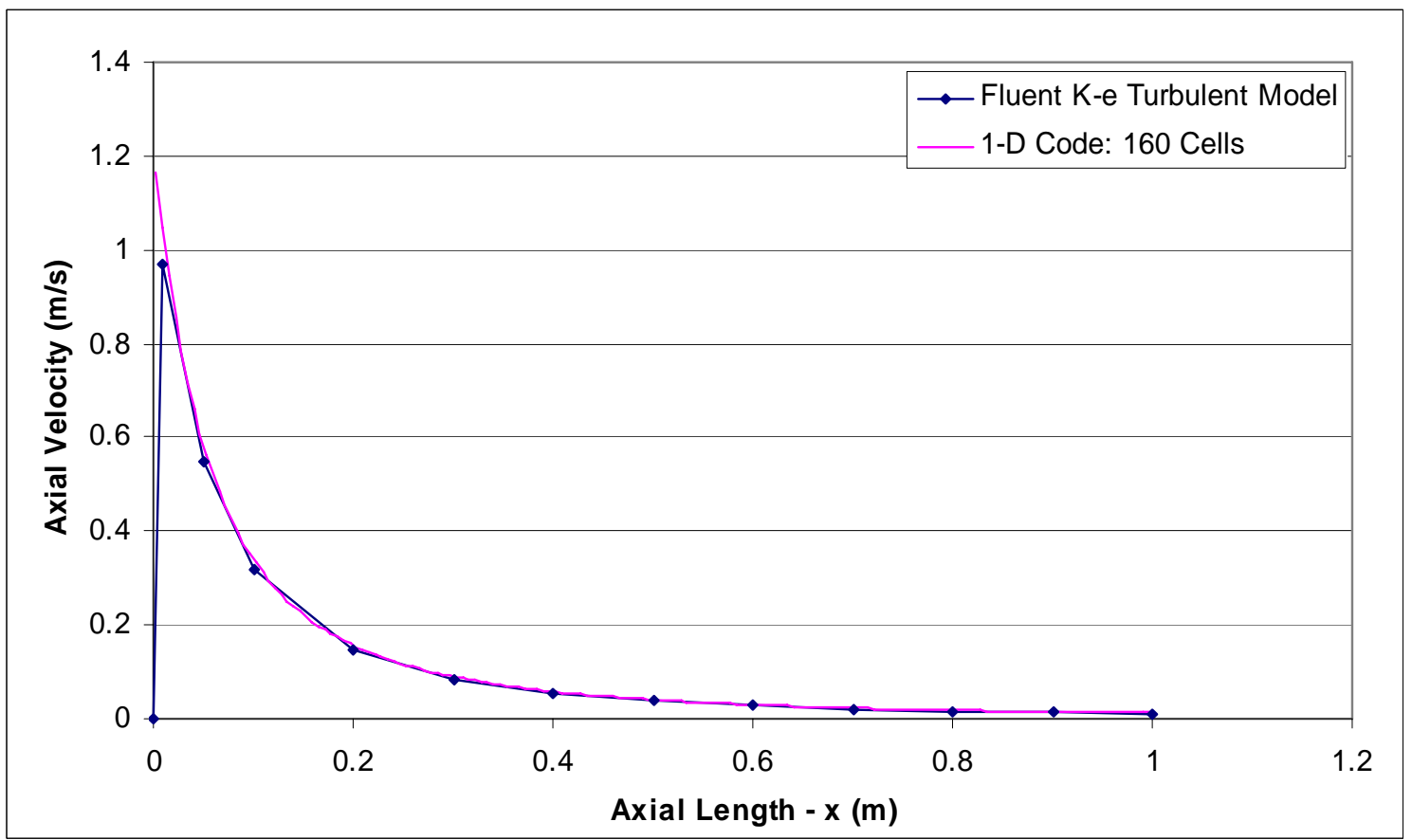

Figure 4-14 Steady-state, isothermal flow $(T=287 \mathrm{~K})$ axial velocity vs. $x$ for Fluent $K-\varepsilon$ model and 1$\mathrm{D}$ model with fully-developed pipe flow friction factor with contraction minor loss $\left(\mathrm{K}_{\mathbf{0}}=0.7, \alpha=\right.$ 10.0). 


\subsection{Temperature Distribution in a Straight Pipe with the Simulink Duct Model}

As a test case to verify the thermal behavior of the Simulink model, a simple case was run of a single circular pipe of $1 \mathrm{~m}$ length with a diameter of $0.0254 \mathrm{~m}$ and a constant wall heat flux of $100 \mathrm{~W} / \mathrm{m}^{2}$. A grid spacing of $\Delta \mathrm{x}=0.1 \mathrm{~m}$ was used for the duct, and the specified pressure at the west and east boundaries of the duct were $101326 \mathrm{~Pa}$ and $101325 \mathrm{~Pa}$, while the specified inlet temperature at the west boundary was $280 \mathrm{~K}$. Bejan [29] gives the solution to such a problem based on several assumptions. To summarize these assumptions, Bejan [29] basically assumes that all terms in the thermal energy equation are negligible except for the convective transport term and the wall heat flux term (radial conduction term). In such a case Bejan [29] gives the steady-state solution for the mean temperature axial profile through the duct as

$T_{m}(x)=\left(\frac{2}{r} \frac{q^{\prime \prime}}{\rho C_{p} U}\right) x+\left.T_{m}\right|_{x=0}$

where $\mathrm{T}_{\mathrm{m}}=$ mean temperature of the flow in the pipe

$$
\begin{aligned}
& q^{\prime \prime}=q^{*} /\left(\pi D_{h}\right)=\text { wall heat flux } \\
& \mathrm{r}=\text { radius of the pipe } \\
& \mathrm{U}=\text { average velocity of the flow over the length of the pipe }
\end{aligned}
$$

The solution to (4-1) was calculated based on the average values of density and velocity and plotted against the Simulink duct model steady-state solution determined using the ODE23t stiff solver in Figure 4-15. This figure shows that the two calculations match identically. As an additional check of the Simulink model, scope and display blocks were placed in one of the thermal energy model blocks to check the values of the terms neglected by Bejan [29] in the thermal energy equation (3-16) (e.g. axial pressure term, axial heat conduction term, etc.). It was found in the steady-state region that even the largest value of the neglected terms in the thermal energy equation was over four orders of magnitude less than the convection and wall heating terms. 


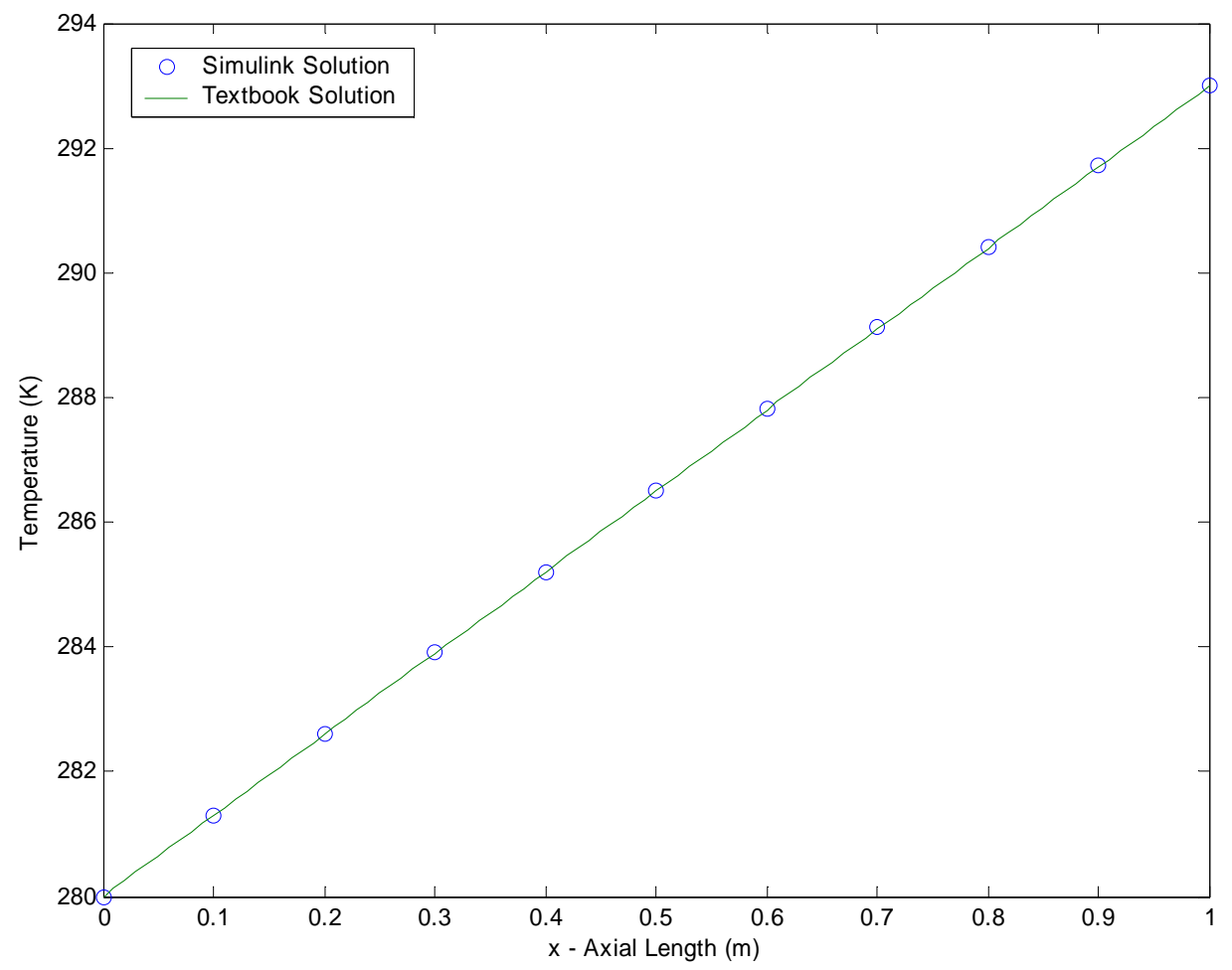

Figure 4-15 Comparison of Simulink duct model solution with that given by Bejan [29] for a steadystate flow through a circular duct with fully-developed flow, fully-developed temperature profile, and constant wall heat flux. Wall heat flux specified as $100 \mathrm{~W} / \mathrm{m} 2$, length of pipe as $1 \mathrm{~m}$, diameter of duct as 1 in., and air as the working fluid.

\subsection{Flow Loss of Elbow vs. Tee Components with One Tee Port Closed}

In order to test the flow loss behavior of the tee and elbow components, a simple system was set up with two straight pipes of length $1 \mathrm{~m}$ and diameter of $0.0254 \mathrm{~m}$. The pressure at the west and east boundaries of the system were specified to be $101327 \mathrm{~Pa}$ and $101325 \mathrm{~Pa}$ respectively, and the isothermal flow was taken to be at $287 \mathrm{~K}$. One port of the tee was blocked off (mass flow rate set equal to zero) in order to simulate the case of a closed valve just past this tee port. The two open ports of the tee were connected to the two pipes and constituted a branch flow scenario. This basic setup is illustrated in Figure 4-16. Note that the grid spacing used for both pipes was $\Delta \mathrm{x}=0.1 \mathrm{~m}$. 


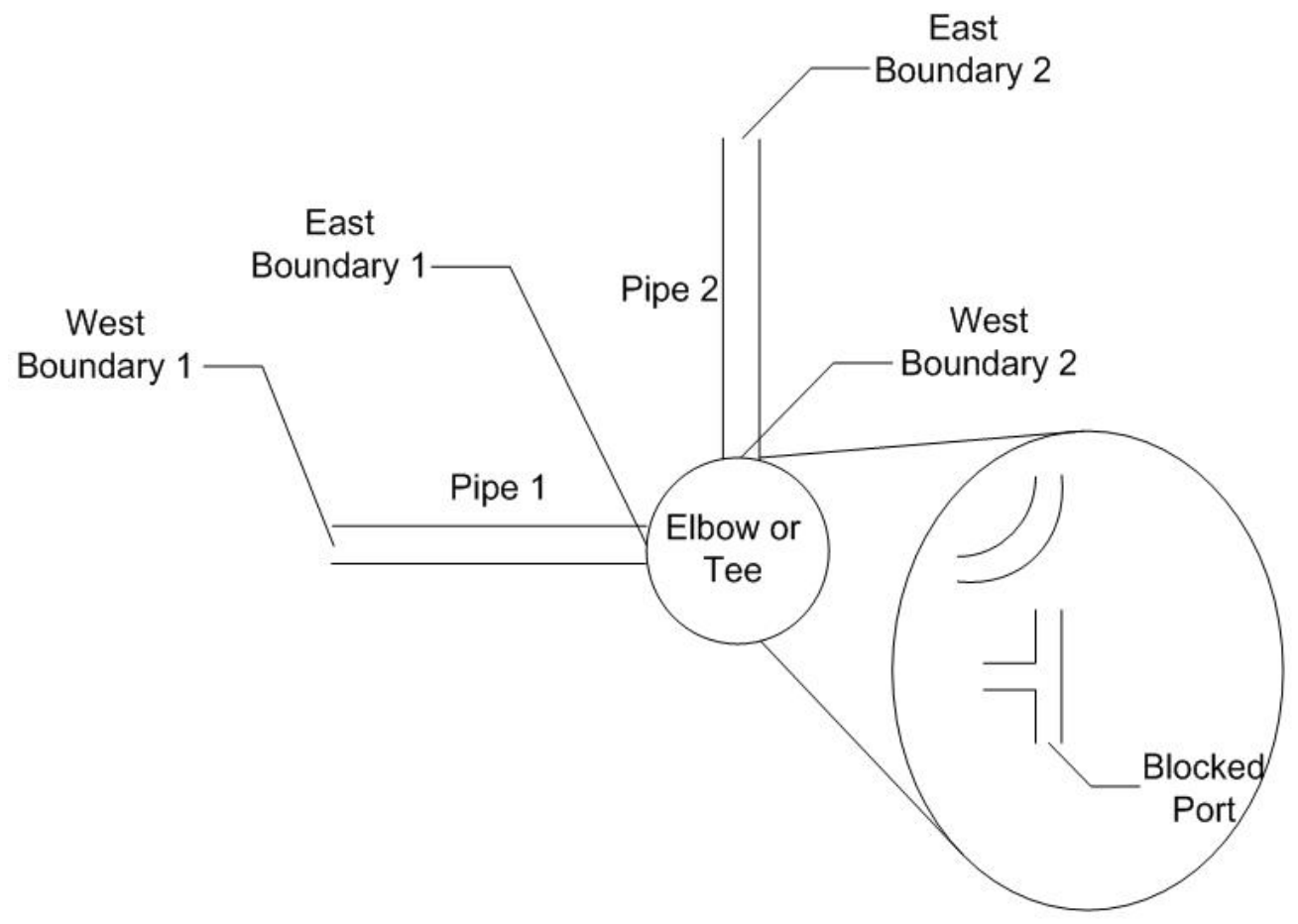

Figure 4-16 Setup simple system to test tee and elbow flow loss coefficients.

In steady-state the simulated mass flow rate through the tee was found to be $2.933 \times 10^{-4} \mathrm{~kg} / \mathrm{s}$ which was approximately $65 \%$ less than the simulated $4.515 \times 10^{-4} \mathrm{~kg} / \mathrm{s}$ mass flow rate through the elbow. This result was expected because the elbow simulated has a smooth bend with well-defined wall boundaries, while a tee with one port blocked and branch flow most likely has flow separation, etc. due to the "dead” region caused by the blocked third branch. If the elbow were not a smooth bend, the losses through the elbow would most likely be greater, thereby decreasing the mass flow rate through it. Additionally as expected in steady-state, the mass flow rates at the west and east boundaries of both pipes (as well as everywhere else in the system) were the same for both the elbow and the tee, as shown in Table 4-1. 
Table 4-1 Mass flow rates of tee and elbow two-pipe system at the west and east boundaries of pipes.

\begin{tabular}{cccc}
\hline & & $\begin{array}{c}\text { Elbow Simulated } \\
\text { Mass Flow Rate } \\
(\mathrm{kg} / \mathrm{s})\end{array}$ & $\begin{array}{c}\text { Tee Simulated } \\
\text { Mass Flow Rate } \\
(\mathrm{kg} / \mathrm{s})\end{array}$ \\
\hline \hline \multirow{2}{*}{ Pipe 1 } & West Boundary & $4.5153 \mathrm{E}-04$ & $2.9331 \mathrm{E}-04$ \\
& East Boundary & $4.5153 \mathrm{E}-04$ & $2.9331 \mathrm{E}-04$ \\
\hline \multirow{2}{*}{ Pipe 2} & West Boundary & $4.5153 \mathrm{E}-04$ & $2.9331 \mathrm{E}-04$ \\
& East Boundary & $4.5153 \mathrm{E}-04$ & $2.9331 \mathrm{E}-04$ \\
\hline
\end{tabular}

\subsection{Isothermal Behavior of Simple Flow Systems with Simulink Models}

In order to compare and contrast the flow behavior of the tee and plenum models, a simple system was created and simulated in Simulink. As illustrated in Figure 4-17, this simple model consisted of three pipes connected to either a tee or plenum. The lengths of all three pipes were $1 \mathrm{~m}$ with diameters of $0.0254 \mathrm{~m}$. When the plenum was used, its volume was taken to be $1 \mathrm{~m}^{3}$. A grid spacing of $\Delta \mathrm{x}=0.1 \mathrm{~m}$ was used for all three pipes.

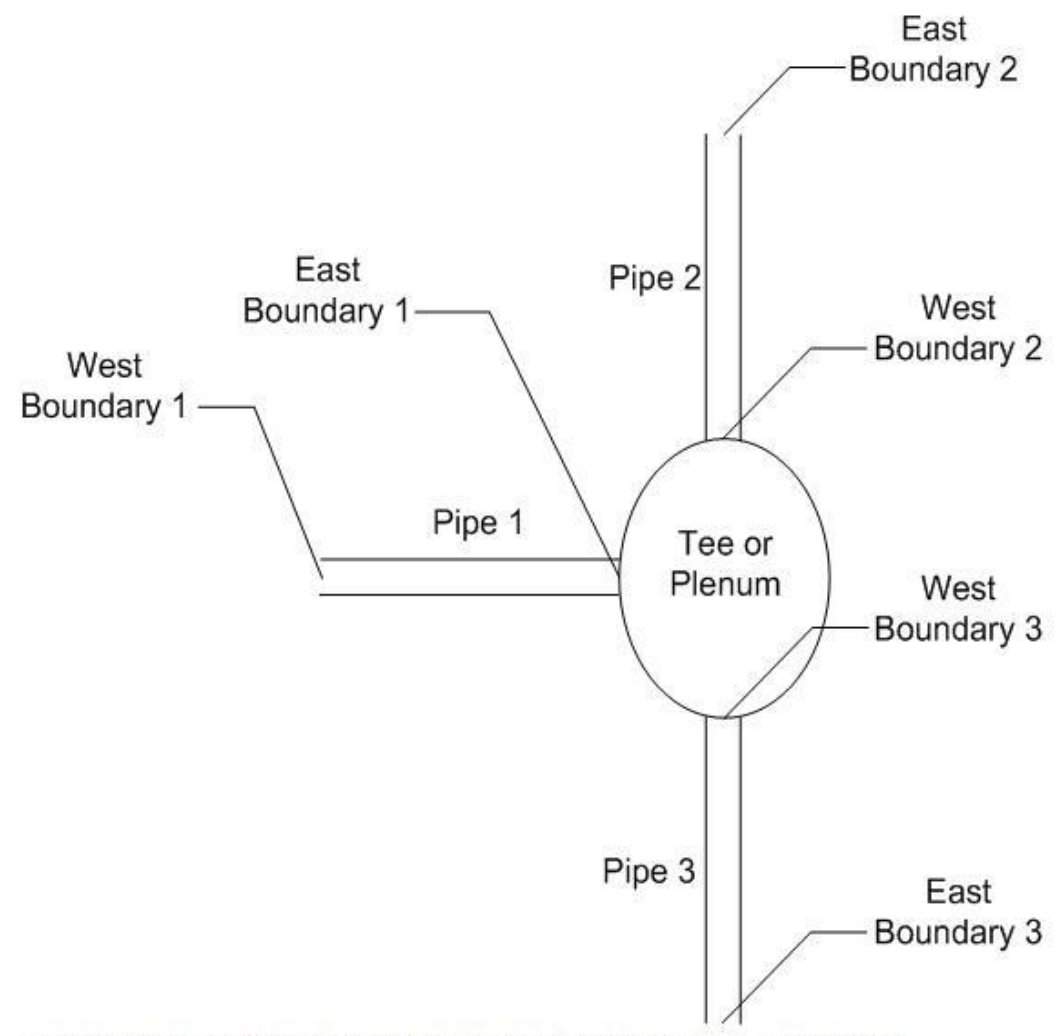

Figure 4-17 Diagram of the simple tee or plenum three pipe system modeled. 
The pressures at the west boundary 1, east boundary 2, and east boundary 3 were specified as given in Figure 4-18. It should be noted that although this figure gives the plot of the gage pressure, the corresponding absolute pressure was actually specified in order to be consistent with the model requirements. The temperature in the system was specified to be $287 \mathrm{~K}$, and the appropriate properties (thermal conductivity, viscosity, and specific heat) were taken at this value for air as the gas in the system. Because there was initially no pressure gradient across the system, the mass flow initial condition was taken everywhere to be zero. These initial and boundary conditions were the same when both the tee and plenum were used.

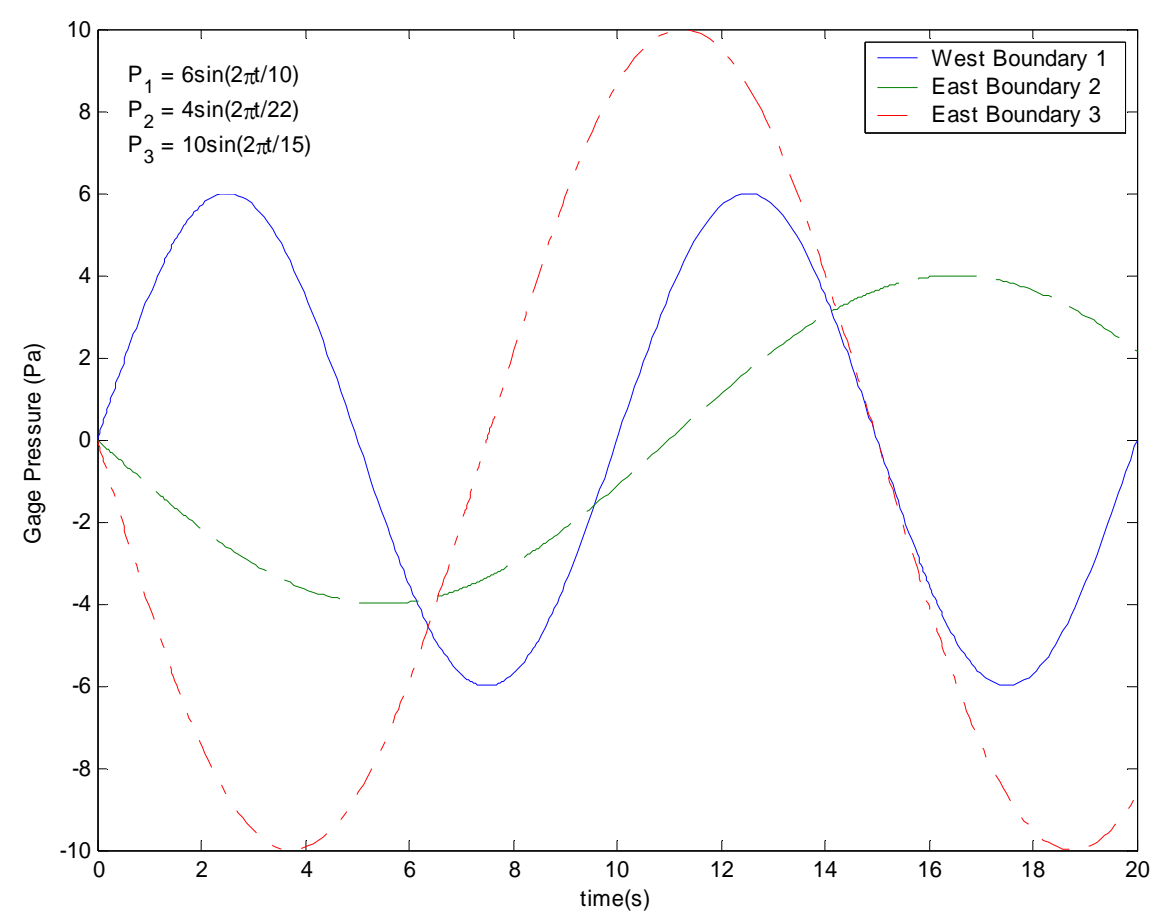

Figure 4-18 Gage pressure specified at boundaries of tee and plenum three pipe systems.

Figure 4-19 shows the calculated mass flow values at the west boundary 1, east boundary 2, and east boundary 3 (at the periphery of the system). The mass flow rates are shown in this figure to oscillate in a smooth manner due to being driven by the specified boundary pressures, and the calculated oscillations are shown to be on the order of $10^{-3} \mathrm{~kg} / \mathrm{s}$. However, Figure 4-20 illustrates that the total net mass flow into the system at any given time was calculated to be on the order of $10^{-8} \mathrm{~kg} / \mathrm{s}$ meaning that the system 
was essentially incompressible. This result should be expected because (1) the system has a relatively low mass capacity, and (2) the pressure gradients across the system are on the order of only 10 Pascals. The point should be made that the mass flows shown in Figure 4-19 and later in Figure 4-21 were plotted with the assumed flow direction in all three branches to be into the tee or plenum. This was done because the point of the figures is to illustrate net mass flow through the system, which is much easier when all three positive directions are assumed into the component.

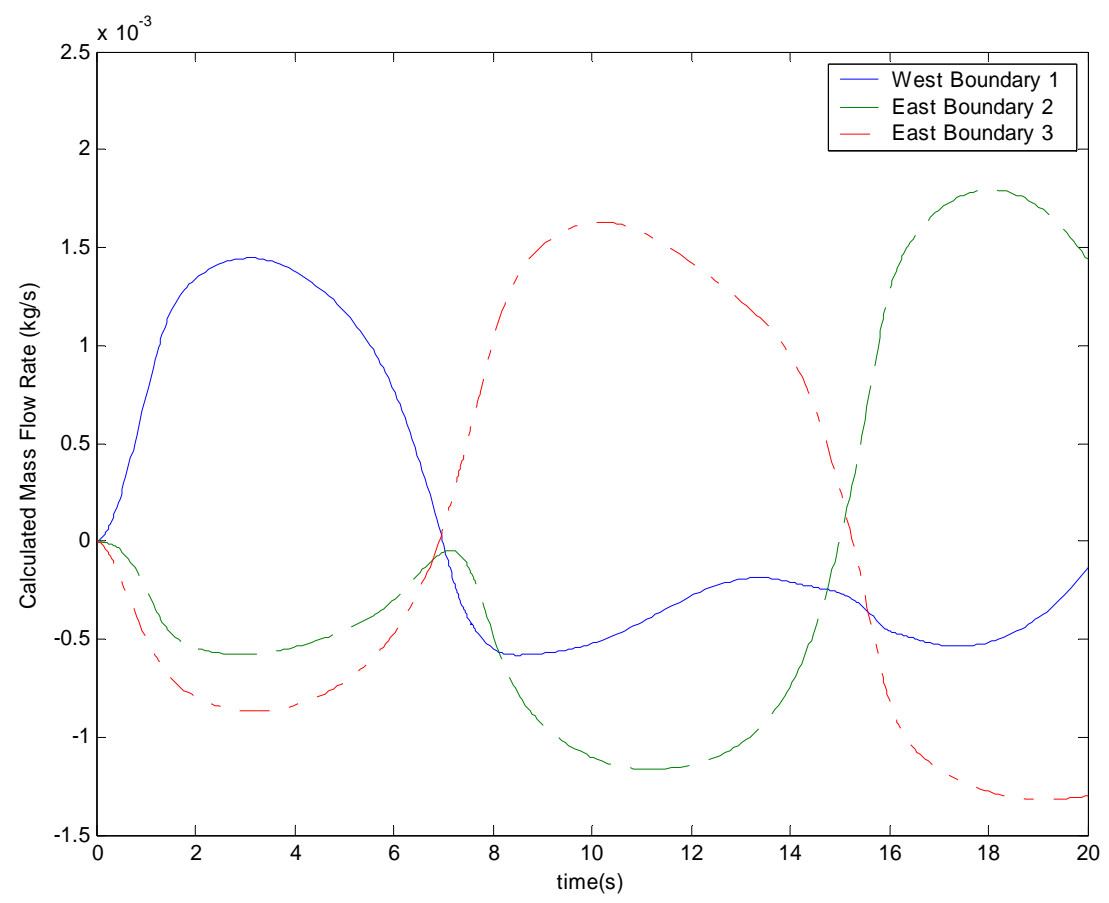

Figure 4-19 Calculated mass flow at boundaries of tee, three pipe system. For this plot, the mass flows were assumed positive into the tee. 


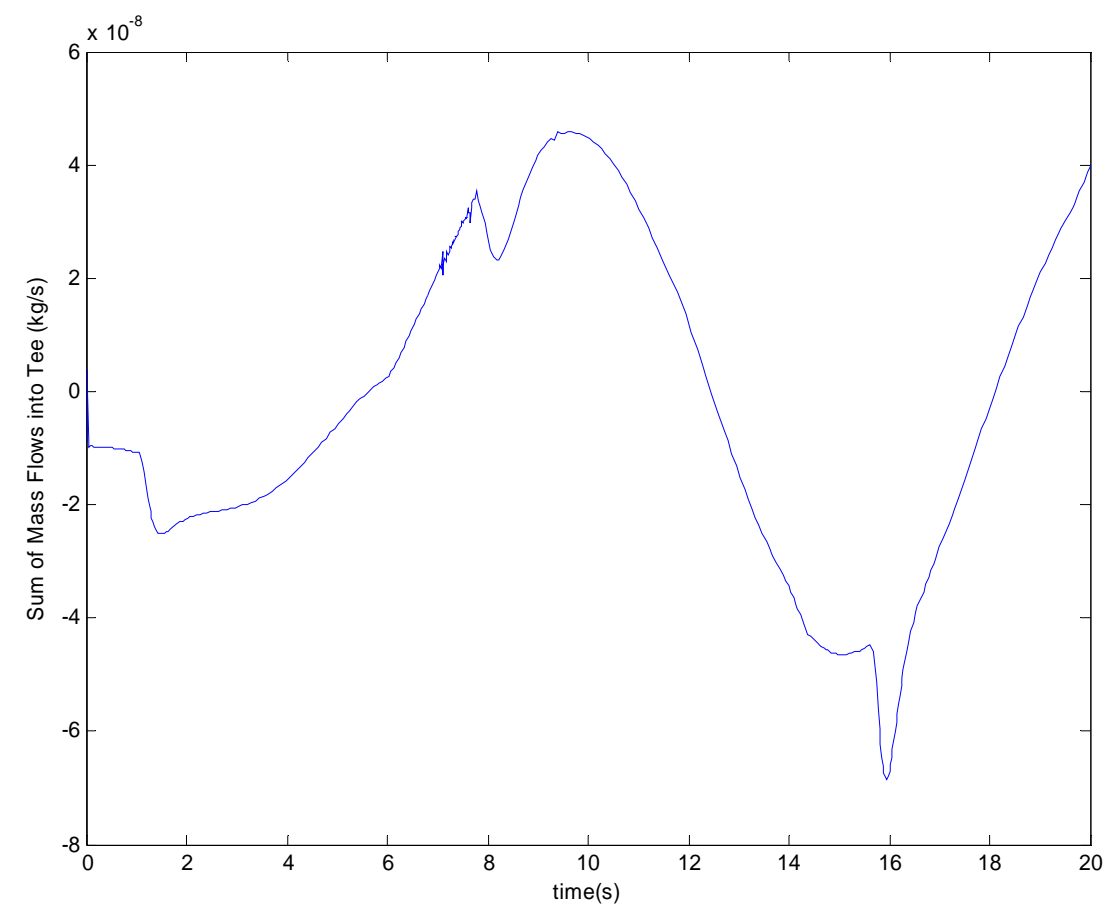

Figure 4-20 Sum of mass flows (net mass flow) into the tee system as calculated by the boundary values.

When the tee was replaced in the system by the plenum, the overall trends of the boundary mass flows remained the same as can be see by comparing Figures 4-18 and 4-21. However, the magnitude of the oscillations with the plenum were different from those with the tee, and as Figure 4-18 shows the greatest difference seemed to be in the mass flow value of the branch with the least mass flow at any given point in time. The most obvious reason for this different behavior is the added capacity of the plenum in the system. As Figure 4-22 illustrates the total net mass flow into the system at any given time was calculated to be on the order of $10^{-5} \mathrm{~kg} / \mathrm{s}$ with the plenum, meaning that the system retained much more mass than with the tee.

Figures 4-20 and 4-22 both show oscillations in the net flow into the system, which are most likely a consequence of the oscillating boundary pressures. However, since these oscillations are approximately five and two orders of magnitude smaller than the actual flow rates through the ducts in the system, these results still seem reasonable. This being the case, the oscillations in the mass flow for the plenum system shown in Figure 4-21 will most likely not die over time. All of these facts highlight the point that 
the system in question is still nearly incompressible. It should be noted that the plenum inlet (expansion) and outlet (contraction) loss coefficients were assumed to be $\mathrm{K}_{\text {expansion }}=$ 1.0 and $\mathrm{K}_{\text {contraction }}=0.4$ as suggested by White [5] for sharp-edged sudden expansions and contractions. Also of note is that all of the simulations performed for this section used the ODE23t stiff solver in Simulink.

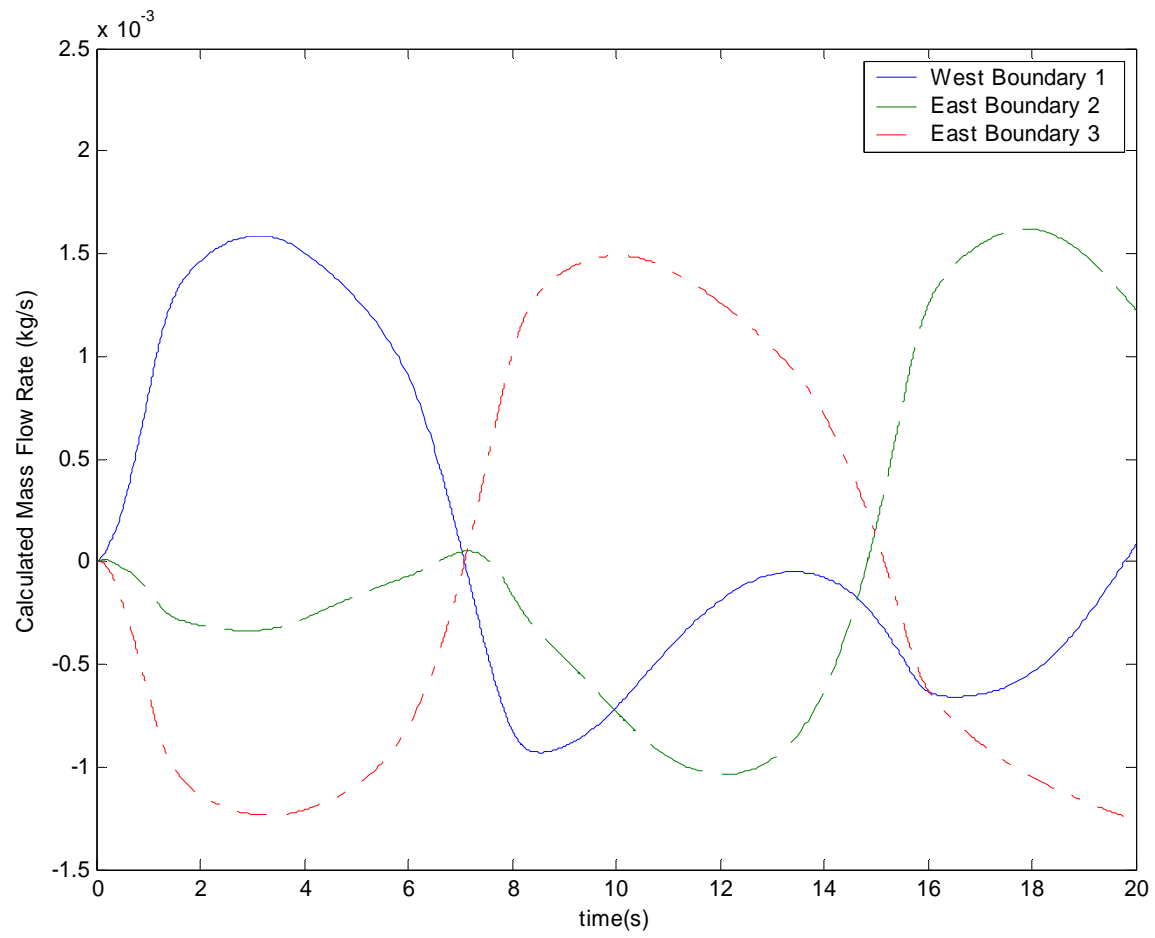

Figure 4-21 Calculated mass flow at boundaries of plenum, three pipe system. For this plot, the mass flows were assumed positive into the plenum. 


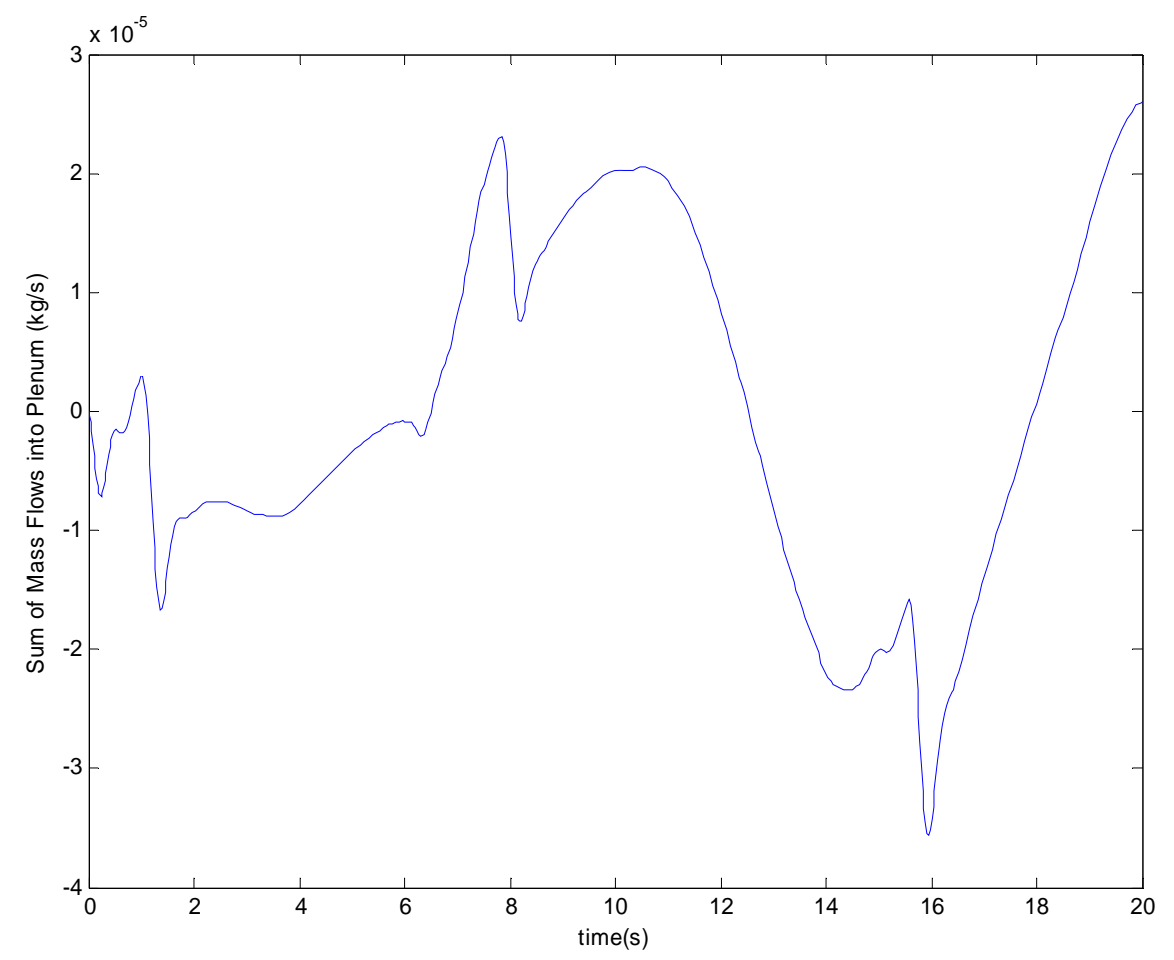

Figure 4-22 Sum of mass flows into the plenum system as calculated by the boundary values.

\subsection{Thermal Behavior of a Simple Flow System with Simulink Models}

As a final representation of the behavior of the Simulink models developed, the simple flow system given by Figure 4-17 in the last section was again utilized. In this example however, the air flow was heated by assuming a $\mathrm{q}^{*}$ value of $2 \mathrm{~W} / \mathrm{m}$ for all three pipes, and a $\dot{Q}$ heat loss value of $10 \mathrm{~W}$ from the plenum. Air was again used as the working fluid and constant values for thermal conductivity, viscosity, and specific heat were used. The same geometry and grid spacing as used in the previous section were used in this example, and the plenum volume was again taken to be $1 \mathrm{~m}^{3}$.

The specified west boundary 1, east boundary 2, and east boundary 3 pressures are shown in Figure 4-23. Since there initially was no pressure gradient across the system, the initial mass flow condition everywhere in the system was once again assumed to be zero. The initial temperature of the air in the system was assumed to be $287 \mathrm{~K}$, and the specified temperature at the west boundary 1, east boundary 2, and east boundary 3 were taken to be $287 \mathrm{~K}$ as well. However, as explained in the Methodology section for 
the duct model, the only boundaries at which the specified air temperatures are important are the ones which have inflow into the system.

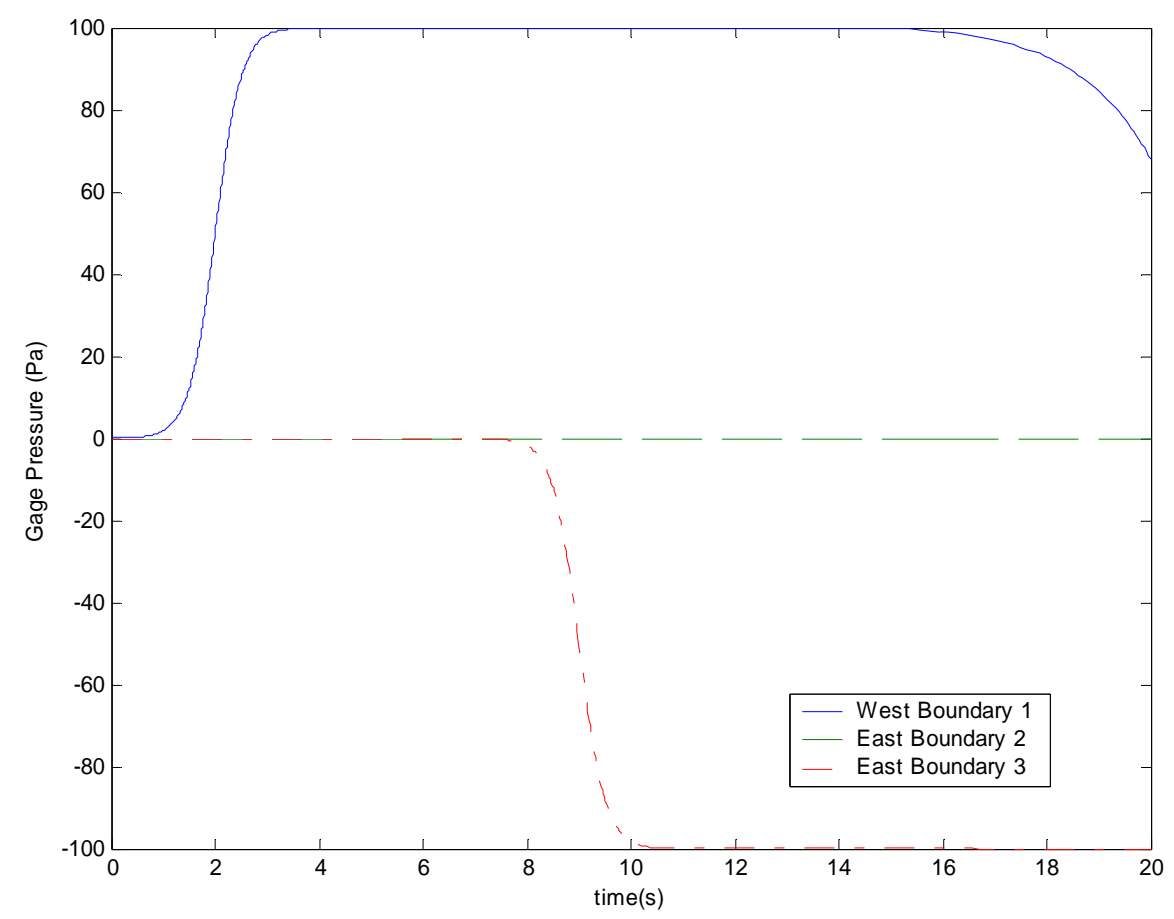

Figure 4-23 Gage pressure specified at boundaries of plenum three pipe system.

Figure 4-24 gives the calculated mass flow rates at the east boundaries of the three pipes, and Figure 4-25 shows the calculated temperatures at the same locations. As the air just began to flow the temperatures first rose to their maximum point, then fell back down. This behavior can be attributed to the fact that at lower flow rates the air has longer to remain in the pipes and absorb the heat being applied, and at higher flow rates, the air does not remain in the system as long and cannot absorb as much heat. This same behavior is evident as the flow changes again starting at about the eight second mark: as the flow rate goes up, the temperature at the east boundary goes down, and visa-versa. It should be noted that the assumed positive mass flow direction in Figure 4-24 is from west to east boundary for each pipe. Also, all of the results from the simulations in this section were generated using the ODE23t stiff solver in Simulink, and the plenum loss coeffients were again taken to be $\mathrm{K}_{\text {expansion }}=1.0$ and $\mathrm{K}_{\text {contraction }}=0.4$. 


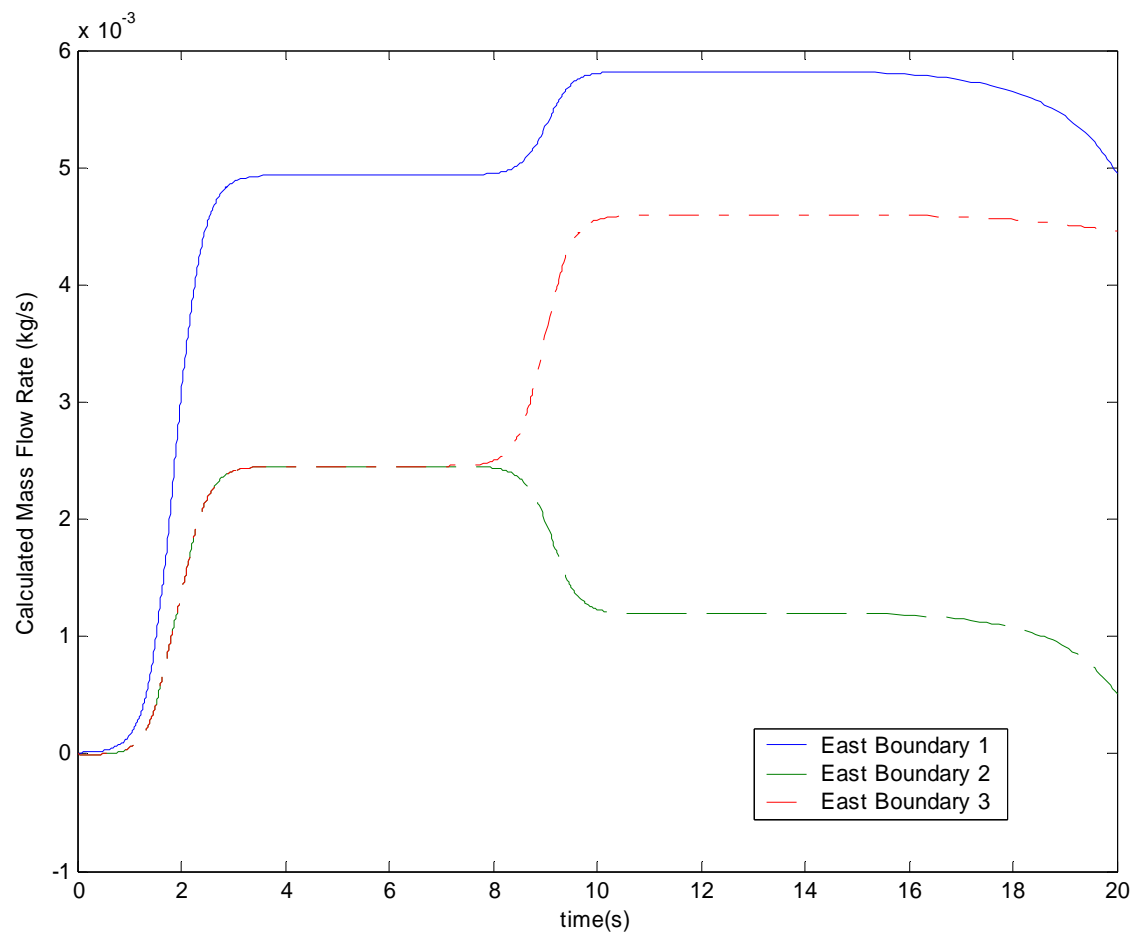

Figure 4-24 Calculated mass flow at east boundaries of the three pipes. For this plot, the mass flows were assumed positive from west to east.

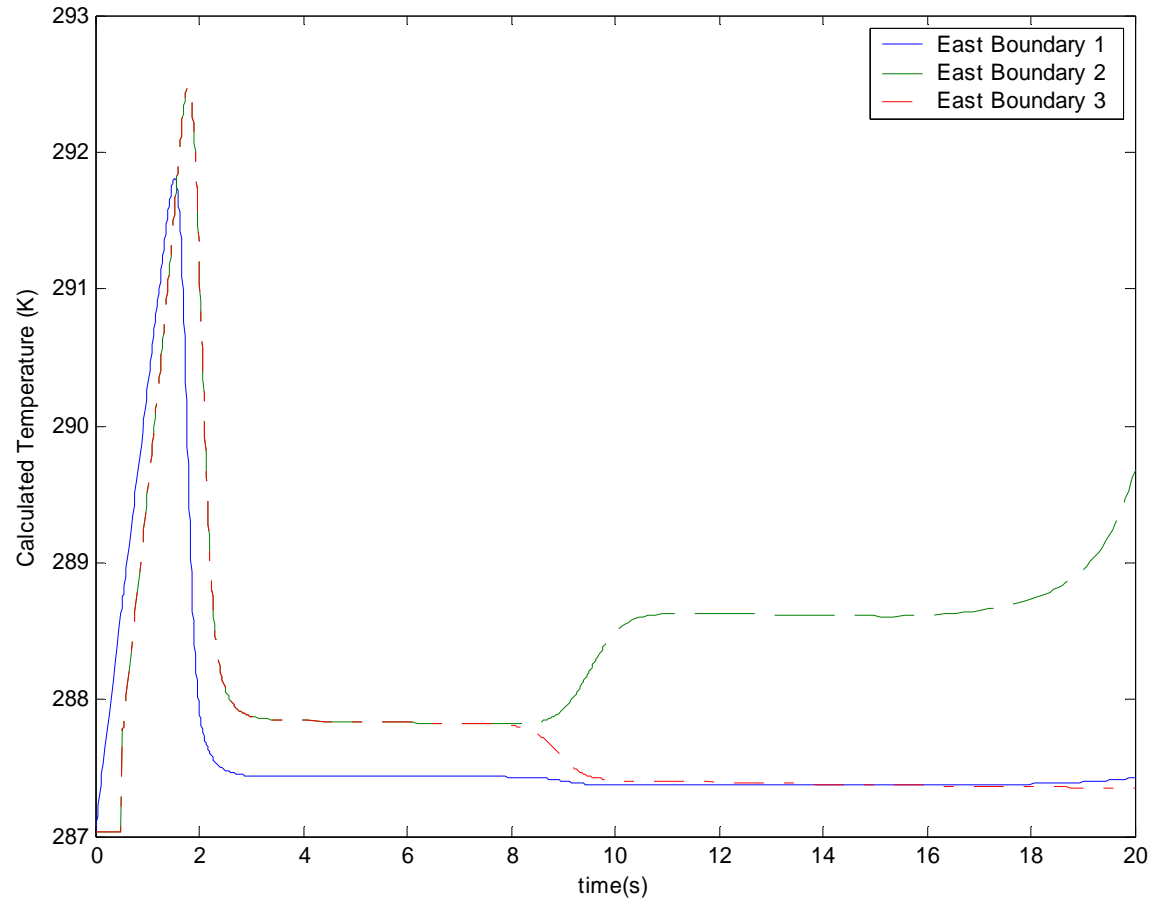

Figure 4-25 Calculated temperatures at the east boundaries of the three pipes. 


\subsection{Comparison with Experimental NETL HYPER Data using Simulink Models}

The results presented in this section are in reference to the portion of the NETL HYPER test facility described in detail in the Methodology section. In order to compare with the experimental results, proper initial conditions had to be determined. In approximately the first minute of data, the system appeared to be at a steady-state condition where the mass flow rate and east and west temperatures and pressures were roughly constant. Therefore, the initial pressure in the system was assumed to drop in a linear fashion between the west and east pressure at the first data point. Likewise, the temperature of the piping/insulation was assumed to drop in a linear fashion between the west and east boundaries. Because the equipment was well insulated and because it was all at steady-state, the lumped temperature of the piping was assumed to be the same as the gas temperature. Proper precautions were taken for the tee, plenum, and elbow in the system. Initial pressure values were assigned based on the minor losses and the linear pressure drop assumed through the piping. Initial temperature drops across the components were determined based on the assumed linear temperature drop between the west and east boundaries of the system and the length of the component. The initial mass flow through all of the components in the system was assumed to be the initial value given by the experimental data.

The boundary conditions for pressure at the west and east faces of the system were taken directly from the experimental data. Values needed between data points were interpolated by Simulink. The temperature at the west boundary face was likewise taken directly from the experimental data. The plots of these pressure and temperature data are given in Figures 4-26 and 4-27. 


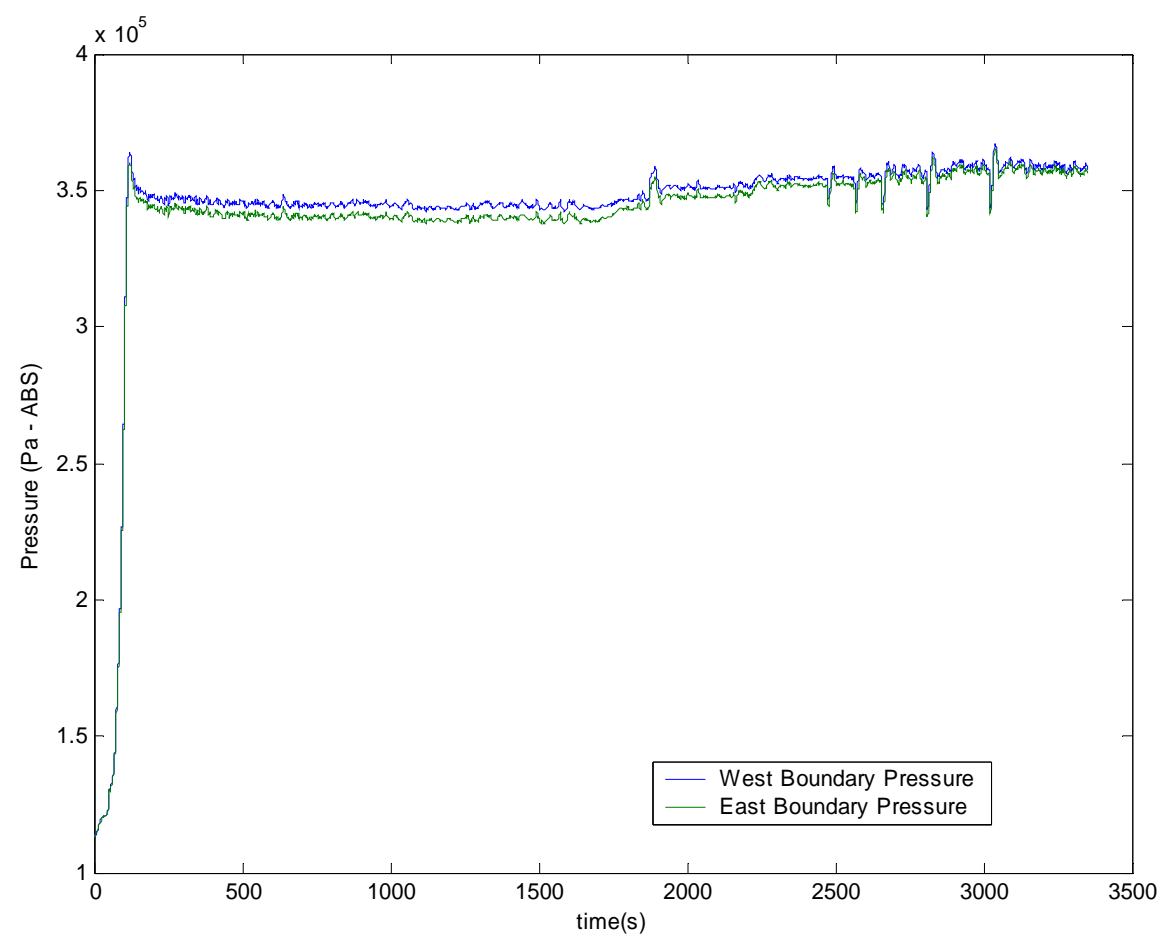

Figure 4-26 East and west face pressure boundary conditions taken from the NETL HYPER experimental data.

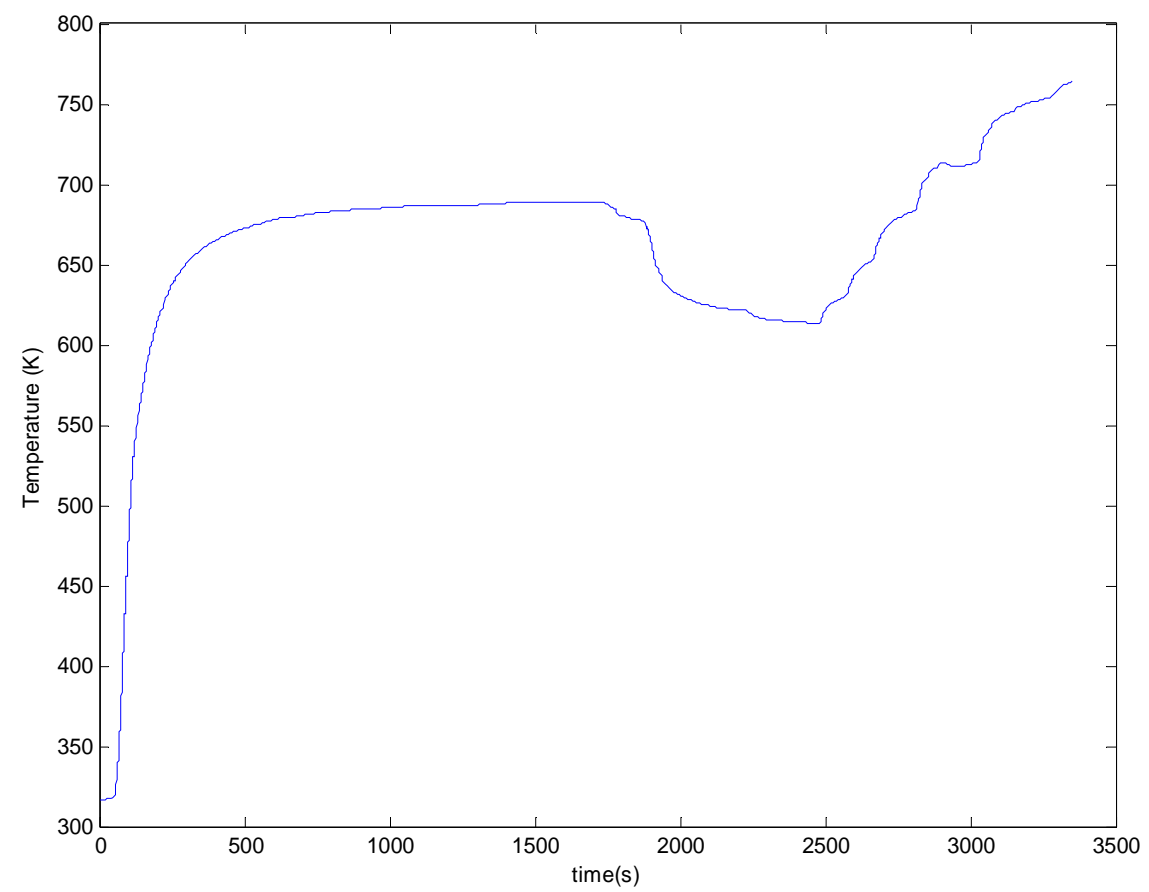

Figure 4-27 West face temperature boundary condition taken from the NETL HYPER experimental data. 
The values for the minor loss coefficients for the tee and elbow components were computed just as they were explained by the two sections for these parts, i.e. the calibrated $\mathrm{K}$ values were used for the tee and equation (3-50) was used for the elbow. The expansion and contraction loss coefficients in the plenum had to be set to reflect the actual geometry of the entrance and exit. As mentioned previously the plenum had an elliptical face where the flow entered. Additionally, the pipe for the exit flow of the plenum was connected to the side of the cylindrical section. Both of these factors cause a "smoothing" effect to the entrance and exit regions. The entrance and exit were also quite possibly rounded to reduce flow losses caused by sharp edge contractions and expansions. Therefore, by consulting White [3], appropriate loss coefficients for the entrance (expansion) and exit (contraction) to be used in conjunction with equation (3-42) were determined to be $\mathrm{K}_{\text {expansion }}=0.95$ and $\mathrm{K}_{\text {contraction }}=0.3$. The ODE23t stiff solver was once again used in Simulink for the simulation.

Figures 4-28, 4-29, and 4-30 show the mass flow rate, plenum pressure, and east boundary temperature from the experimental data as compared with the Simulink model as described in the Methodology section. These three figures show that the simulation did a very good job in predicting the transient trends in the data for all three parameters. This is evident as even most of the minor fluctuations in the data were captured by the simulation. It should be noted that these minor fluctuations were able to be captured because the specified boundary conditions (west boundary pressure, east boundary pressure, and west boundary temperature) were taken directly from the experimental data.

Figure 4-28 shows that the simulated mass flow rate was lower than the measured mass flow rate over the entire simulation period. The maximum error in the mass flow calculation was approximately $22 \%$ of the total range recorded. One reason for this difference in simulated and experimental mass flow rates is the fact that the system was modeled with dry atmospheric air, while the actual system air certainly contained water vapor. Another possible reason for the discrepancy in mass flow rate is the values used for the minor losses in the tee and plenum. As mentioned in the Methodology section, even the values for tee loss coefficients given by White [5] and Munson, et. al. [7] are ball-park values, with error in the approximate range of $+/-50 \%$ (White [5]). The loss coefficients are very geometry dependent, and vary from manufacturer to manufacturer. 
The calibrated loss coefficients for the tee given in Table 3-1 were based on these ballpark values, and therefore carry along this error. Additionally, the minor loss coefficients used for the plenum entrance (expansion) and exit (contraction) could be slightly off from the actual values due to slightly more rounding of the edges in the entrance and exit regions. A further cause for this discrepancy could be the assumed friction factor used in the simulation (see Figure 3-27). The data used for the equivalent sand roughness surely has some error as different manufacturing processes could produce more or less surface roughness. Also, this assumed friction factor is for the case of idealized fully-developed pipe flow, which is not the case here. It should be noted that since even the highest reduced pressure of the air in the experimental data was about 0.1 , and because the reduced temperature in the test data was at least about 2.4, the use of the ideal gas equation should not induce much error, i.e. the generalized compressibility factor ( $\mathrm{z}=$ $\mathrm{Pv} / \mathrm{RT}$ ) should be very close to 1.0 (e.g. see the compressibility chart given by Moran, et. al. [6]).

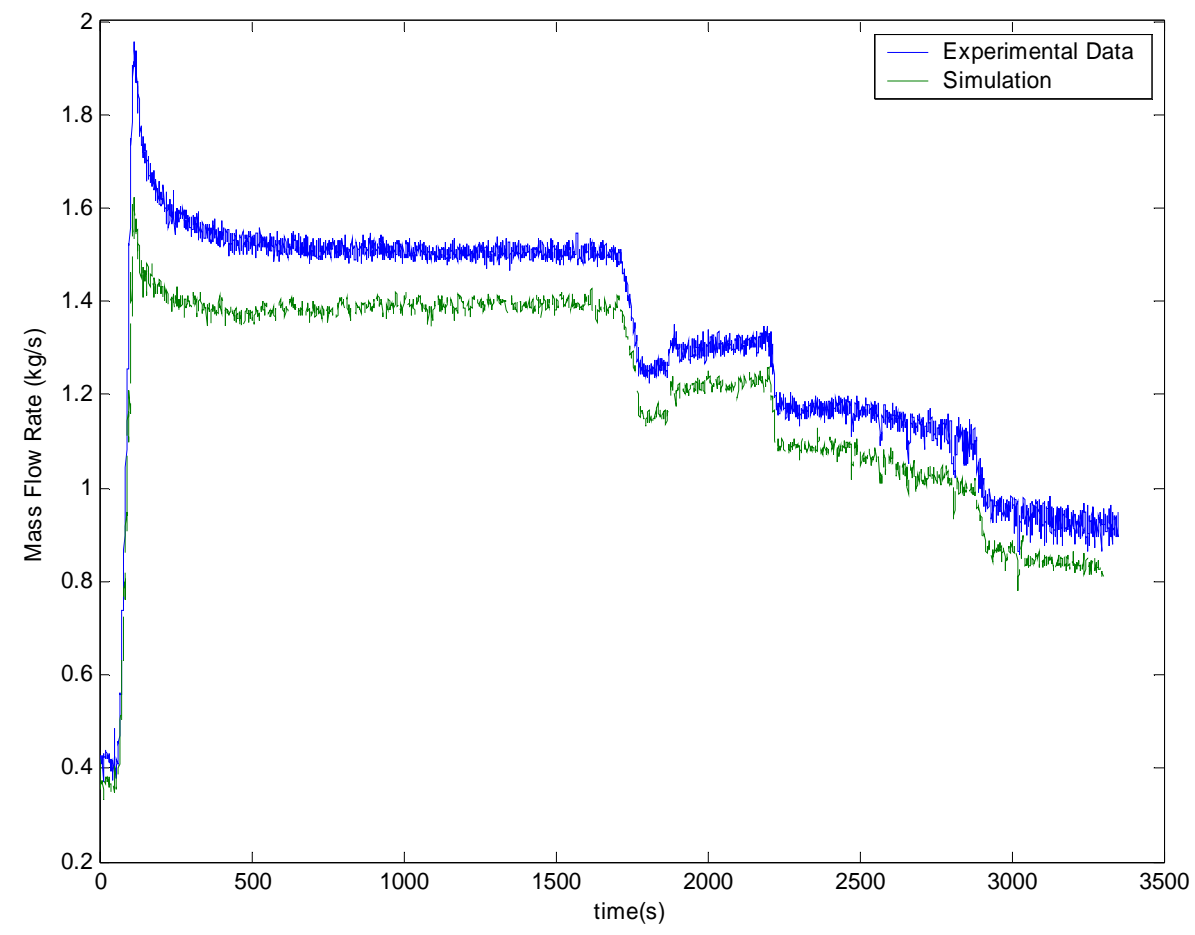

Figure 4-28 Comparison of the air mass flow rate at probe location given by experimental data and simulation. 
The simulated and experimental plenum pressures were nearly identical as shown in Figure 4-29 (a) and (b). Part (a) of this figure shows the expanded view of the plenum pressure, and part (b) illustrates the zoomed view of the pressure values after approximately 100s in order to better analyze how close the two values actually are.

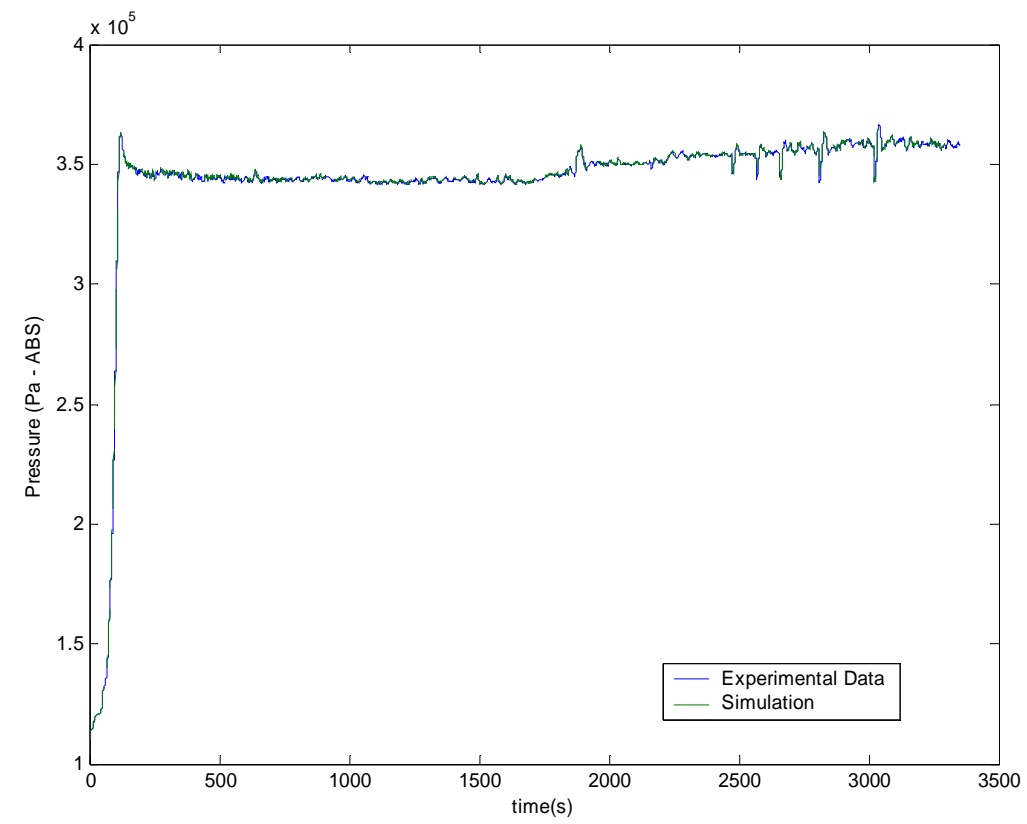

(a)

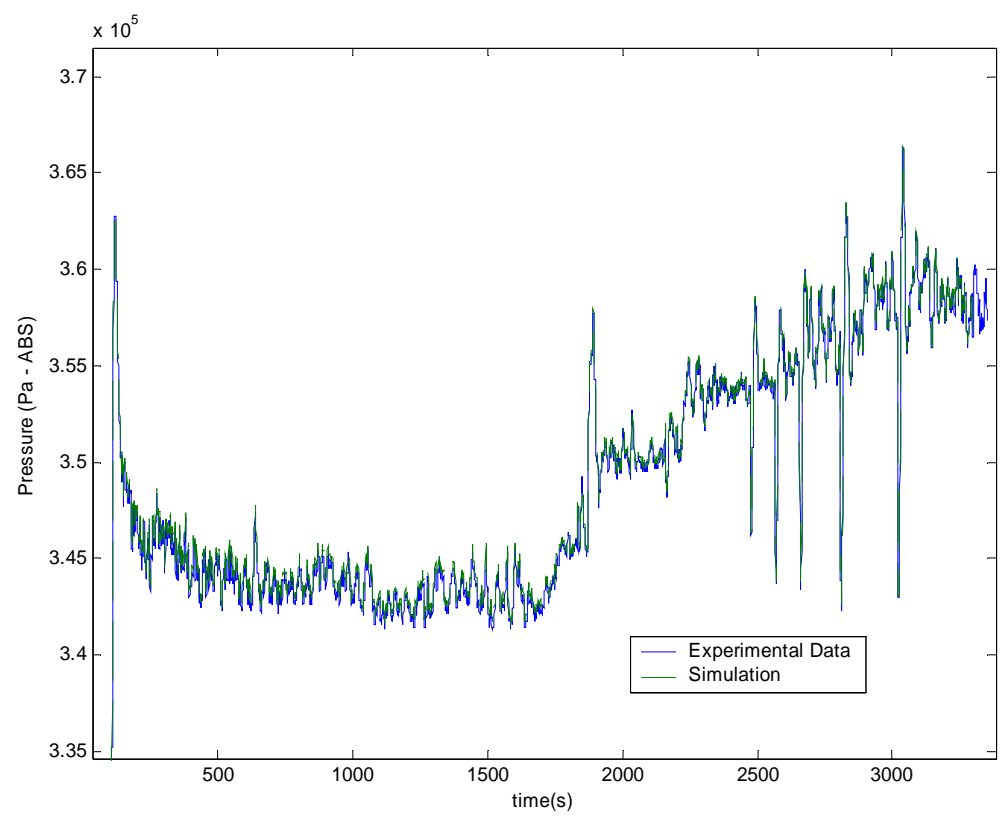

(b)

Figure 4-29 Comparison of the experimental and simulated plenum pressures; (a) wide view and (b) zoomed view. 
The simulated and experimental east boundary temperature values shown in Figure 4-30 have a maximum difference of about $10 \%$ based on the overall temperature range of the experimental data. The similar trends give credence to the assumed internal Nusselt number relationship based on the effective friction factor, Reynolds number, and Prandtl number. This having been said, the internal Nusselt number was probably not high enough over the range of data. In the range of time up to about 1000s, the west boundary air temperature increased (see Figure 4-27) and therefore the air was heating the steel and insulation. In this range the simulated temperature was greater than the measured temperature, leading one to the conclusion that the internal Nusselt number was too low. At approximately 1800s, the west boundary air temperature dropped. At this time the air was most likely heated by the surrounding steel. The simulated temperature in this region was lower than the measured temperature, leading one again to the conclusion that the internal Nusselt number was too small. However, this behavior could also be attributed to the assumption of the constant external Nusselt number, or to the rather elementary lumped model used to simulate the thermal capacity of the steel and insulation.

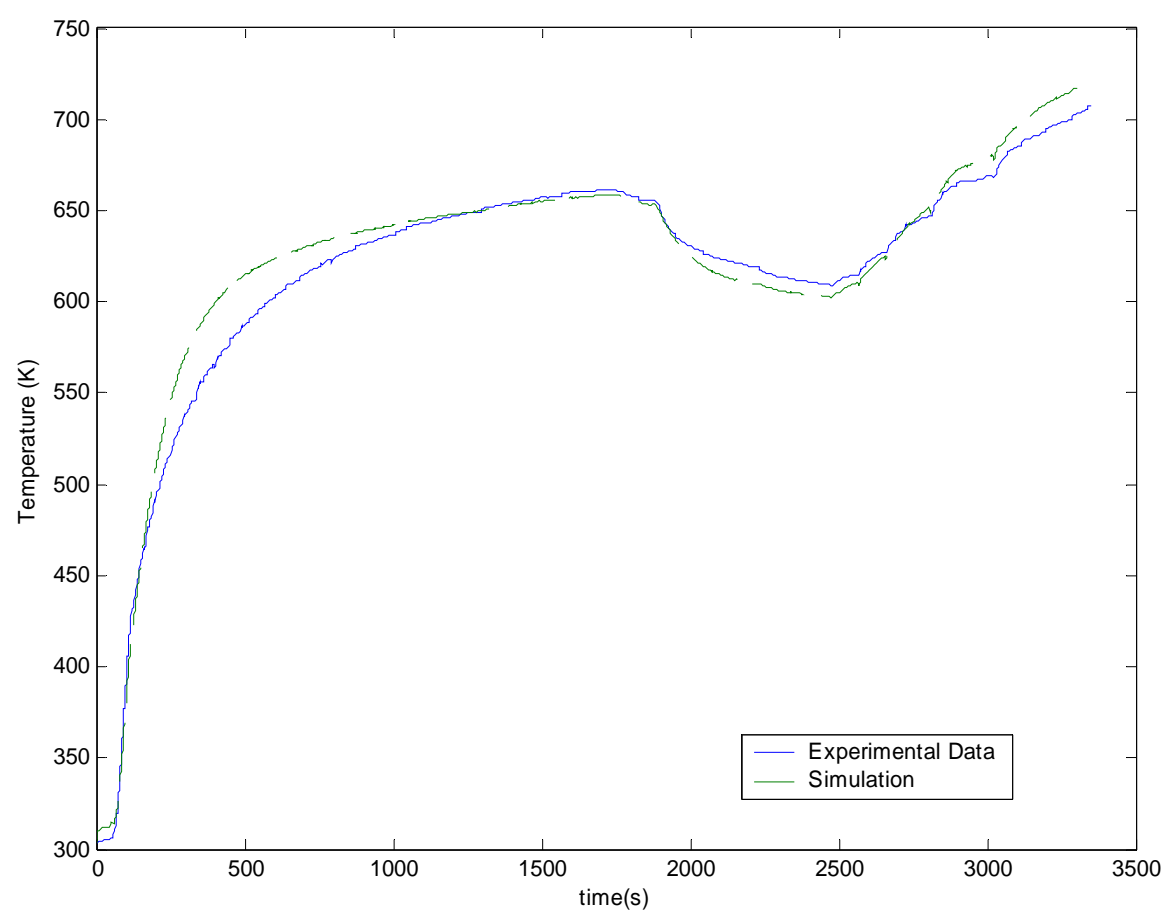

Figure 4-30 Comparison of east boundary air temperature given by experimental data and simulation. 
It is obvious that there were a fair number of assumptions and a certain amount of empiricism used in order to properly simulate the flow through this system. While this is far from ideal, it seems simply to be a fact of life when trying to model a complicated three-dimensional turbulent flow with a simple one-dimensional model. One could sit for days to try and find the "optimal" minor loss coefficients, friction scale factor for the internal Nusselt number calculation, etc. Additionally, these values are surely dependent on the particular system modeled, each with its own flow disturbances due to the location of tees, elbows, etc. In the simulation shown here, the mass flow rate was the parameter in worst agreement with the experimental results. If more appropriate values were determined for the minor loss coefficients, etc. bringing the simulated mass flow closer to the experimental results, the pressure and temperature results would most definitely be affected. This would in turn lead to the altering of other factors such as the friction scale factor for the Nusselt number, etc. These facts are mentioned to underline the point that the most important thing shown by these results is that the transient behavior of the system was modeled very well by the method presented.

Finally, while the physics of the flow and temperature seemed to be captured well by the model, the computational expense was rather high. The Simulink model took approximately nine hours to simulate 3300 seconds ( 0.92 hrs) on a Pentium IV $3.6 \mathrm{GHz}$ machine, or almost ten times the actual time. Reducing the execution time of the model can be accomplished by reducing the number of MATLAB functions used and creating S-functions. In the development of the FORTRAN code, it was observed that an equivalent MATLAB code took significantly longer to run. Therefore, by implementing S-functions in the Simulink model, a significant reduction in the execution time will most likely be realized. 


\section{Summary}

A one-dimensional transient CFD model was developed that is capable of simulating both the flow and thermal behavior of a gas in a variable-area duct. The isothermal flow characteristics of this model were studied for a rather complicated plenum, diffuser geometry using a FORTRAN code. The steady-state results from the FORTRAN code for this geometry were shown to be in fairly good agreement with more detailed CFD simulations performed in Fluent when proper precautions were taken to account for minor losses.

The same one-dimensional model was also implemented in the Simulink workspace and additional transient models for plenums, tees, and elbows were also created. Utilizing the Simulink solvers and blocks, these parts were connected in several arrangements creating some simple flow systems. Both the flow and thermal behavior of these systems were studied, and the results from these simple flow systems seemed to be consistent with the expected outcome. As a way of verifying the work performed, a model of a portion of the NETL HYPER test facility was created in Simulink which consisted of four ducts, a plenum, and a tee. Calculated mass flow, plenum pressure, and temperature results from this simulation were compared with experimental results and were shown to be in good agreement. The maximum error in the simulated mass flow over the entire test period was shown to be about 22\%, the maximum error in the temperature in the same time was approximately $10 \%$, and the error in the plenum pressure was hardly noticeable. More importantly, the fluctuations and transient behavior in the mass flow, plenum pressure, and temperature were captured very well by the model. The model did however take approximately nine hours to simulate a time period of about 3300 seconds. 


\section{Conclusions}

The transient one-dimensional variable-area duct model developed was shown to be fairy effective in all tests and cases simulated. The transient plenum, tee, and elbow models developed likewise seemed to give good results when tested. The simulated portion of the NETL HYPER test facility was in good agreement with the experimental results thereby giving credence to the models created and methods used in implementing them. The execution time of the models in the Simulink workspace was undesirably slow, with a simulation to actual time ratio of about 10:1 when used to simulate the section of the NETL HYPER test facility. However, the execution time of the model developed should still be significantly less than the execution time required to simulate the same system with a two- or three-dimensional CFD code. Additionally, the added labor and time it would take to create a two- or three-dimensional mesh for even the

portion of the NETL HYPER test facility modeled would be much greater than the setup time for the Simulink model developed here. 


\section{Future Work}

1. Increase the computational efficiency of the Simulink model by writing S-functions for the duct, plenum, tee, and elbow models.

2. Refine lumped capacity model used for the heating of the steel and insulation.

3. Develop transient models for additional system parts such as heat exchangers and valves.

4. Incorporate work into an overall system model. 


\section{References}

[1] Department of Energy web site:

http://www.netl.doe.gov/publications/press/2002/tl_fuelcellhybrid_startup.html

[2] Tucker, David A., private conversations, Department of Energy, National Energy Technology Laboratory (NETL), Morgantown, WV

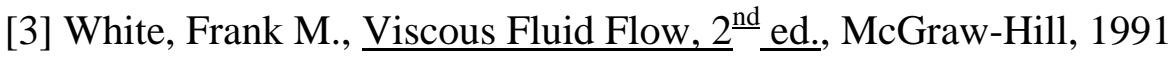

[4] Anderson, John D., Computational Fluid Dynamics, The Basics with Applications, McGraw-Hill, 1995

[5] White, Frank M., Fluid Mechanics, $5^{\text {th }}$ ed., McGraw-Hill, 2003

[6] Moran, Michael J. and Shapiro, Howard N., Fundamentals of Engineering Thermodynamics, $5^{\text {th }}$ ed., John Wiley and Sons, 2004

[7] Munson, Bruce R.; Young, Donald F.; and Okiishi, Theodore H., Fundamentals of

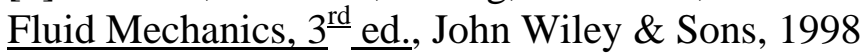

[8] Celik, Ismail B. and Shelton, Michael S., "Dynamic Models for a Hybrid Performance(HYPER) Power Generation System”, Final Report MAE-IC04TR_\#2, Mechanical and Aerospace Engineering Department, West Virginia University, Morgantown, WV, Dec. 2004

[9] Shelton, Michael S., A Study in the Process Modeling of a Fuel Cell/Micro turbine Hybrid System Under Ambient Conditions, Masters Thesis, Mechanical and Aerospace Engineering Department, College of Engineering and Mineral Resources, West Virginia University, Morgantown, West Virginia, 2004

[10] Schobeiri, M. T.; Attia, M. and Lippke, C., "GETRAN: A Generic, Modularly Structured Computer Code for Simulation of Dynamic Behavior of Aero- and Power Generation Gas Turbine Engines”, Journal of Engineering for Gas Turbines and Power, Vol. 116, July 1994, pp. 483-494

[11] Chiang, Edward C.; Huang, George P. C.; Chang, Zintai and Johnson, John, H., “A One-Dimensional Transient Compressible Flow Model for Cooling Airflow Rate Computation”, SAE Technical Paper Series, Paper 900721, International Congress and Exposition, Detroit, Michigan, February 26 - March 2, 1990

[12] Goodson, R. E. and Leonard, R. G., "A Survey of Modeling Techniques for Fluid Line Transients”, Journal of Basic Engineering, June 1972, pp. 474-482 
[13] Wongputorn, Patompong; Hullender, David; Woods, Robert; and King, John, "Application of MATLAB Functions for Time Domain Simulation of Systems With Lines With Fluid Transients”, Journal of Fluids Engineering, Vol. 127, January 2005, pp. $177-182$

[14] Pence, Deborah V., "Reduced Pumping Power and Wall Temperature in Microchannel Heat Sinks with Fractal-Like Branching Channel Networks”, Microscale Thermophysical Engineering, 6(4), 2002, pp. 319-330

[15] Alharbi, Ali Y.; Pence, Deborah V. and Cullion, Rebecca N., "Fluid Flow Through Microscale Fractal-Like Branching Channel Networks", Journal of Fluids Engineering, Vol. 125, November 2003, pp. 1051-1057

[16] Kimijima, Shinji and Kasagi, Nobuhide, "Performance Evaluation of Gas Turbine Fuel Cell Hybrid Micro Generation System”, GT-2002-30111, Proceedings of ASME Turbo Expo 2002, June 3-6, 2002, Amsterdam, The Netherlands

[17] Uechi, Hideyuki; Kimijima, Shinji and Kasagi, Nobuhide, "Cycle Analysis of Gas Turbine - Fuel Cell Hybrid Micro Generation System”, JPGC-2001/PWR-19171, Proceedings of 2001 International Joint Power Generation Conference (JPGC'01), New Orleans, Louisiana, June 4-7, 2001

[18] Massardo, A. F.; McDonald, C. F. and Korakianitis, T., "Microturbine/Fuel-Cell Coupling for High-Efficiency Electrical-Power Generation”, Journal of Engineering for Gas Turbines and Power, Vol. 124, January 2002, pp. 110-116

[19] Gemmen, Randall S.; Liese, Eric; Rivera, Jose G.; Jabbari, Faryar and Brouwer, Jacob, "Development of Dynamic Modeling Tools for Solid Oxide and Molten Carbonate Hybrid Fuel Cell Gas Turbine Systems”, International Gas Turbine Institute meeting of the American Society of Mechanical Engineers, May 8-12, 2000

[20] Hahn, Adam, Modeling and Control of Solid Oxide Fuel Cell - Gas Turbine Power Plant Systems, Masters Thesis, University of Pittsburgh, School of Engineering, Department of Mechanical Engineering, 2004

[21] Tucker, David; Lawson, Larry; Gemmen, Randy; and Dennis, Richard, "Evaluation of Hybrid Fuel Cell Turbine System Startup with Compressor Bleed”, ASME Turbo Expo 2005, June 6-9, 2005, Reno, NV, USA

[22] Zitney, Stephen E.; Prinkey, Michael T.; Shahnam, Mehrdad and Rogers, William A., "Coupled CFD and Process Simulation of a Fuel Cell Auxiliary Power Unit", FUELCELL2004-2490, Fuel Cell Science, Engineering and Technology - 2004, June 1416, 2004, Rochester, New York 
[23] Celik, Ismail B., Lecture notes from the class MAE593G, "Introduction to Fuel Cell Technology”, Fall 2004, West Virginia University, College of Engineering and Mineral Resources, Department of Mechanical and Aerospace Engineering

[24] Pakalapati, Suryanarayana R., A Numerical Study of Current Distribution Inside the Cathode and Electrolyte of a Solid Oxide Fuel Cell, Masters Thesis, West Virginia University, College of Engineering and Mineral Resources, Mechanical and Aerospace Engineering Department, 2003

[25] Larminie, James and Dicks, Andrew, Fuel Cell Systems Explained, $2^{\text {nd }}$ ed., John Wiley and Sons, 2003

[26] Samanta, I.; Shah, R. K. and Wagner, A., "Fuel Processing for Fuel Cell Applications”, FUELCELL2004-2515, Fuel Cell Science, Engineering and Technology 2004, June 14-16, 2004, Rochester, New York

[27] Celik, Ismail B.; Ersahin, Cem and Tatli, Emre, “GFS-1D: One-Dimensional Transient Solver for Transport Phenomena”, West Virginia University, Department of Mechanical and Aerospace Engineering, Computational Fluid Dynamics and Applied Multi-Physics (CFD\&AMP) Center, July 2004

[28] Bird, R. Byron; Stewart, Warren E. and Lightfoot, Edwin N., Transport Phenomena, $\underline{2}^{\text {nd }}$ ed., John Wiley and Sons, 2002

[29] Bejan, Adrian, Convection Heat Transfer, $2^{\text {nd }}$ ed., John Wiley and Sons, 1995

[30] Microtherm product literature, June 11, 2001, Microtherm International Ltd., 1 Arrowe Brooke Road, Upton, WIRRAL, CH49 1SX, U.K., www.microtherm.uk.com

[31] Mills, A. F., Basic Heat and Mass Transfer, $2^{\text {nd }}$ ed., Prentice Hall, 1999

[32] Sandvik Materials Technology, www.sandvik.com

[33] Shelton, Michael S., private conversations, Department of Energy, National Energy Technology Laboratory (NETL), Morgantown, WV 


\section{Appendix: Derivation of One-Dimensional Variable-Area Duct Flow Equations}

The law of conservation of mass can be stated in the following manner:

$$
\left\{\begin{array}{l}
\text { Rate of Increase } \\
\text { of Mass Within } \\
\text { Control Volume }
\end{array}\right\}=\left\{\begin{array}{l}
\text { Net Flux of } \\
\text { Mass Into the } \\
\text { Control Volume }
\end{array}\right\}
$$

Figure A-1 shows a control volume for a variable-area duct with the mass flux through the open boundaries at $\mathrm{x}$ and $\mathrm{x}+\Delta \mathrm{x}$.

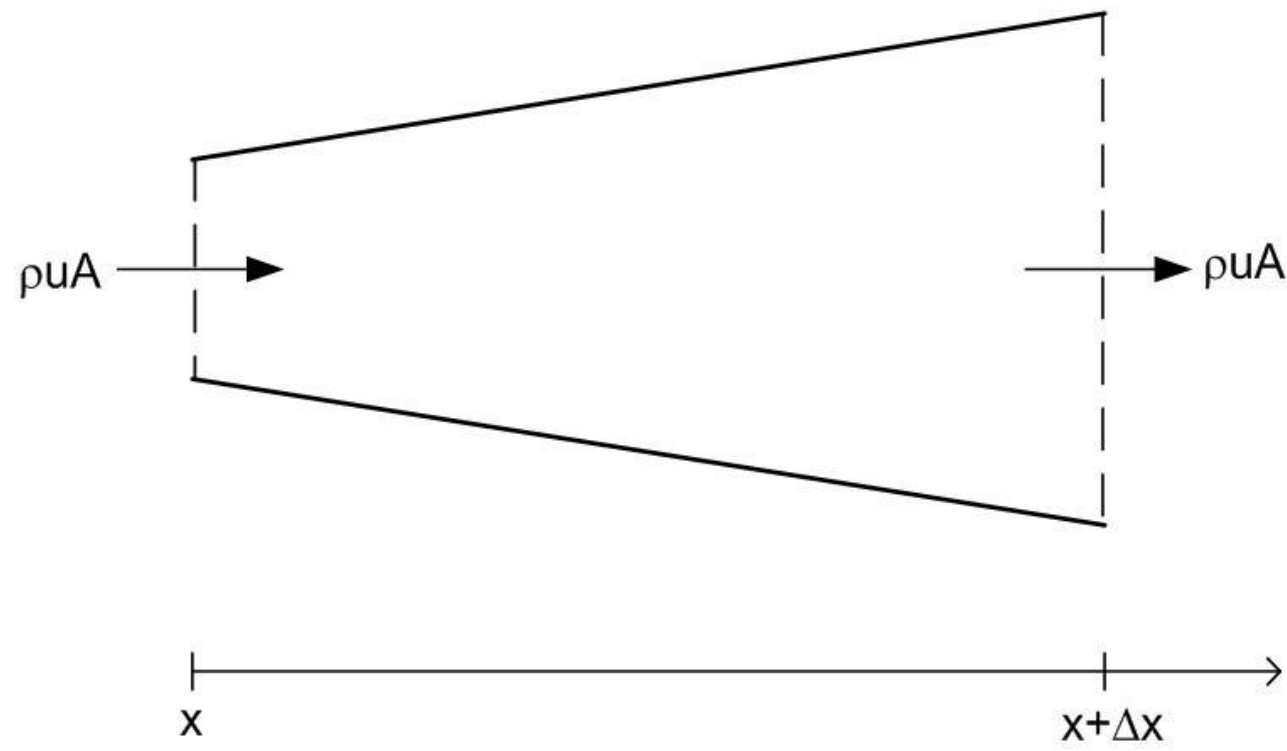

Figure A-1 Generic variable-area control volume showing mass flux across open boundaries.

Assuming a one-dimensional flow, this statement can be rewritten for the system shown in Figure A-1 yielding the following equation:

$$
\begin{aligned}
& \frac{\partial}{\partial t}[\rho \forall]=-[\rho u A]_{x+\Delta x}+[\rho u A]_{x} \\
& \text { where } \rho=\text { density of the fluid } \\
& \forall=\text { volume of the control volume } \\
& \mathrm{u}=\text { average axial velocity of the fluid }
\end{aligned}
$$




$$
\begin{aligned}
& A=\text { cross-sectional area } \\
& t=\text { time }
\end{aligned}
$$

Further making the assumption that the volume can be estimated by $\forall=\bar{A} \Delta x$ (where the bar over the A stands for its average value over the length $\Delta x$ ), dividing both sides by $\Delta x$, and taking the limit as $\Delta x \rightarrow 0$ yields the continuity equation for a variable-area duct:

$$
\begin{aligned}
\frac{\partial(\rho A)}{\partial t} & =-\frac{\partial \dot{m}}{\partial x} \\
& \text { where } \dot{m}=\rho u A=\text { mass flow rate }
\end{aligned}
$$

Newton's second law may be stated as

$$
\left\{\begin{array}{l}
\text { Rate of Increase } \\
\text { of Momentum Within } \\
\text { Control Volume }
\end{array}\right\}=\left\{\begin{array}{l}
\text { Net Flux of } \\
\text { Momentum Into } \\
\text { the Control Volume }
\end{array}\right\}+\left\{\begin{array}{l}
\text { Body and Surface } \\
\text { Forces Acting on } \\
\text { the Control Volume }
\end{array}\right\}
$$

Figure A-2 illustrates once again a control volume for a variable-area duct with the momentum flux through the open boundaries at $\mathrm{x}$ and $\mathrm{x}+\Delta \mathrm{x}$, along with the body and surface forces acting on the control volume.

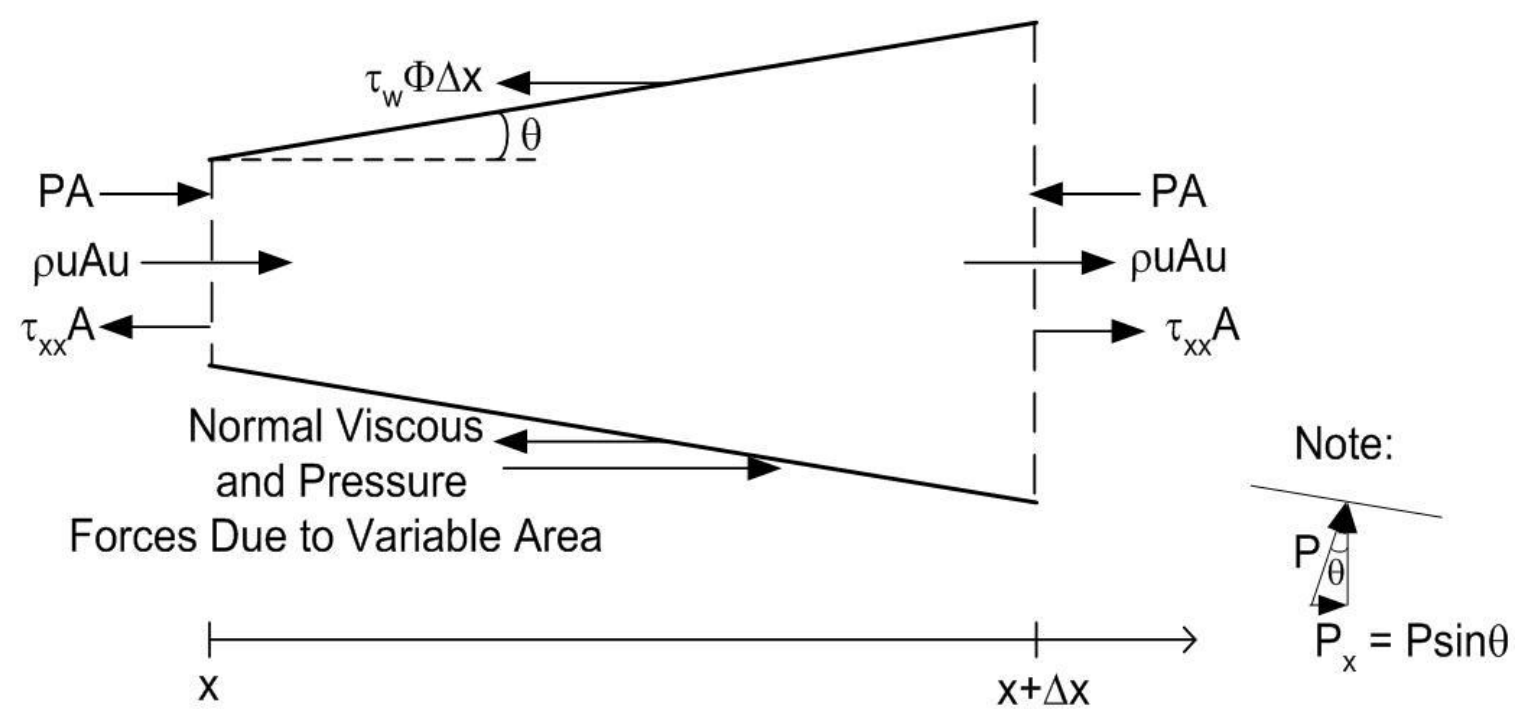

Figure A-2 Generic variable-area control volume showing momentum flux across open boundaries along with external forces. 
Newton's second law is actually a vector quantity, but in this simplified one-dimensional model, the flow is assumed to be primarily in this axial direction. This leads to the following mathematical expression of (A-4):

$$
\begin{gathered}
\frac{\partial}{\partial t}[\rho u \forall]=\left[-(\rho u A u)_{x+\Delta x}+(\rho u A u)_{x}\right]+\left[-(P A)_{x+\Delta x}+(P A)_{x}\right] \\
+\left[\left(\tau_{x x} A\right)_{x+\Delta x}-\left(\tau_{x x} A\right)_{x}\right]-\overline{\tau_{w}} \bar{\Phi} \Delta x+\bar{P}\left[A_{x+\Delta x}-A_{x}\right] \\
-\overline{\tau_{x x}}\left[A_{x+\Delta x}-A_{x}\right]-S_{\text {minor }} \Delta x \\
\text { where } \mathrm{P}=\text { pressure } \\
\tau_{\mathrm{xx}}=\text { normal viscous shear stress } \\
\tau_{\mathrm{w}}=\text { wall shear stress } \\
\Phi=\text { perimeter of the duct } \approx \pi \mathrm{D}_{\mathrm{h}} \\
\mathrm{D}_{\mathrm{h}}=\text { hydraulic diameter of duct } \\
\mathrm{S}_{\text {minor } \Delta \mathrm{x}=\text { minor loss term over the length } \Delta \mathrm{x}}
\end{gathered}
$$

A few things are of note here. First of all the bar over the $\mathrm{P}, \tau_{\mathrm{w}}$, etc. stands for the average value of the particular quantity over the length $\Delta x$. Second, the appearance of the $\mathrm{S}_{\text {minor }}$ term is a consequence of trying to predict a multi-dimensional flow with a simplified one-dimensional model. If there is a secondary flow, flow separation, etc. within the duct, this acts as a sink of axial-direction momentum and must be accounted for in the one-dimensional representation (A-5). Third, the terms $\bar{P}\left[A_{x+\Delta x}-A_{x}\right]$ and $-\overline{\tau_{x x}}\left[A_{x+\Delta x}-A_{x}\right]$ come from the pressure and normal shear forces in the axial direction along the perimeter of the duct due to its variable area. For the control volume shown in Figure $\mathrm{A}-2$, the difference in area between the $\mathrm{x}+\Delta \mathrm{x}$ and $\mathrm{x}$ faces $\left(A_{x+\Delta x}-A_{x}\right)$ is essentially the normal component of the surface area of the solid duct walls in the axial direction for which normal viscous shear and pressure act upon. This point is further illustrated by Figure A-3. 


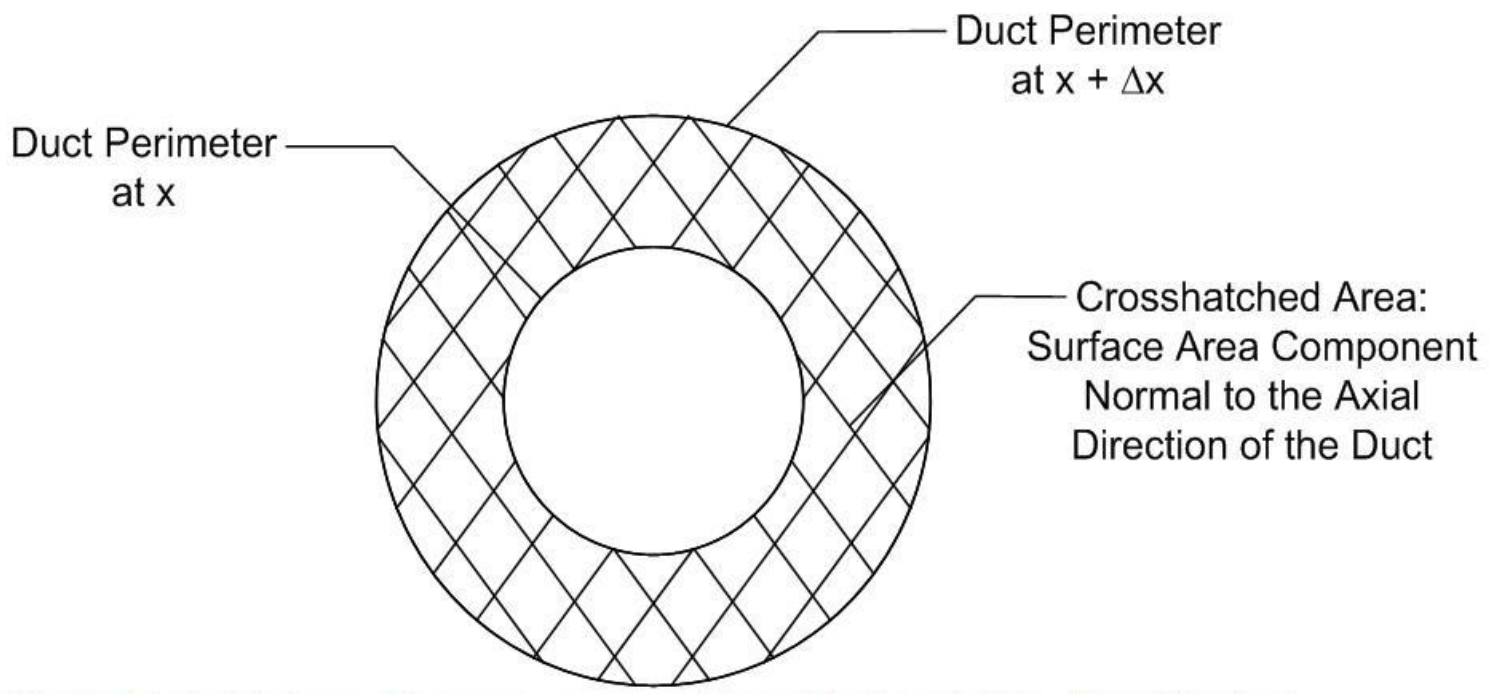

Figure A-3 Axial view: surface area component normal to the axial direction of the duct.

By once again substituting $\forall=\bar{A} \Delta x$ into (A-5), dividing both sides by $\Delta \mathrm{x}$ and taking the limit as $\Delta x \rightarrow 0$ :

$$
\frac{\partial}{\partial t}(\dot{m})=-\frac{\partial}{\partial x}(u \dot{m})-\frac{\partial(P A)}{\partial x}+P \frac{\partial A}{\partial x}+\frac{\partial\left(\tau_{x x} A\right)}{\partial x}-\tau_{x x} \frac{\partial A}{\partial x}-\tau_{w} \Phi-S_{\text {minor }}
$$

Further combining the pressure and normal shear derivatives yields the following form of the conservative, differential, one-dimensional momentum equation:

$$
\frac{\partial}{\partial t}(\dot{m})=-\frac{\partial}{\partial x}(u \dot{m})-A \frac{\partial P}{\partial x}+A \frac{\partial \tau_{x x}}{\partial x}-\tau_{w} \Phi-S_{\text {minor }}
$$

Finally, the non-conservative form of the one-dimensional momentum equation can be derived by multiplying the continuity equation (A-3) by u and subtracting it from (A-7):

$$
\frac{\partial u}{\partial t}=-u \frac{\partial u}{\partial x}-\frac{1}{\rho} \frac{\partial P}{\partial x}+\frac{1}{\rho} \frac{\partial \tau_{x x}}{\partial x}-\frac{\tau_{w} \Phi}{\rho A}-\frac{S_{\text {minor }}}{\rho A}
$$

Note that in going from (A-7) to (A-8) both sides were divided by the quantity $\rho \mathrm{A}$.

The most convenient way to obtain the kinetic energy equation is to multiply equation (A-8) by u:

$$
u \frac{\partial u}{\partial t}=-u^{2} \frac{\partial u}{\partial x}-\frac{u}{\rho} \frac{\partial P}{\partial x}+\frac{u}{\rho} \frac{\partial \tau_{x x}}{\partial x}-\frac{u \tau_{w} \Phi}{\rho A}-\frac{u S_{\text {minor }}}{\rho A}
$$


Further utilizing the chain rule, (A-9) can be expressed in the non-conservative form of the kinetic energy equation:

$$
\begin{array}{r}
\frac{\partial K}{\partial t}=-u \frac{\partial K}{\partial x}-\frac{u}{\rho} \frac{\partial P}{\partial x}+\frac{u}{\rho} \frac{\partial \tau_{x x}}{\partial x}-\frac{u \tau_{w} \Phi}{\rho A}-\frac{u S_{\text {minor }}}{\rho A} \\
\text { where } \mathrm{K}=\text { specific kinetic energy }=\mathrm{u}^{2} / 2
\end{array}
$$

Equation (A-10) can be put into conservative form by first multiplying both sides by $\rho \mathrm{A}$ and then multiplying the continuity equation (A-3) by $\mathrm{K}$ and adding it to the result:

$$
\frac{\partial(\rho A K)}{\partial t}=-\frac{\partial(\dot{m} K)}{\partial x}-u A \frac{\partial P}{\partial x}+u A \frac{\partial \tau_{x x}}{\partial x}-u \tau_{w} \Phi-u S_{\text {minor }}
$$

For discussion purposes the pressure and normal shear stress differentials can be split:

$$
\begin{aligned}
\frac{\partial(\rho A K)}{\partial t}= & -\frac{\partial(\dot{m} K)}{\partial x}-\frac{\partial(u A P)}{\partial x}+P \frac{\partial(u A)}{\partial x}+\frac{\partial\left(u A \tau_{x x}\right)}{\partial x} \\
& -\tau_{x x} \frac{\partial(u A)}{\partial x}-u \tau_{w} \Phi-u S_{\text {minor }}
\end{aligned}
$$

A few things here are of note. First of all the pressure and normal viscous terms in expression (A-12) are precisely analogous to those given by Bird, et. al. [28] for a three-dimensional cubic differential volume (the kinetic energy equation used in the derivation of the Navier-Stokes energy equation). In the derivation of Bird et. al. [28] the pressure and normal viscous terms on the right-hand side of the kinetic energy equation are $-\frac{\partial\left(P u_{j}\right)}{\partial x_{j}}+P \frac{\partial u_{j}}{\partial x_{j}}+\frac{\partial\left(u_{i} \tau_{j i}\right)}{\partial x_{j}}-\tau_{j i} \frac{\partial u_{i}}{\partial x_{j}}$, where the first term stands for the rate of work done by the pressure, the second term stands for the rate of reversible conversion of kinetic energy into internal energy, the third term stands for the rate of work done by viscous forces, and the final term stands for the rate of irreversible conversion from kinetic to internal energy. For an incompressible flow the continuity equation for the Navier-Stokes formulation becomes $\frac{\partial u_{i}}{\partial x_{i}}=0$, and for the variable-area duct becomes 
$\frac{\partial(u A)}{\partial x}=0$. As should be expected, in both cases the reversible and irreversible rates of conversion of kinetic energy to internal energy go to zero for the incompressible limit. Additionally, the one-dimensional version of the kinetic energy equation given by Bird et. al. [28] goes to the one-dimensional kinetic energy equation derived here (A-12) when the area is considered constant.

The law of conservation of energy may be stated as

$$
\begin{aligned}
\left\{\begin{array}{l}
\text { Rate of Increase } \\
\text { of Energy Within } \\
\text { Control Volume }
\end{array}\right\} & =\left\{\begin{array}{l}
\text { Net Flux Energy } \\
\text { Into the Control } \\
\text { Volume }
\end{array}\right\}+\left\{\begin{array}{l}
\text { Rate of Work } \\
\text { Done on the } \\
\text { Control Volume }
\end{array}\right\} \\
& +\left\{\begin{array}{l}
\text { Rate of Heat } \\
\text { Addition to the } \\
\text { Control Volume }
\end{array}\right\}
\end{aligned}
$$

Figure A-4 illustrates the net flux of energy, rate of work, and rate of heat addition to the control volume.

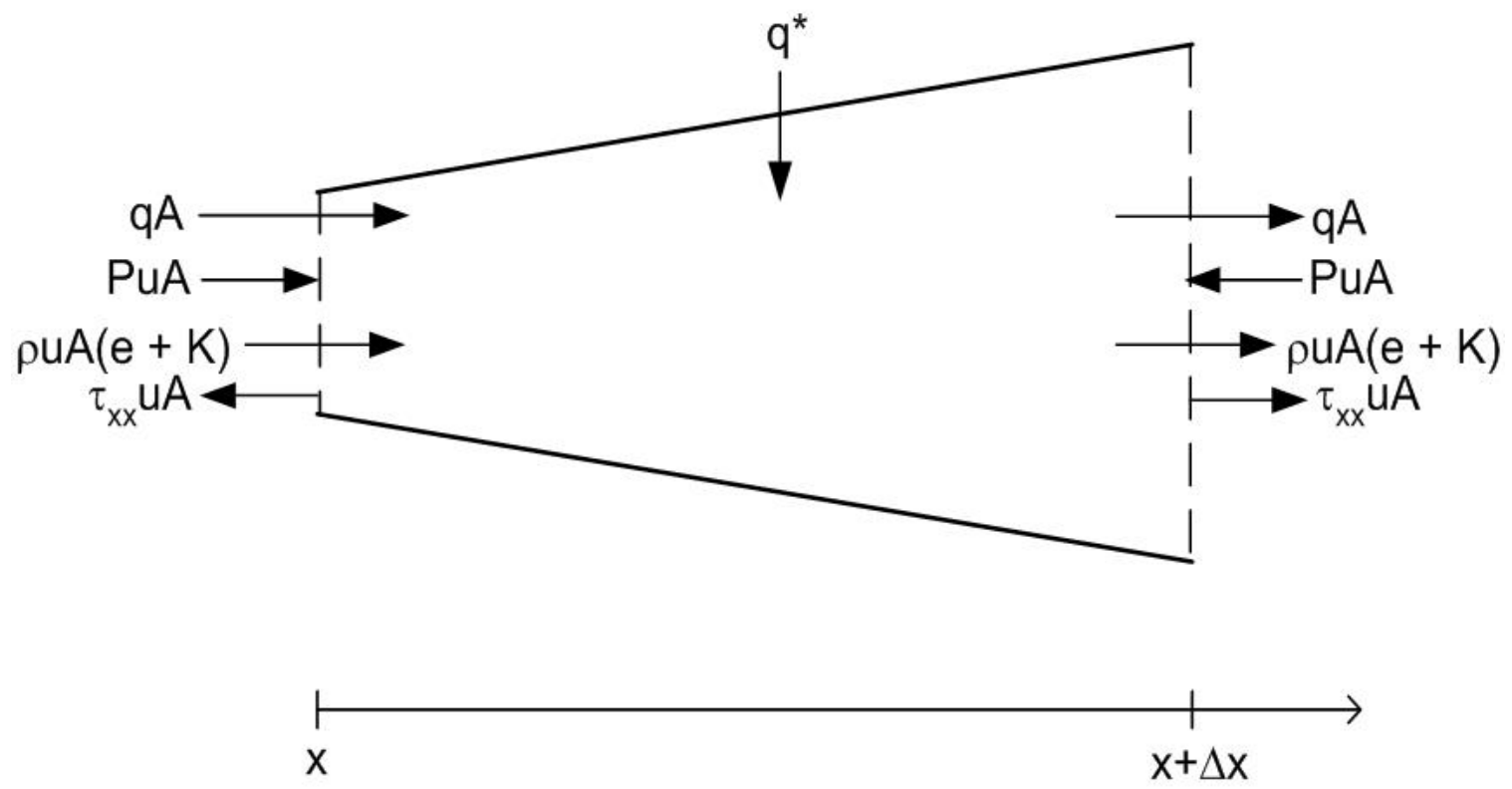

Figure A-4 Generic variable-area control volume showing net flux of energy, rate of work done, and rate of heat addition. 
With reference to Figure A-4, the mathematical equivalence to (A-13) becomes

$$
\begin{aligned}
\frac{\partial}{\partial t}[\rho \forall(e+K)]= & {\left[-[\rho u A(e+K)]_{x+\Delta x}+[\rho u A(e+K)]_{x}\right] } \\
& +\left[-(P u A)_{x+\Delta x}+(P u A)_{x}\right]+\left[\left(\tau_{x x} u A\right)_{x+\Delta x}-\left(\tau_{x x} u A\right)_{x}\right] \\
& +\overline{q^{*}} \Delta x+\left[-(q A)_{x+\Delta x}+(q A)_{x}\right]-u S_{\text {minor }} \Delta x
\end{aligned}
$$

where $e=$ specific internal energy

$\mathrm{q}^{*}=$ heat rate into fluid per unit length of duct

$\mathrm{q}=$ axial heat conduction

Note again the use of the minor loss term to account for the loss of kinetic energy due to secondary flows, flow separation, etc. Substituting $\forall=\bar{A} \Delta x$ into (A-14), dividing both sides by $\Delta \mathrm{x}$ and taking the limit as $\Delta x \rightarrow 0$ :

$$
\begin{aligned}
\frac{\partial}{\partial t}[\rho A(e+K)]= & -\frac{\partial}{\partial x}[\rho u A(e+K)]-\frac{\partial(P u A)}{\partial x} \\
& +\frac{\partial\left(\tau_{x x} u A\right)}{\partial x}+q^{*}-\frac{\partial(q A)}{\partial x}-u S_{\text {minor }}
\end{aligned}
$$

Adding and subtracting $\frac{\partial(A P)}{\partial t}$ from the left-hand side and rearranging the pressure term on the right-hand side gives

$$
\left\{\begin{array}{l}
\frac{\partial}{\partial t}[\rho A(e+P / \rho)]-\frac{\partial(P A)}{\partial t} \\
+\frac{\partial(\rho A K)}{\partial t}+\frac{\partial(\dot{m} K)}{\partial x}
\end{array}\right\}=\left\{\begin{array}{l}
-\frac{\partial(\dot{m} e)}{\partial x}-\frac{\partial(\dot{m} P / \rho)}{\partial x}+\frac{\partial\left(\tau_{x x} u A\right)}{\partial x} \\
+q^{*}-\frac{\partial(q A)}{\partial x}-u S_{\text {minor }}
\end{array}\right\}
$$

Substituting in the for the definition of specific enthalpy $h=e+P / \rho$ and rearranging to get the transient kinetic energy term on the left-hand side gives

$$
\begin{aligned}
\frac{\partial(\rho A K)}{\partial t}= & -\frac{\partial(\dot{m} K)}{\partial x}-\frac{\partial(\rho A h)}{\partial t}-\frac{\partial(\dot{m} h)}{\partial x}+\frac{\partial(P A)}{\partial t} \\
& +\frac{\partial\left(\tau_{x x} u A\right)}{\partial x}+q^{*}-\frac{\partial(q A)}{\partial x}-u S_{\text {minor }}
\end{aligned}
$$


Finally substituting equation (A-11) into the left-hand side of (A-17) and canceling like terms yields the differential, conservative form of the thermal energy equation:

$$
\begin{aligned}
\frac{\partial(\rho A h)}{\partial t}= & -\frac{\partial(\dot{m} h)}{\partial x}+\frac{\partial(P A)}{\partial t}+u A \frac{\partial P}{\partial x} \\
& +\tau_{x x} \frac{\partial(u A)}{\partial x}+u \tau_{w} \Phi+q^{*}-\frac{\partial(q A)}{\partial x}
\end{aligned}
$$

By multiplying the continuity equation (A-3) by h and subtracting it from (A-18) the nonconservative form of the thermal energy equation is derived:

$$
\begin{aligned}
\frac{\partial h}{\partial t}= & -u \frac{\partial h}{\partial x}+\frac{1}{\rho A} \frac{\partial(P A)}{\partial t}+\frac{u}{\rho} \frac{\partial P}{\partial x}+\frac{\tau_{x x}}{\rho A} \frac{\partial(u A)}{\partial x} \\
& +\frac{u \tau_{w} \Phi}{\rho A}+\frac{q^{*}}{\rho A}-\frac{1}{\rho A} \frac{\partial(q A)}{\partial x}
\end{aligned}
$$

For closure, by substituting $h=e+P / \rho$ into (A-18) and rearranging gives the thermal energy equation in terms of internal energy:

$$
\frac{\partial(\rho A e)}{\partial t}=-\frac{\partial(\dot{m} e)}{\partial x}-P \frac{\partial(u A)}{\partial x}+\tau_{x x} \frac{\partial(u A)}{\partial x}+u \tau_{w} \Phi+q^{*}-\frac{\partial(q A)}{\partial x}
$$

Equation (A-20) is once again analogous with the result given by Bird, et. al. [28] for the cubic differential volume (Navier-Stokes) energy equation in terms of internal energy. Additionally, as should be the case, the reversible rate of exchange between internal and kinetic energies (the pressure term in (A-20)) has opposite signs in the kinetic energy (A-12) and thermal energy (A-20) equations, meaning that it is a source in one equation and a sink in the other. Likewise, the irreversible rate of conversion of kinetic energy to internal (the normal viscous term in (A-20)) has opposite signs in the kinetic energy (A-12) and thermal energy (A-20) equations. This term is essentially the viscous dissipation term, but also has an additional term which is a consequence of the geometry which is discussed in more detail in Section 3.2.

Two more things should be noted. First, the perimeter of the duct can be estimated by $\Phi=\pi D_{h}$, the axial direction heat flux is given by Fourier's law as 
$q=-k \frac{\partial T}{\partial x}$, and the normal viscous shear for a Newtonian fluid is given by $\tau_{x x}=2 \mu \frac{\partial u}{\partial x}$. These relationships were substituted into the equations derived in this appendix before they were used in the main body. Second, all of the equations derived here are for gases. Therefore, the assumption is made that the potential energy can be neglected: this should be a good assumption as long as the gases modeled with these equations have a low density and the domain in question has only modest changes in elevation. 